\title{
Energy Management System
}

in Naval Submarines

by

Byeongdoo Jeon

\section{A Dissertation Presented in Partial Fulfillment of the Requirements for the Degree Master of Science}

Approved April 2020 by the Graduate Supervisory Committee:

\author{
Mojdeh Khorsand, Chair \\ Keith E. Holbert \\ Meng Wu
}

ARIZONA STATE UNIVERSITY

May 2020 


\begin{abstract}
An optimal energy scheduling procedure is essential in an isolated environment such as naval submarines. Conventional naval submarines include diesel-electric propulsion systems, which utilize diesel generators along with batteries and fuel cells. Submarines can charge the batteries by running diesel-electric generators only at the surface or at snorkeling depth. This is the most dangerous time for submarines to be detectable by acoustic and non-acoustic sensors of enemy assets. Optimizing the energy resources while reducing the need for snorkeling is the main factor to enhance underwater endurance. This thesis introduces an energy management system (EMS) as a supervisory tool for the officers onboard to plan energy schedules in order to complete various missions. The EMS for a 4,000-ton class conventional submarine is developed to minimize snorkeling and satisfy various conditions of practically designed missions by optimizing the energy resources, such as Lithium-ion batteries, Proton-exchange membrane fuel cells, and diesel-electric generators. Eventually, the optimized energy schedules with the minimum snorkeling hours are produced for five mission scenarios. More importantly, this EMS performs deterministic and stochastic operational scheduling processes to provide secured optimal schedules which contains outages in the power generation and storage systems.
\end{abstract}




\section{DEDICATION}

In the hopes that this work may in some way contribute to the development of naval warfare. I want to dedicate this research to the navy personnel, who are serving the country in the dark sea even right at this moment. 


\section{ACKNOWLEDGEMENTS}

Foremost, I would like to thank my wife Mee for her personal support and patience. It would not have been possible to pursue my master's degree without her consistent help and sacrifice.

I would like to express my sincere gratitude to my advisor Dr.Mojdeh Khorsand for the support of my master's study and research, for her patience, motivation, enthusiasm, and immense knowledge. Her guidance helped me in all the time of research and writing of this thesis. I could not have imagined having a better advisor and mentor for my master's study. It was a great privilege and honor to work and study under her instructions.

Besides my advisor, I would like to thank the rest of my thesis committee: Dr.Keith E. Holbert and Dr.Meng $\mathrm{Wu}$, for their encouragement, insightful comments, and hard questions. Especially, I am very grateful to Dr.Holbert for offering the high-equality education and well organized courses in nuclear power generation program, which was absolutely the best I have ever experienced for my life.

Last but not the least, I would like to acknowledge that the Republic of Korea Navy offered me the academic opportunity for this master's study and the financial support. I thank my all fellow officers who presented me visions in the navy. 


\section{TABLE OF CONTENTS}

Page

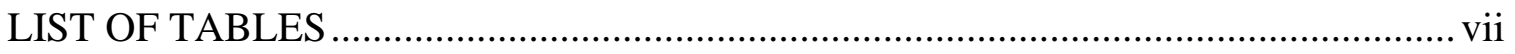

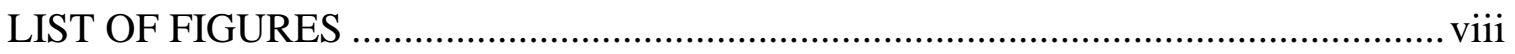

LIST OF ACRONYMS …..............................................................................

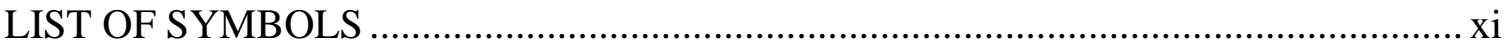

\section{CHAPTER}

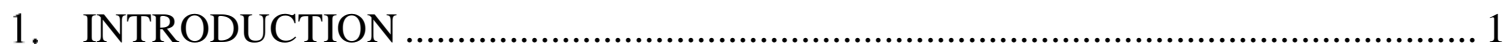

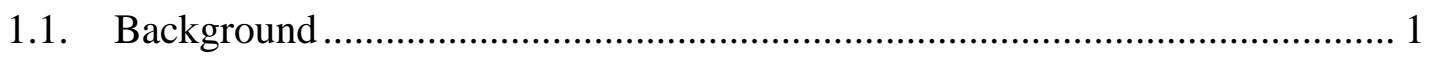

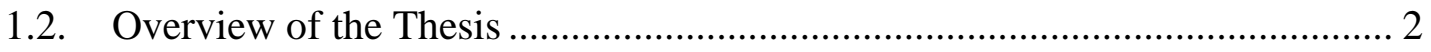

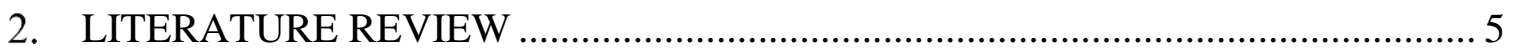

2.1. Modern Naval Submarines ................................................................. 5

2.1.1. History of Modern Naval Submarines .............................................. 5

2.1.2. Pros and Cons of Conventional and Nuclear Submarines ..................... 8

2.2. Power Generation and Storage Systems for Naval Submarines .................... 11

2.2.1. Diesel Electric Propulsion Systems .............................................. 11

2.2.2. Air Independent Propulsion Systems ............................................ 11

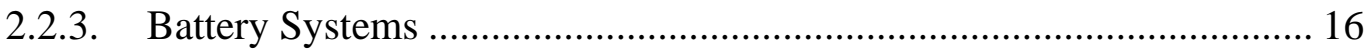

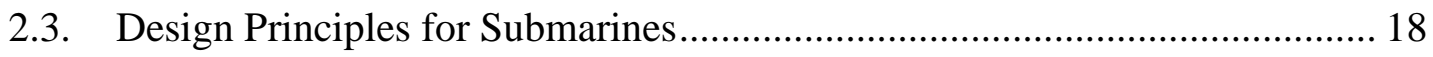

2.4. Review of Energy Management System and Operational Scheduling .......... 20

3. EMS MODEL FOR 4,000-TON CLASS CONVENTIONAL SUBMARINE ......... 24

3.1. 4,000-ton Class Conventional Submarine Model ........................................ 24

3.2. Energy Management System and Operational Scheduling ......................... 28 
3.2.1. Deterministic Operational Scheduling .................................................. 30

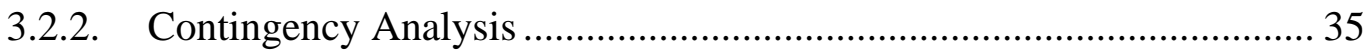

3.2.3. Stochastic Operational Scheduling ...................................................... 41

3.3. Electrical Load Profile .................................................................................... 47

3.4. Power Generation and Storage Components ................................................. 50

3.4.1. Snorkel System - Diesel-Electric Generators and Diesel Fuel Tanks.... 50

3.4.2. AIP System - PEMFC and Oxygen/Hydrogen Storages ......................... 51

3.4.3. Lithium-Ion Battery Cells ........................................................................ 53

3.4.4. Evaluation of Power Generation and Storage Systems........................... 54

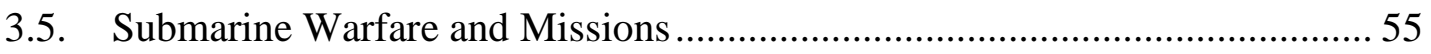

3.5.1. Surveillance and Information Gathering ................................................ 57

3.5.2. Landing of Special Operations Force ……………………………....... 58

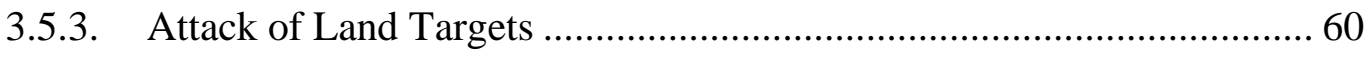

3.5.4. Protection of Task Forces and Merchant Shipping ................................. 61

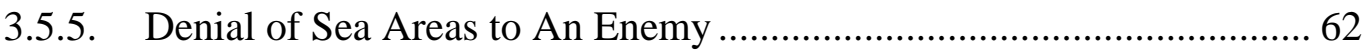

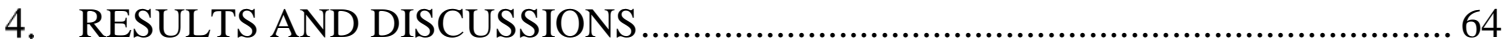

4.1. M1: Surveillance and Information Gathering ................................................. 65

4.2. M2: Landing of Special Operations Forces ................................................... 67

4.3. M3: Attack of Land Targets.......................................................................... 71

4.4. M4: Protection of Task Forces and Merchant Shipping .................................. 74

4.5. M5: Denial of Sea Areas to An Enemy ......................................................... 78 


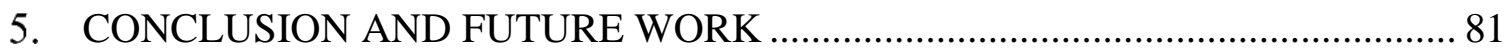

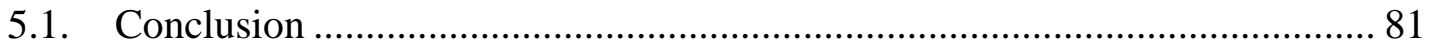

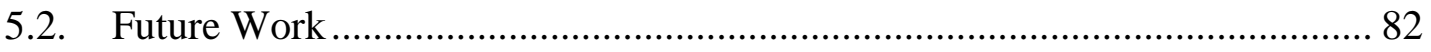

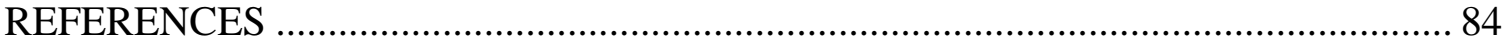




\section{LIST OF TABLES}

Table

Page

1. 17 Outage Cases for Contingency Analysis................................................... 36

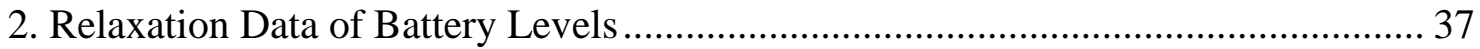

3. Maximum and Minimum Electrical Loads of All Systems in the Submarine .......... 49

4. The Proportions of Power Generation and Storage Systems................................. 55 


\section{LIST OF FIGURES}

Figure

Page

1. A submarine at Snorkeling Depth ............................................................... 1

2. Oxygen Consumption rates of Four AIP systems [22] .................................... 13

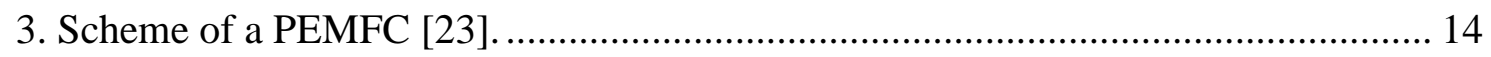

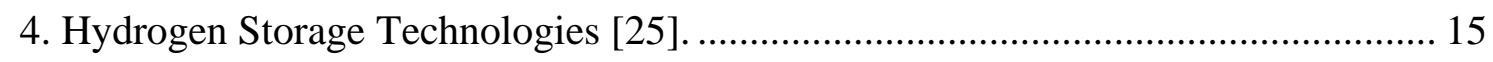

5. Energy Density Comparison of Batteries [32] .............................................. 18

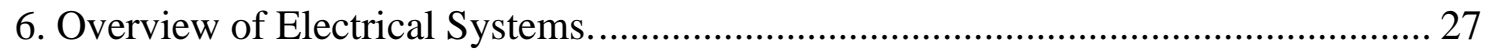

7. Flow Chart of Operational Scheduling Process ..................................................... 29

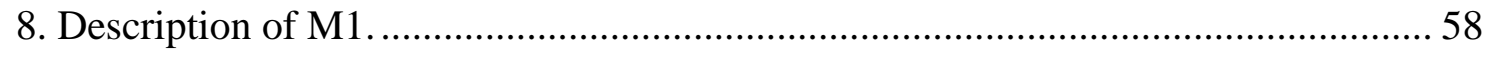

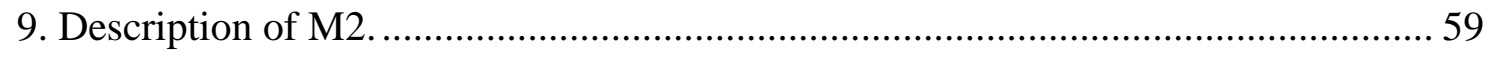

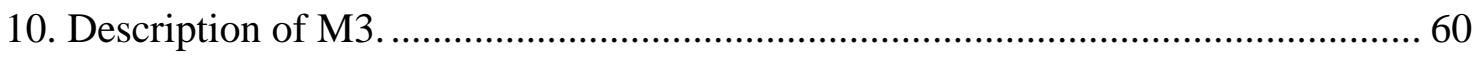

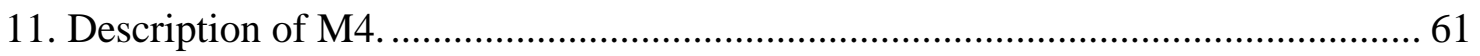

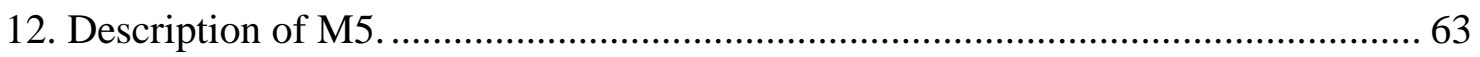

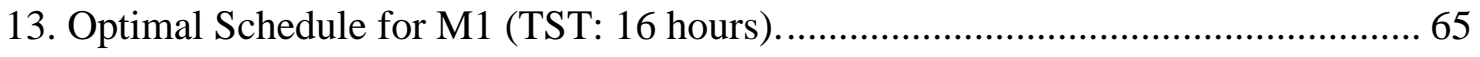

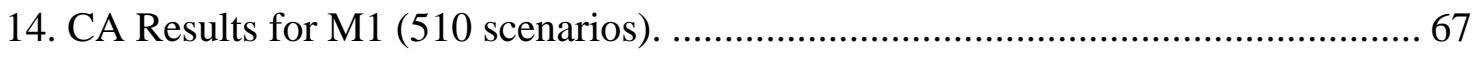

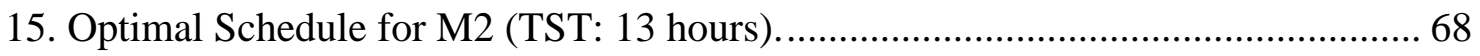

16. Results of CA on Optimal Schedule for M2 (510 Cases)................................. 69

17. Stochastic Optimal Schedule for M2 (TST: 13 hours). ................................... 70

18. Results of CA on Stochastic Optimal Schedule for M2 (510 Cases). .................. 71

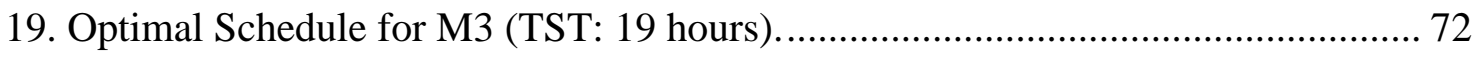

20. CA Results for M3 (510 Cases) ................................................................. 72

21. Stochastic Optimal Schedule for M3 (TST: 20 hours). ................................... 73 
Figure

22. Results of CA on Stochastic Optimal Schedule for M3 (510 Cases). 74

23. Optimal Schedule for M4 (TST: 17 hours) ................................................... 75

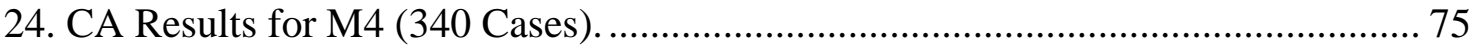

25. Stochastic Optimal Schedule for M4 (TST: 17 hours). ...................................... 76

26. Results of CA on Stochastic Optimal Schedule for M4 (340 Cases). .................... 76

27. Stochastic Optimal Schedule for M4 (TST: 18 hours). ....................................... 77

28. Results of CA on Stochastic Optimal Schedule for M4 (340 Cases). .................... 78

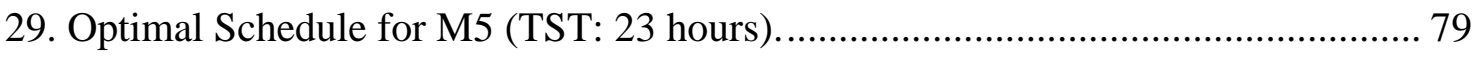

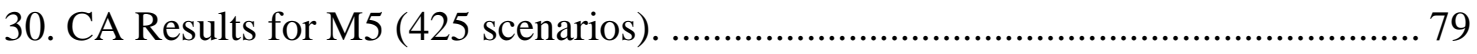




\section{LIST OF ACRONYMS}

Acronym

Meaning

AES

All-Electric Ship

$\mathrm{AL}$

Auxiliary Load

ASW

Anti-Submarine Warfare

ASuW Anti-Surface Warfare

BL

Base Load

CA

Contingency Analysis

DL Daily Load

EMS Energy Management System

FC Fuel Cell

HL Hotel Load

LOX Liquid Oxygen

M1 Mission One

M2 Mission Two

M3 Mission Three

M4 Mission Four

M5 Mission Five

P1 Mission Phase One

P2 Mission Phase Two

P2-1 Mission Phase Two-One

P2-2 Mission Phase Two-Two

P3 Mission Phase Three PEMFC Proton Exchange Membrane Fuel Cell

PL .Propulsion Load SONAR Sound Navigation Ranging TST Total Snorkeling Time 


\section{LIST OF SYMBOLS}

Set

Meaning

$\mathrm{T}$. Set of time periods

M. Set of missions

C. Set of scenarios

G. Set of outages $\mathrm{P}$ Set of propulsion loads

H. ...Set of hotel loads

A. Set of auxiliary loads W Set of ASW/ASuW hours

Index

Meaning

$\mathrm{t}$ Index of time periods

$\mathrm{m}$ Index of missions

c... g......

p.

h.

a...

W... Index of scenarios

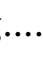
Index of outages .Index of propulsion loads

h......... Index of hotel loads Index of auxiliary loads Index of ASW/ASuW hours

Parameter

Meaning

$M_{m}$ Total duration of mission $m$ [hours] $P h 1_{m}$ Duration of phase 1 in mission $m$ [hours]

$P h 2_{m}$ Duration of phase 2 in mission $m$ [hours]

$P h 3_{m}$ Duration of phase 3 in mission $m$ [hours]

$D L_{m}$ Daily load in mission $m[k W h]$

$U T s_{m}$ Minimum up time for DGs in mission $m$ [hours] $D T s_{m}$ Minimum down time for DGs in mission $m$ [hours] 


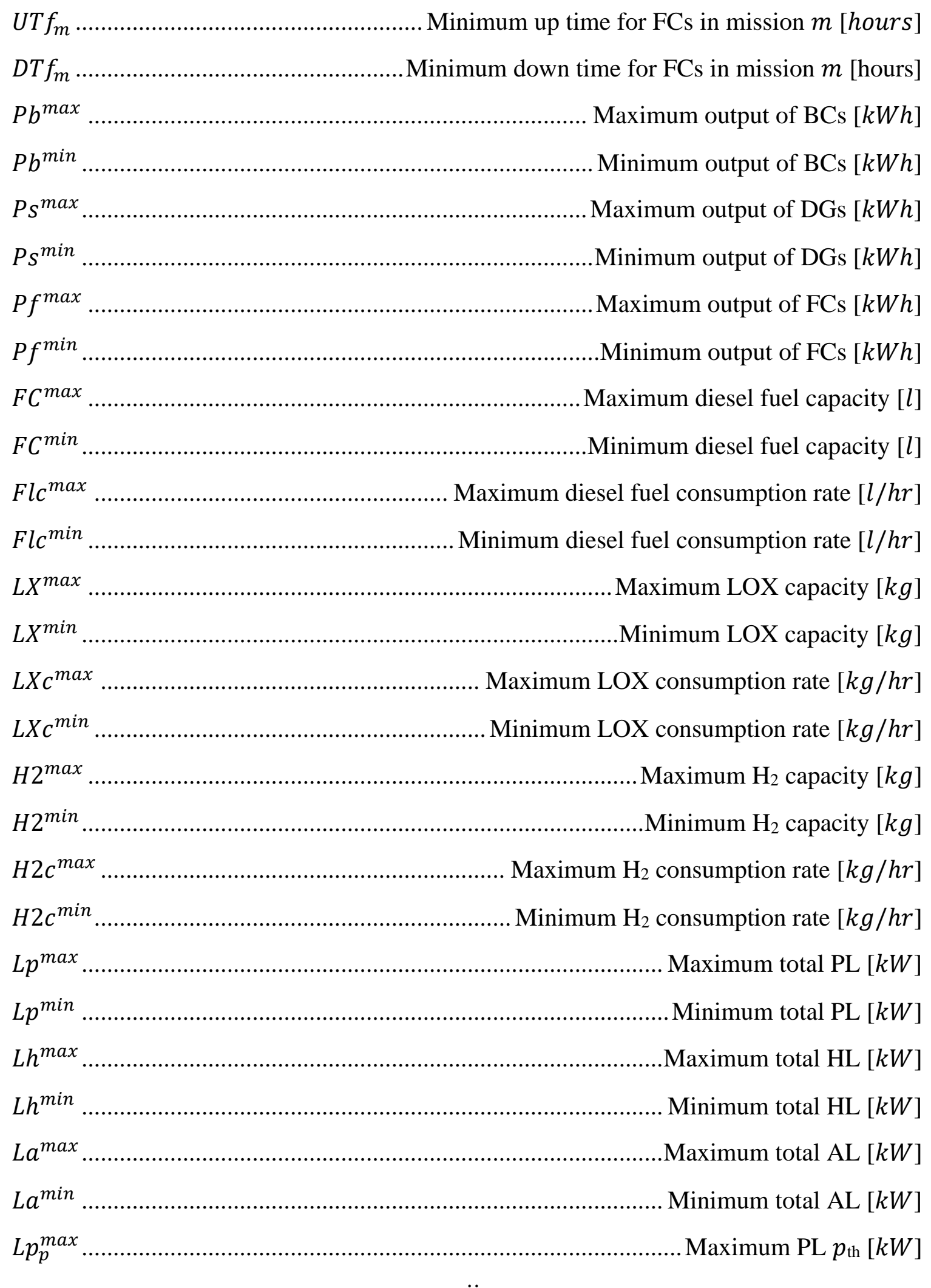




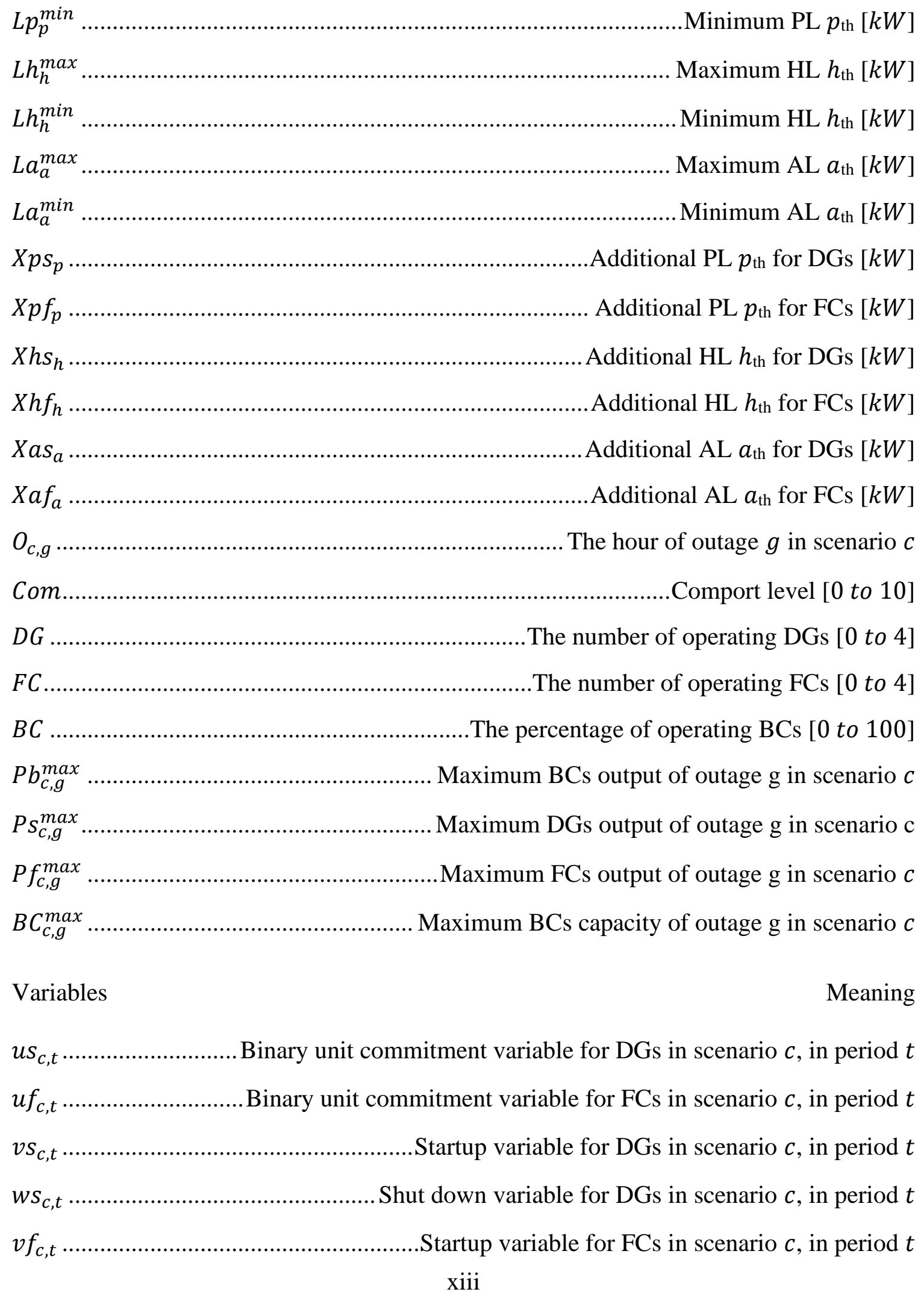


Shut down variable for FCs in scenario $c$, in period $t$

$P b_{c, t}$ BCs output in scenario $c$, in period $t$ $P b_{C, t}^{\max }$ Maximum BCs output in scenario $c$, in period $t$

$P S_{C}$ DGs output in scenario $c$, in period $t$

$P s_{c, t}^{\max }$ Maximum DGs output in scenario $c$, in period $t$

$P f_{c, t}$ FCs output in scenario $c$, in period $t$ $P f_{c, t}^{\max }$ Maximum FCs output in scenario $c$, in period $t$

$B C_{c, t}$ Battery capacity in scenario $c$, in period $t$ $B C_{c, t}^{\max }$ Maximum battery capacity in scenario $c$, in period $t$ $B C_{c, t}^{\min }$ Minimum battery capacity in scenario $c$, in period $t$ $B C_{C, t}^{\operatorname{minlvl}}$ Min battery level in scenario $c$, in period $t$ $F C_{c, t}$ Diesel fuel capacity in scenario $c$, in period $t$

$F l c_{c, t}$ Diesel fuel consumption rate in scenario $c$, in period $t$ $L X_{c, t}$ LOX capacity in scenario $c$, in period $t$ $L X c_{c, t}$ LOX consumption rate in scenario $c$, in period $t$

$H 2_{c, t}$ $\mathrm{H}_{2}$ capacity in scenario $c$, in period $t$ $H 2 c_{c, t}$ $\mathrm{H}_{2}$ consumption rate in scenario $c$, in period $t$ $L p_{c, t}$ Total PL in scenario $c$, in period $t$

$L h_{c, t}$ Total HL in scenario $c$, in period $t$

$L a_{c, t}$ Total AL in scenario $c$, in period $t$ $L p_{c, t}^{\max }$ Maximum total PL in scenario $c$, in period $t$ $L p_{c, t}^{\min }$ Minimum total PL in scenario $c$, in period $t$ $L h_{c, t}^{\max }$ Maximum total HL in scenario $c$, in period $t$ $L h_{c, t}^{\min }$ Minimum total $\mathrm{HL}$ in scenario $c$, in period $t$ $L a_{c, t}^{\max }$ Maximum total AL in scenario $c$, in period $t$ $L a_{c, t}^{\min }$ Minimum total $\mathrm{AL}$ in scenario $c$, in period $t$ xiv 
$L p_{c, p, t}$

$L p_{c, p, t}^{\max }$

$L p_{c, p, t}^{\min }$

$L h_{c, h, t}$

$L h_{c, h, t}^{\max }$

$L h_{c, h, t}^{\min }$

$L a_{c, a, t}$

$L a_{c, a, t}^{\min }$

$L a_{c, a, t}^{\max }$

$B C_{c, t}^{\operatorname{minlvl}}$ 


\section{INTRODUCTION}

\subsection{Background}

In naval warfare, submarines have been serving as a game changer since World War I when they were first employed into a full-scale war, with invisible and silent services. Since then, many countries have started to introduce submarines in order to achieve maritime dominance. Conventional submarines, which are equipped with diesel generators and batteries, dominated submarine warfare at the beginning, but through the second half of the $20^{\text {th }}$ century, as nuclear energy based solutions received attention, many countries such as the U.S. and Russia started using nuclear-powered submarines.

Submarines are capable of navigating all over the world unseen and undetected, gathering information and launching missiles when necessary, and this capability is ultimately proportional to their underwater endurance. Unlike nuclear-powered submarines, conventional diesel-electric submarines have limited power resources available onboard. The submarines need to operate diesel-electric generators right below the surface to charge the batteries while the masts are exposed above the surface, making loud noises and spreading them through the water as shown in Figure 1 [1]. This process, which is known

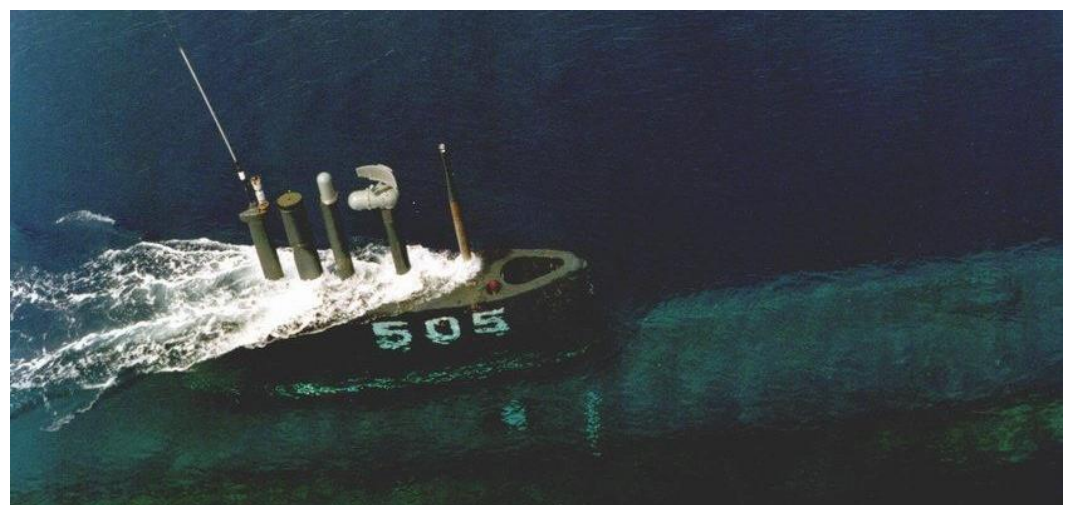

Figure 1. A Submarine at Snorkeling Depth 
as snorkeling, is the most dangerous time for submarines, as it makes them easily detectable by acoustic and non-acoustic sensors of enemy assets. This imposes a significant concern for the conventional submarines, including the boats with fuel cells. Thus, optimizing the energy resources while reducing the need for snorkeling is a key factor to enhance underwater endurance [2], [3].

Optimal energy scheduling is an essential procedure in an isolated environment such as naval submarines. For the officers onboard, an energy management system (EMS) can support them as a supervisory tool to optimize energy resources while they plan operational schedules for various missions. The EMS, which optimally schedules submarines' available energy resources for multiple missions, may substantially reduce the need for excessive snorkeling and the danger of being exposed to enemies. The flexibility of energy consumption for a mission's duration, purposes, and available energy resources must be simultaneously considered in operational scheduling processes, so as to obtain effective operational schedules and longer underwater endurance. In this work, the proposed EMS can produce hourly, daily, and weekly energy generation and consumption schedules for the designed mission scenarios. Additionally, such an EMS tool can be enhanced to account for outages in the systems and risky events in order to support submarine officers to make critical decisions at sea.

\subsection{Overview of the Thesis}

In this thesis, an EMS is modeled for a 4,000-ton class conventional submarine which is equipped with diesel-electric generators, fuel cells, batteries as well as their subordinate storage systems. In consideration of naval warfare, five types of missions are designed to dispatch the submarine model to examine its performance. The proposed EMS monitors 
all the energy flows from generation phase to consumption phase and plans their timings and the amount of energy by accessing every data point. Essentially, the EMS performs operational scheduling processes to produce optimal schedules in accordance with the conditions of the mission scenarios and the specifications of the power generation and storage systems.

In the literature review chapter, the history of modern naval submarines is explained to understand how electric power systems were adapted to naval submarines, and why the adaptation of the electric power systems was indispensable in the course of history. Power systems for naval submarines are described as mainly four types including their storage systems. Moreover, submarine design principles are reviewed for building the 4,000-ton class submarine model. Finally, EMS and operational scheduling processes are studied to examine how they can be implemented under the particular conditions of submarine operations.

Chapter 3 explains the proposed energy management algorithms for the EMS, which are developed as optimization models based on deterministic and stochastic operational scheduling processes. The EMS proposed in this study can be used for a submarine that is equipped with diesel-electric generators (DG), proton exchange membrane fuel cells (PEMFC), lithium-ion (Li-ion) battery cells (BC), and other subordinate systems. In order to investigate how this EMS performs with the power systems, five practical mission scenarios are designed and described as sets of constraints which impose energy demanding situations to the submarine model.

In the results and discussions, it is shown that the EMS creates operational schedules by deploying the submarine model into the mission scenarios. In the deterministic 
operational scheduling process, optimal schedules with the minimum snorkeling times are generated for each mission scenario, and then, the EMS performs contingency analysis (CA) by applying outages on the power system components based on the optimal schedules. By analyzing the CA results, stochastic operational scheduling process produces a new optimal schedule, and it goes back to the next cycle of CA. Essentially, these processes operate as a loop until all outage scenarios result in secured optimal schedules.

Lastly, the conclusion chapter provides an overview of the results from the proposed EMS and its performance, which explain the worth of the conducted research in naval submarine warfare. The future work shows how this presented work can be connected with other technology in submarine engineering, especially in power generation and storage systems. 


\section{LITERATURE REVIEW}

\subsection{Modern Naval Submarines}

\subsubsection{History of Modern Naval Submarines}

Introduction of electric power to submersible vessels was the very first step in modern submarine development. Before that, power source of submersible vessels had started from human power and then moved to mechanical power in the 1800 s. Electric battery technology enabled the submersible vessels to be submarines, and the first electrically propelled boats were built in the 1880s in Spain, France, and England.

At the end of 19th century, modern submarines made a remarkable advance in their development with various important technologies' appearance. The leading countries who manufactured submarines such as the United States, France, Russia, and England started adopting and establishing diesel propulsion systems, electric batteries and periscopes. Batteries were utilized as they stay underwater, and gasoline (petrol) or diesel engines operated to charge the batteries on the surface. Historically, gasoline was used at the early stages of development, kerosene in the middle, and diesel became dominant due to reduced flammability. As the submarine became famous as a powerful weapon, naval warfare of $20^{\text {th }}$ century was expected to be more complicated and complex than ever before.

The U.S. Navy introduced the first commissioned submarine, USS Holland, on 11 April 1900. It was originally named the Holland Type VI submarine which was designed by the Irish inventor John Philip Holland in 1896. The submarine, which was equipped with internal combustion engines and electric batteries, was launched on 17 May 1897 in Elizabeth, New Jersey. After conducting the sea trial, it was purchased by the U.S. Navy. 
Meanwhile, a competition was accelerated in building similar types of submarines among the Royal Navy, the Imperial Russian Navy, and the French Navy.

At the time diesel submarines needed to be fully surfaced to take air from outside for running their engines and carry very large batteries to be submerged. This requirement limited the submarines just as submergible boats. Nonetheless, naval submarines played a significant role in World War I. The first submarine war patrol in history occurred at the North Sea in August 1914, when a group of ten German U-boats attacked Royal Navy warships. More submersibles than true submarines, U-boats sailed primarily on the surface by running diesel engines, and they submerge relying on electric batteries before attacking an enemy. During World War I, more than 5,000 Allied ships were sunk by U-boats [4].

During World War II, two critical innovations for diesel submarines took place, which expanded submerged duration considerably. The first innovation was the development of the snorkel system. The first boat to be fitted with the snorkel system was German U-58, which was on a sea trial in the Baltic Sea in 1943. Prior to the introduction of U-58, once the batteries ran out, submarines had to be surfaced to recharge their batteries, and hence the submerged duration was only up to a few hours. However, the snorkel system allowed diesel submarines to charge the batteries while they stay underwater. The second innovation was the invention of the diesel-electric propulsion. Early diesel submarines had diesel engines and electric motors on the same shaft which also connected to propellers via clutches in order to drive electric motors while the engines recharged the batteries and propel the submarine at the same time. In the 1930s, this mechanism has been modified for the U.S. Navy and the British submarines. Diesel engines became no longer connected to motors directly but were linked to separate generators. Propellers mainly connected to 
motors which powered by batteries, not directly by diesel engines. The combination of the snorkel system and the diesel-electric propulsion opened a new era of diesel submarines, because submarines were able to patrol at low speeds while diesel engines were running at maximum rated power to recharge batteries as quickly as possible by snorkeling.

After WWI and WWII, the Cold War era emerged, during which the U.S. and the Soviet Union constructed very large military assets to outwardly display their power. The nuclear-powered submarines were the perfect platform for threatening the other and demonstrating their power. The concept of the nuclear-powered submarine was suggested first in the U.S. Navy by the Naval Research Laboratory in 1939. The world's first nuclearpowered submarine was constructed by military-industrial-academic collaboration for the development of a nuclear propulsion plant. As a result of this project, USS Nautilus (SSN571) was commissioned on 30 September 1954. After 4 years, the Soviet Navy also launched their own nuclear-powered submarine, which was K-3 Leninskiy Komsomol of the Project 627 Kit class, called a November-class submarine by NATO in 1958. Today, six countries deploy nuclear-powered submarines: the U.S., Russia, France, the U.K., China, and India.

Nuclear-powered submarines have nuclear reactors for power generation. The reactors are mainly used for generating electricity to power electric motors aligned with the shaft and propeller. In order to fit inside submarines, these reactors, which are designed relatively smaller than commercial ones, produce more than enough power to go faster and operate all subsystems by utilizing highly enriched fuel. Beside the nuclear reactors, all nuclear-powered submarines have diesel-electric generators and batteries as a backup power supply. If an emergency shutdown occurs, a cooling system for reactor decay heat 
removal should be operated automatically, powered by the diesel generators. Additionally, the diesel engines can support an emergency propulsion system. The most advantageous feature of nuclear-powered submarines is that they can perform missions all over the world for maximum 30 years without refueling. This was revolutionary for submarines because they do not need to factor batteries discharging over time. Initially, the major superpowers kept building diesel submarines along with nuclear ones, but since 1959, the U.S. Navy effectively has stopped building nonnuclear-powered submarines [5].

From the 1960s to 1990s, many countries around the world started to construct their own submarines for their defense. In 1968, the Chinese Navy began to build nuclearpowered submarines, meanwhile building and buying many nonnuclear-powered submarines. Meanwhile, India started purchasing and constructing diesel-electric submarines and the first nuclear-powered submarine was introduced in 1998. Since the disorganization of the Soviet Union in 1991, a combination of nuclear-powered and conventional submarines has been the policy of the Russian Navy.

In recent years, energy technologies have been developing such as air independent propulsion system, lithium batteries and advanced nuclear reactors. As these newly improved technologies were adapted to naval submarines, their performance at sea has been improved significantly in order to govern naval warfare.

\subsubsection{Pros and Cons of Conventional and Nuclear Submarines}

Conventional submarines, which mostly employ diesel-electric systems, have two critical limitations [6], [7]. Stealth with being the first, while conventional submarines are submerged and using batteries at low speed, they are reasonably difficult to detect by acoustic sensors due to the quietness. As is well known, maintaining stealth is the key 
factor for all submarines, including nuclear-powered submarines, to survive at sea. Since batteries contain finite electrical energy, conventional submarines need to charge batteries by snorkeling before they meet the floor bound. For snorkeling, submarines need to proceed to periscope depth which is right below the surface and raise the snorkel mast above the surface in order to inhale air, thereby making operation of diesel generators possible. While they are running to recharge the batteries, the stealth is no longer sustained acoustically and non-acoustically. The noise makes their own SONAR systems degrade severely by interrupting sounds coming from outside of the hull. Conversely it spread out through underwater and may be able to reach an enemy's detection systems. Moreover, the mast exposed above surface can be visually located by enemy assets. Hence, snorkeling time is the most vulnerable period to the submarines making them a possible target by losing their element of stealth.

The second is mobility that decides how far and fast submarines can move. Mobility, speed, distance, and efficiency are interconnected under the limitation of batteries [8]. Moving at high speeds makes their batteries drain rapidly but navigating at economic speed has longer duration and range with the same amount of energy from the same batteries. From a perspective of war, submarines need to be deployed in a designated location at the right time with enough mobility, which is equivalent to electrical energy, to complete their missions. However, due to the limitation of mobility, conventional submarines are normally dispatched in areas like near enemy harbors or the entrance of straits, which can be achieved by beforehand maneuvers.

Although nuclear-powered submarines do not need to snorkel, stealth is the first limitation as well [9], [10]. Since nuclear reactors are always in operation, the noise from 
the steam turbines and the reactor pumps make constant resonance which could be heard on an enemies' sound navigation ranging (SONAR) systems. In addition, typical conversion efficiency of nuclear to electrical energy is about 33\%. This means somehow almost $70 \%$ of the heat generated by the reactor needs to be dissipated effectively. The only solution to this dilemma can be taken by releasing the heat into the sea water. This indispensable phenomenon is called as "thermal wake", a warmed water with lower density. This, in turn, might be observed by enemy's thermal detection systems such as infrared cameras.

Nuclear-powered submarines are one of the most extremely expensive military assets to construct and operate. The Virginia class, which is the new generation of nuclearpowered fast attack submarines in the U.S. Navy, costs US $\$ 2.6$ billion per boat [11]. The cost is three to four times more expensive than conventional submarines. Whereas, the Soryu class [12] is diesel-electric attack submarines, which are the latest and biggest among Japanese submarines, and costs US $\$ 0.54$ billion per boat, which is less than one-fourth of the Virginia class.

From a safety perspective, nuclear-powered submarines receive critical attention. Obviously, the number of accidents is much larger from diesel-electric submarines, since all modern naval submarines developed from early diesel submarines. Moreover, the fundamental safety features have been mostly improved through many sea trials and battles before their induction into the navy. Despite this fact, nuclear-powered submarines are more likely to be considered as the dangerous. When people think about nuclear reactors, they immediately respond with "radioactive" and "dangerous" rather than "low greenhouse gas emission" and "high power supply". Because, although the number of accidents is very 
small, they quite quickly become major catastrophe such as well-known Chernobyl and Fukushima incidents [13], [14].

\subsection{Power Generation and Storage Systems for Naval Submarines}

\subsubsection{Diesel Electric Propulsion Systems}

When diesel engines were introduced to submergible vessels at first, they drove propellers directly only at the surface [15], [16]. However, in the 1930s, the U.S. Navy changed the mechanism for better performance. By making diesel engines separable from propeller shafts, they can either charge batteries or drive electric motors [3], [8]. This adjustment enabled diesel generators to charge batteries independently regardless of the speed of electric motors. While diesel generators are running at maximum power, electric motors can stay at economic speed to avoid consuming unnecessary energy and to charge batteries more efficiently. Additionally, this arrangement allows that the submarines may move slowly to recharge batteries quickly, minimizing time at the surface for snorkeling. The diesel electric mechanism with snorkel system had been improved through WWII and fundamentally completed by the 1960s. Although modern diesel electric propulsion systems work in a way like that of the systems in 1960s, there have been many technological and material improvements to enhance their generative performance and efficiency, such as shock proofing for mounting systems, magnetically compensated materials, and high efficiency advanced diesel engines [17].

\subsubsection{Air Independent Propulsion Systems}

The essential element is air, more particularly oxygen, which is required for internal combustion inside diesel engines, and diesel submarines must inhale oxygen through 
snorkel mast for the combustion to occur. In order to reduce these vulnerable moments, air independent propulsion (AIP) systems, which can offer additional option to extend underwater endurance, are introduced to naval submarines [18].

Several countries have been developing different types of AIP systems for naval submarines such as closed cycle steam turbines, Stirling cycle engines and fuel cells. In the first case, the French shipyard Direction des Constructions Navales Serices (DCNS) developed Module d'Energie Sous-Marine Autonome (MESMA) system, which was installed in Agosta 90B and Scorpene-class submarines, an example of a steam turbine, powered by steam from the combustion of ethanol and stored oxygen at 60 atmospheric pressure (atm). This pressured fire allows release of carbon dioxide emissions to outside of the boat at any depth without an exhaust compressor [19], [20]. In the second case, three Gotland-class submarines with an auxiliary Stirling engine were made by the Swedish marine company Kockums for the Swedish Navy. Liquid oxygen (LOX) and diesel fuel are mixed and burned in the Stirling engine to drive the electrical generators for either propulsion or for charging batteries. Recently, new Japanese Soryu-class and Swedish Blekinge-class submarines have been and continue to be built with Stirling engines to enhance their underwater endurance. Last, but not least, the third method is chemical energy being converted into electrical energy using fuel cells. By facilitating a reaction between the hydrogen and oxygen, fuel cells generate electricity producing only water as its byproduct without any emission. Siemens from Germany has been responsible for manufacturing fuel cell units, which are equipped in Type 212A submarine from Howaldswerke Deutsche Werft AG (HDW) for the German Navy [21]. 


\section{Oxygen consumption}

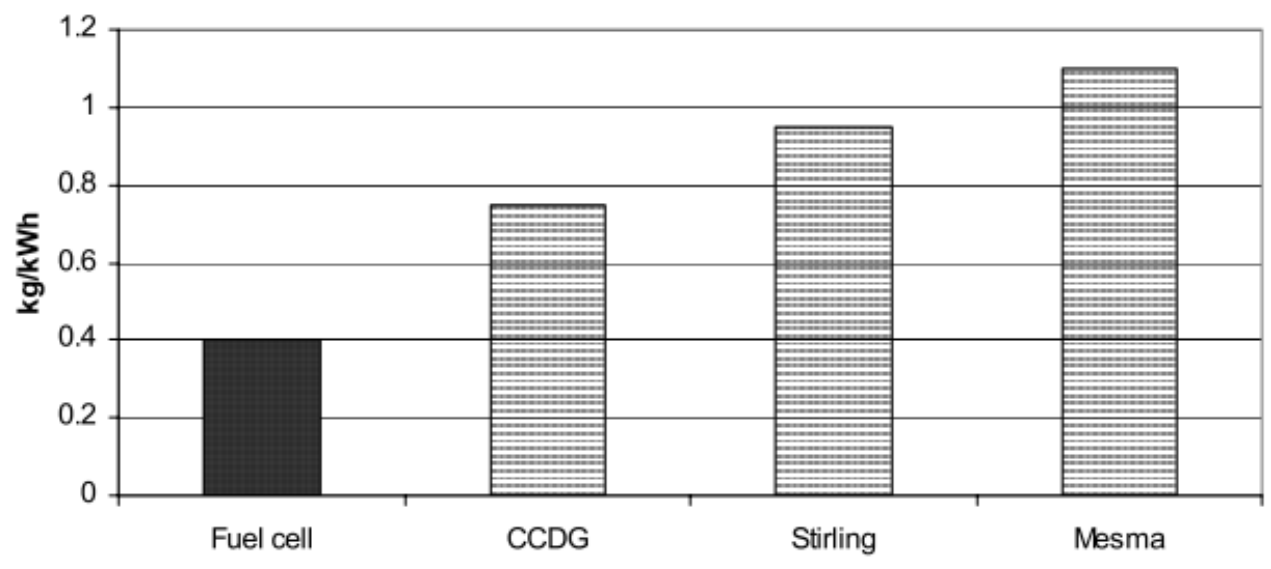

Figure 2. Oxygen Consumption rates of Four AIP systems [22].

However, AIP systems must be qualified for the environment of submarine operation, such as low noise level, low heat transfer to the sea water, low magnetic signatures, and operation without surfacing over longer period [22]. All the above-mentioned AIP systems, except fuel cells, have mechanical components utilizing piston movement, which makes noise with a relatively lower fuel and oxidant efficiency. Whereas, an electrochemical energy converter, i.e. fuel cells, do not contain moving parts and hence they can provide electrical energy more efficiently by using less oxygen and making relatively low noise. The comparison data [23] of four AIP systems for oxygen consumption rates are presented in Figure 2.

Fuel cells are the most applicable AIP system for diesel-electric submarines due to the following characteristics [22]:

- High efficiency of up to $70 \%\left(\mathrm{H}_{2} / \mathrm{O}_{2}\right.$ operation).

- The quietness of the energy generation process, normally only achievable with battery operation. 
- Depth independence during the operation.

- Good operational and control features.

- Balancing weights by easily storing the product water.

Types of fuel cells are determined by the electrolyte used and operating temperature varies considerably in range. Solid oxide fuel cells take high temperature range, from 1382 to $1832{ }^{\circ} \mathrm{F}$ (from 750 to $1000{ }^{\circ} \mathrm{C}$ ), with ceramic materials for electrolyte and electrodes. Molten carbonate fuel cells work at around $1202^{\circ} \mathrm{F}\left(650^{\circ} \mathrm{C}\right)$. These two types can possibly be utilized as internal reformers for future submarines. Phosphoric acid fuel cells operate at $392{ }^{\circ} \mathrm{F}\left(200{ }^{\circ} \mathrm{C}\right)$ [23]. When considering the isolated environment of submarines and thermal stability at low temperature, proton exchange membrane fuel cell (PEMFC) is the most suitable type of fuel cells, which can be used for underwater vessels because it operates at up to $176^{\circ} \mathrm{F}\left(80^{\circ} \mathrm{C}\right)$.

Furthermore, PEMFC has the highest gravimetric and volumetric power density among all currently available fuel cell technologies [2], [23], [24]. Because PEMFC is built as a bipolar stack in a filter press arrangement and each membrane-electrode assembly

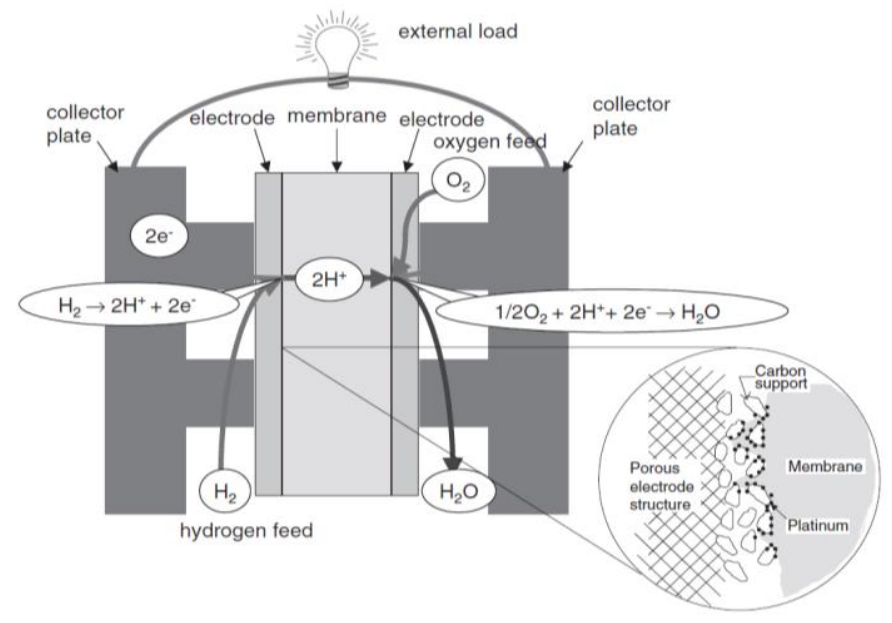

Figure 3. Scheme of a PEMFC [23]. 
consists of a very thin proton-conducting polymer membrane, an electrolyte with a layer of carbon-supported platinum catalyst, an anode, and a cathode. The bipolar collector plates are responsible for storing electric current and the distribution of reactant gases as illustrated in Figure 3.

All fuel cell systems need typically hydrogen and an oxidant, usually oxygen, for the reaction to generate electricity. These gaseous elements must be stored somehow on board safely. With that, there are several methods to store hydrogen and oxygen on submarines. Hydrogen can be stored in various chemical states, such as compressed gas form, liquid form at cryogenic temperatures, and solid forms in some hydrides. Many studies showed that the most efficient way is in a gaseous state [24] but due to safety issues and instability, compressed gas perhaps is not the best way to proceed. Metal hydrides are not the most efficient method but are indeed the safest way to store hydrogen because the containers are full of metal hydrides without any free gas. Various hydrogen storage methods are presented in Figure 4 [24] [25].

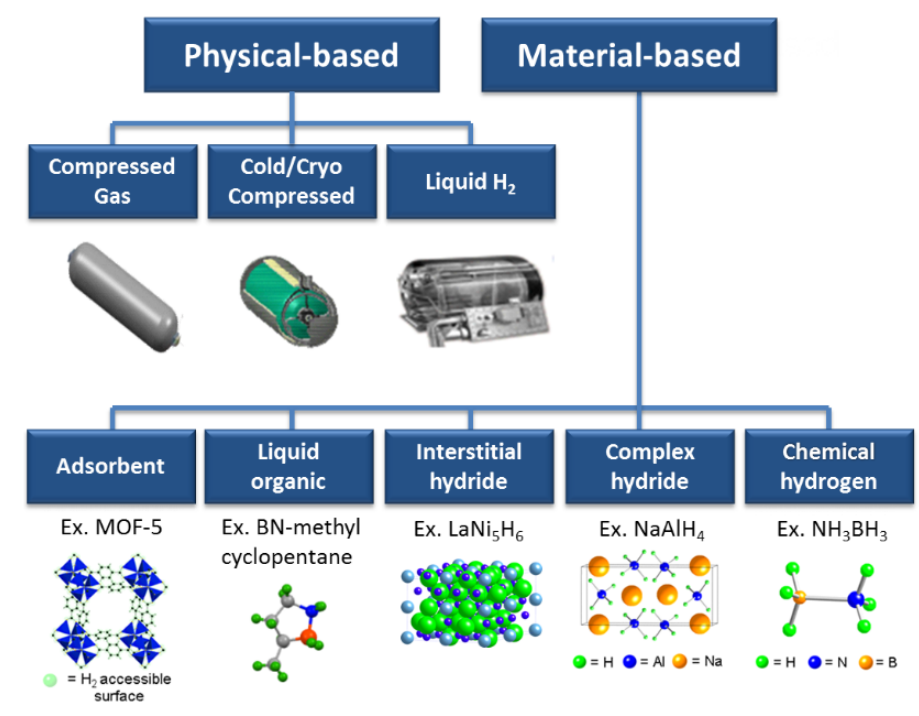

Figure 4. Hydrogen Storage Technologies [25]. 
The most common storage methods for oxygen are as gaseous form or LOX. LOX is the most efficient method to store oxygen because of high volumetric and gravimetric density. LOX storage with a cryogenic system can hold oxygen at subcritical state in very low temperatures and high pressures [24].

Metal hydrides as hydrogen storage and LOX storage systems are utilized in PEMFCs by HDW from Germany to be installed in Type 212A submarines and Type 214 submarines. Type 212A submarines have 18 hydride tanks, which weighs of 4.4 tons with the volume of 1200 liters each, along with 1 MWh of energy [23]. The 18 hydride tanks, which hardly need maintenance, are located outside and around the pressure hull, so that a huge mass of them can prevent low-frequency noise from spreading into the sea water. Super-insulated tanks for LOX storage are installed outside the pressure hull for Type 212A submarines and inside the pressure hull for Type 214 submarines. The tanks require highly reliable safety features to manage LOX at extremely low temperature, $-292{ }^{\circ} \mathrm{F}\left(-180{ }^{\circ} \mathrm{C}\right)$, and high pressure (50 bar) to withstand leakage, shock, and rust [23].

\subsubsection{Battery Systems}

Lead-acid batteries have been serving as the main power source of conventional submarines for decades [26]. However, as battery technology is improved, lithium-ion (Liion) batteries receive great attention as an alternative to lead-acid batteries [27]. Li-ion batteries have been developing for electric vehicles and small devices like cell phones and laptops since the early 2000s [28]. In terms of energy density, power density, life, safety and cost, Li-ion batteries can provide much better performance than lead-acid batteries [29]. When compared to lead-acid batteries, they last easily twice as long under the same physical conditions. Energy density comparison of various battery types is shown in Figure 
5. Energy density of batteries mainly determines underwater endurance of submarines, and maintaining stealth is reasonably dependent on underwater endurance. If batteries with higher energy density fit into smaller spaces, it reduces the size of battery rooms in submarines and the saved space can be converted into room for other purposes such as ammunitions. Therefore, Li-ion batteries make submarines utilize more energy with the same size, when compared to lead-acid batteries. In addition to higher energy density, there are several advantages in Li-ion batteries as follows [30], [31].

- Substantially larger energy storage capacity, when compared to lead-acid batteries.

- Battery cells are gas-tight in normal operations.

- Power is not governed by the state of charge.

- 30-50\% increase in effective capacity during snorkel operation.

- Better performance in low state of charge with no memory effects.

- Significantly less maintenance required.

Japan launched the first diesel electric submarine equipped with Li-ion batteries in 2018 [12]. Mitsubishi Heavy Industries and Kawasaki Shipbuilding Corporation have been working on Soryu-class submarines to deliver to the Japan Maritime Self-Defense Force in 2020. The first submarine of the Soryu-class, in length of 84 meters and about 3,000 tons, can reach maximum speed of 20 knots [12]. It has a diesel-electric system with Liion batteries expected to provide enhanced hybrid propulsion performance such as longerendurance, reduced snorkel time, less acoustic signature, and extended range. 


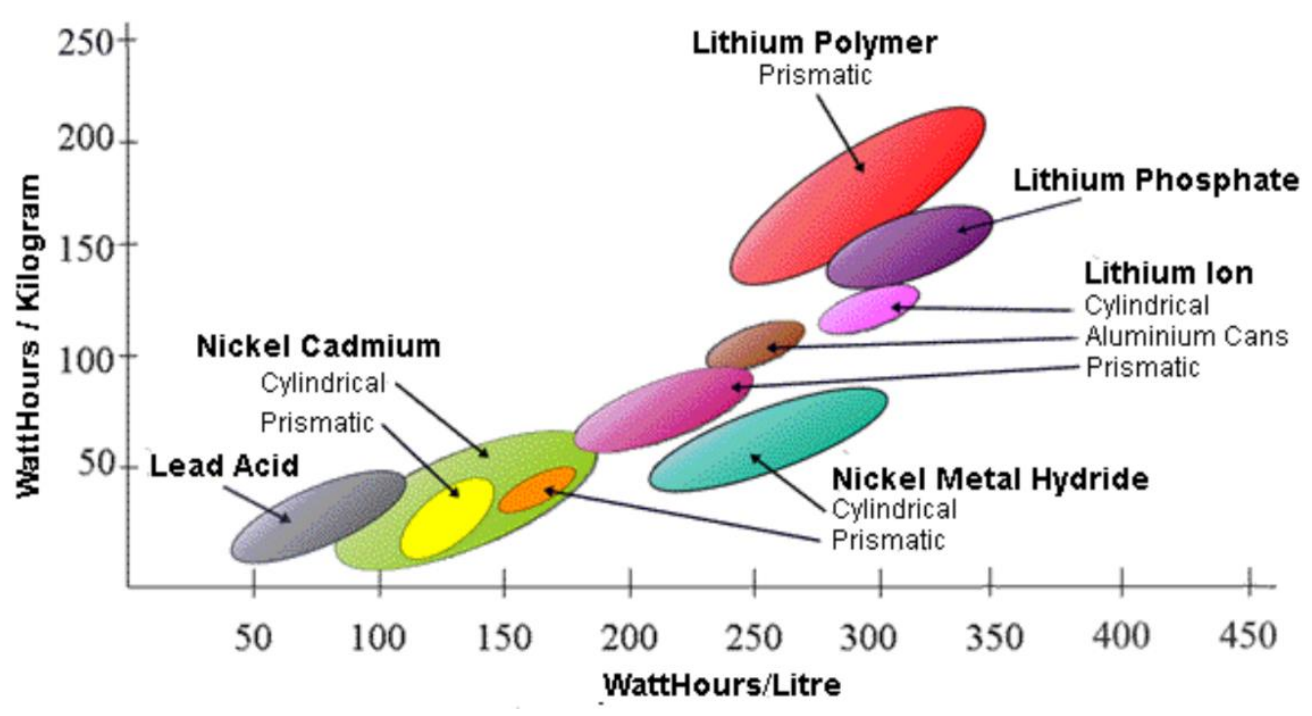

Figure 5. Energy Density Comparison of Batteries [32].

South Korea announced that the next-generation diesel attack submarines, which are expected to launch in the mid-2020s [32], [33] and they will be equipped with Li-ion batteries to double the operation hours. Samsung SDI, the Li-ion battery manufacturer for various platforms, developed the battery modules for the second batch of three KSS-III submarines, which are built by Daewoo Shipbuilding \& Marine Engineering. The first submarine, in length of 83.5 meters and more than 3,000 tons, can reach maximum speed of 20 knots.

\subsection{Design Principles for Submarines}

Generally, every engineering design principle must be focused on satisfying certain specific requirements. Meanwhile they share common features which originated from basic engineering background. Likewise, submarines need to be designed specially to operate under water and have similar features with any other marine vessels.

There are many considerable aspects for submarine design objectives but the primary objectives [34] are as these three: 
- The submarine should perform the functional purpose of the customer or operator.

- The design should be practical for being constructed using the capable technology and the available resources.

- The cost of the product should be acceptable by the customer.

The objectives are interactive and inseparable with one another because they support each other and combined with engineering features. The design process normally starts with setting up the requirements and ends with a complete construction of the product. Let's look at the detailed steps of the design process. First, operational requirements should be specified for further process. Second, concept studies are performed to determine the size, cost, payload, performance, etc. Third, subsystems and materials should be selected through feasibility studies. Last but not the least, the product must be completed as a whole with full functionality and detailed arrangements. Fundamentally, the production design is completed by following above steps and contains the following [34].

- Structure: Main pressure hull configuration, main internal structure scantlings, external tankage and free flood structure, major spaces for large equipment.

- Arrangements: General arrangement drawings for all components, plans for locating major systems and items, layouts for spaces and cabinets, specific arrangements of sensors, masts, weapons and payload.

- Hydrodynamics: Model tests for propulsion and resistance, control and dynamic stability tests, power demand, propulsor model tests.

- Systems: Power generation and storage capacity, pipes and cables, main valves, switches and penetrations, appropriate standards and specifications. 
- Hydrostatics: Buoyance contributions, center of gravity, sizes and locations of main ballast tanks and trim, size of compensating tanks, permanent ballast based on longitudinal balance and transverse stability (surfaced and submerged).

In this work, the entire submarine design process will not be discussed, however the study will mainly focus on the design of power generation and storage systems.

\subsection{Review of Energy Management System and Operational Scheduling}

Energy management involves planning, scheduling and operation of energy generation and consumption components [35], and its goals are optimization of schedule, resource saving, and energy conservation [36]. EMS started from the need for electric equipment manufacturers to operate their systems as efficiently as possible [37]. Furthermore, EMS is employed to monitor, control, estimate, and optimize the performance of power generation systems and its resources by utilizing computer-based algorithms. EMS not only can monitor energy utilization of equipment, vehicles, buildings, industry, and factories by following the pre-defined algorithms, but also control energy flows through distribution system in accordance with various purposes. Additionally, EMS can access any data point within the power generation, distribution, and storage systems and the collected data are analyzed for better operation of the entire systems [38]. More importantly, EMS is designed to manage subordinate systems to accomplish energy efficiency by optimizing serial processes from generation to consumption.

EMS is an essential advisory tool for operators in naval surface ships and submarines since they only have limited resources in an isolated environment [38], [39], [40]. In addition to that, since all-electric ships (AES) including submarines are becoming a 
standard in recent years, power resources in hybrid propulsion systems need more highly efficient management systems [41]. Moreover, AES has a significant feature of the integrated power systems (IPS), which utilize dc power distribution systems which require advanced control and management [38], [42], [43]. Furthermore, shipboard energy management algorithms start implementing renewable energy resources such as wind turbines and photovoltaics these days [44].

Unlike normal AES, conventional submarines are supplied electric energy mainly from snorkeling process. This process is not a simple action like turning the switch on and off, and it is easily affected by internal or external circumstances. Furthermore, there are multiple uncertainties that can take place under the sea such as severe weather conditions and an encounter with an enemy. Therefore, EMS required to be modeled as a core part of submarines because EMS can be a crucial assistant to the officers onboard in order to offer optimal performance.

Scheduling is a process managing utilization of resources and their timings following pre-defined rules. From the perspective of operation in power systems, generation, distribution, and consumption of electrical energy are set to be organized by the operators within given conditions [35]. On behalf of the operators, EMS can arrange the process by building algorithms for operational scheduling, including the objective, which reflects what the operators ultimately intend to achieve, and the constraints, which precisely describe the technical specifications of the systems. EMS can produce energy schedules by running the algorithms through operational scheduling processes. According to the types of missions given to submarines, energy demand changes over time, while energy generation is not flexible in time, as a result operational scheduling is a critical procedure to optimize the 
resources and determine when and how much energy submarines need to hold in the storage systems.

Before discussing the detailed roles of EMS in power generation and storage systems in submarines, tasks being done by crew should be recognized specifically so that it can be understood what should be prioritized during missions. Simply saying, everything in a submarine is all about dealing with noise. All activities must be scheduled according to how noisy they are and when is suitable time to execute them. For example, the officers manage when sewage tanks should be full and emptied by controlling water supply, and the sewage is normally discharged only during snorkeling. Because the pumps for discharging make noise due to the difference of pressures between inside and outside the hull and the snorkeling, which is the noisiest activity, can cover the noise from the pumps. The snorkeling breaks acoustic and non-acoustic stealth of submarines by generating extremely huge noise and exposing the masts above the surface, but it is the most important activity for supplying energy to the systems at the same time. Since snorkeling is dominant way to produce electricity, many activities are affected by snorkeling and scheduled in close accordance with it to avoid losing their stealth [34].

If snorkeling time during missions can be reduced by optimizing energy resources, it will be obviously beneficial for the officers to complete missions safely, avoiding unnecessary exposures. Moreover, if snorkeling hours are scheduled by EMS, the other activities also can be managed in line with the schedule without generating additional noise and running extra machinery. In this respect, EMS is not only working on maximizing resources onboard, but also enhancing the performance of submarines by minimizing the noise and exposure. 
In reality, the officers schedule when and where snorkeling needs to be done based on real-time and cumulative data by monitoring the systems. Even though they have assistant tools for scheduling resources, the process is normally done by human beings due to the uncertainties, such as weather, locations of enemies, communications, time availability, and tiredness of the crew. Although we are not able to include all factors simultaneously, if operational schedules can be produced by EMS with possibly available practical constraints, the officers will be able to utilize the operational schedules for the better performance and tactical purposes. Operational scheduling may be executed before deploying submarines and it also can be performed anytime as necessary during missions. Furthermore, operational scheduling processes offer the flexibility in responding to the uncertainties such as encounters with enemy assets and outages on power systems. 


\section{EMS MODEL FOR 4,000-TON CLASS CONVENTIONAL SUBMARINE}

\subsection{4,000-ton Class Conventional Submarine Model}

Even after the end of World War II and the appearance of nuclear-powered submarines, diesel-electric submarines have been built and adopted due to affordability and strategic purposes in many countries. As mentioned in the previous chapters, diesel-electric submarines can be built with less complexity and less budget compared to nuclear-powered submarines. As an example, with the price of a single U.S. Virginia-class nuclear-powered submarine, four to six conventional submarines like the German Type 212 class can be purchased. Additionally, conventional submarines are more suitable to operate in shallow waters and perform special missions near enemy territory since they are smaller than their nuclear-powered counterparts, and they are much quieter due to the absence of nuclear reactors and steam turbines.

In terms of size, conventional submarines were normally in the range of 1,500 to 2,500 tons but recently they are required to be more than 3,000 tons or even bigger. In comparison, nuclear-powered submarines start from at least 5,000 to 7,000 tons, going up to more than 20,000 tons, according to various requirements [45], [46]. In order to achieve higher operational excellence with longer underwater endurance and enough payload for ammunitions, conventional submarines are necessitated to equipped with more energy resources, which have higher energy density.

Recently, as the strategic importance of submarines rises among the navies that have no nuclear-powered submarines, diesel-electric submarines are built with advanced diesel engines and snorkel systems along with up-to-date battery technology. Moreover, the new generation of diesel-electric submarines improve the underwater endurance by 
implementing AIP systems. As a result, diesel-electric submarines become larger to accommodate more energy resources, and their size is significantly dependent on the power generation and storage systems. Also, larger submarines are able to contain more payload for other purposes such as ammunitions, vertical missile launchers, SONAR systems, and even unmanned surveillance vehicles.

In this work, to reflect this trend in the new generation of diesel-electric submarines, power generation and storage systems will be designed specifically for 4,000-ton class diesel-electric submarine.

In order to model the submarine, the top priority task is to determine weight and volume proportions which are available to power generation and storage systems. The proportions of weight and volume of the systems are determined by various considerations related to the fundamentals of submarine design such as hydrostatics, structures, equipment, and balance. Looking at a submarine as a whole, power generation and storage systems occupy $35 \%$ of weight and $50 \%$ of volume in total, which are the biggest proportions available for a single system group in a submarine [34]. In this work, the arrangement of the components and hydrostatics are not included in the design process, but it is assumed that they fulfill the design requirements. The proportions of weight and volume which are utilized for powering the submarine are calculated from the total weight of 4,000 metric ton, which is $4,000,000 \mathrm{~kg}$ and the total volume of $3,907.78 \mathrm{~m}^{3}$ (which is converted by sea water density, $1,023.6 \mathrm{~kg} / \mathrm{m}^{3}$ at a temperature of $25{ }^{\circ} \mathrm{C}$ and salinity of $35 \mathrm{~g} / \mathrm{kg}$, and $1 \mathrm{~atm}$ pressure). As a result, $35 \%$ of the total weight, 1,400 ton, and 50\% of the total volume, $1953.89 \mathrm{~m}^{3}$, are available to accommodate power generation and storage systems for this submarine. 
The power generation and storage systems of the submarine consist of four dieselelectric generators, four PEMFC modules, more than 9,000 Li-ion battery cells, and their auxiliary and subordinate parts such as storages, piping systems as well as casings, and the weight and volumetric proportions must include all the systems as a complete set. The proportions of every component of the power generation and storage systems must be designed according to electrical loads, underwater endurance, the maximum speed, and durations of missions. The following conditions need to be satisfied by the systems for powering the submarine.

- The maximum length of a deployment is 50 days.

- Base load (BL) of the submarine is $250 \mathrm{~kW}$ [2], [3].

- The submarine can be propelled for a considerable distance by diesel-electric power alone when the submarine is not able to submerge.

- AIP system serves BL at least 18 days without snorkeling [47].

- Oxygen and hydrogen are kept in storages which have enough capacities to serve the AIP system, maintaining chemical stability.

- Battery rooms are secured on the bottom of the hull for balancing the hydrostatics and structure.

- The capacity of battery cells has adequate energy to support the submarine at maximum speed for several hours.

The power generation components which are proved reliable in the related industries that are introduced previously will make this work practical. Later this chapter, the electrical specifications of the components will be explained along with why they are 
chosen to meet the conditions of powering the submarine. Additionally, the electrical load profile is presented in detail with numerical values for every subordinate system.

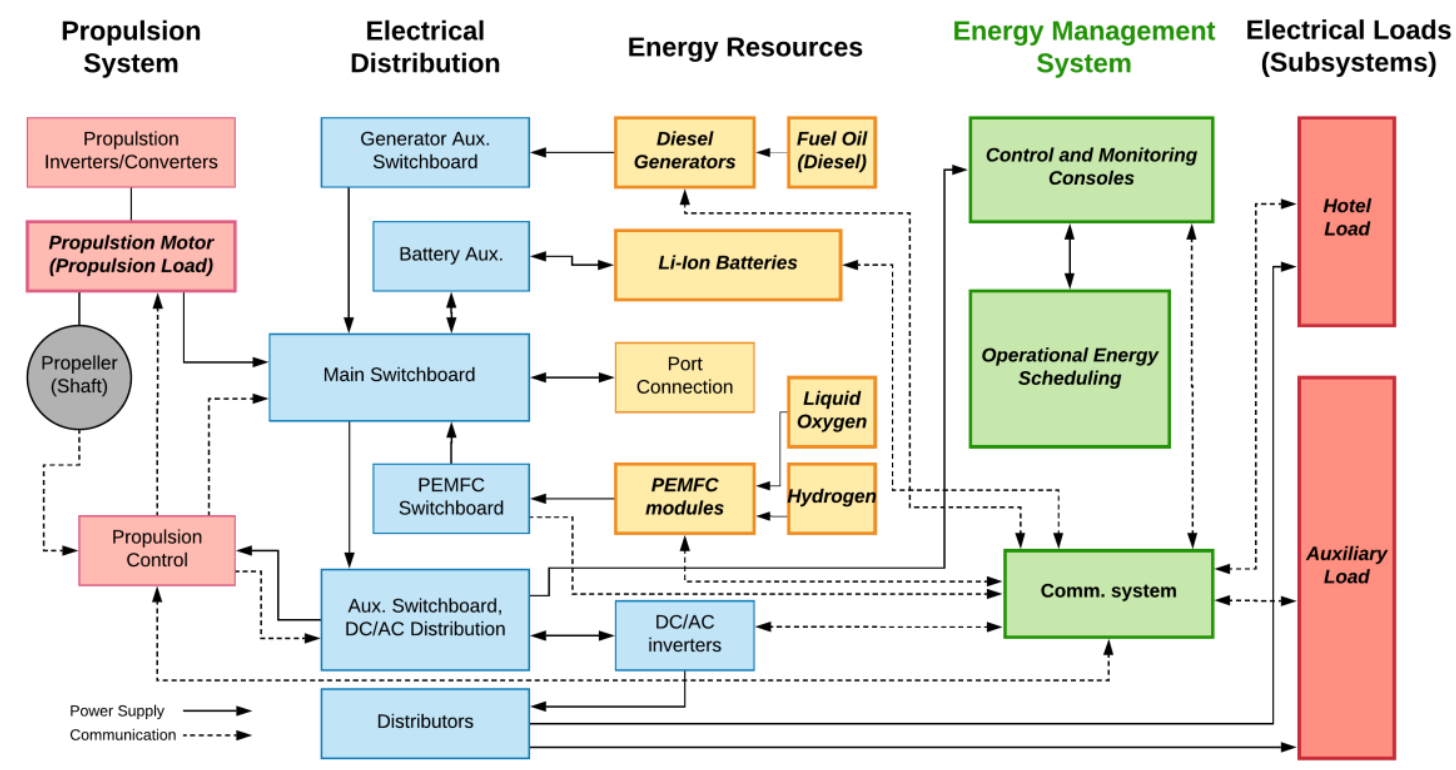

Figure 6. Overview of Electrical Systems.

Electrical systems are combined and interconnected by each group such as propulsion system, electrical distribution, energy resources, electrical loads as well as EMS, as shown in Figure 6 [48]. Electrical energy is generated by the two types of power generation components and can be directly deposited into the battery cells, or it is transmitted to propulsion systems and all other systems via distribution systems. On the top of this chain, EMS takes place as a commanding tower which controls and monitors all energy flows across the whole system. Moreover, by accessing every system remotely, EMS can respond to operators' command in real time. Furthermore, EMS produces operational energy schedules in accordance with mission scenarios, and the output is transmitted to the consoles so that the operators can access and modify it. 
Electrical loads are normally accompanied by fluctuations and uncertainties originated from situations like battles at sea or outages on the systems. Even if all power generation and storage systems satisfy the conditions which are stated above and serve the electrical loads effectively, there remains uncertainties coming from the fact that the machines cannot adapt to circumstances on the go. Additionally, since the submarine has only limited power resources, optimal utilization of them is rather a critical aspect, and outages being likely to appear on the systems need to be well covered by the other systems. Therefore, power generation and storage systems need to be examined under realistic surroundings such as various elaborately designed mission scenarios, during which we can see how the systems react and what operators should do to achieve optimal and reliable results. More importantly, the officers onboard can have more controllable and monitorable systems as well as optimized energy schedules by introducing EMS.

In the following chapters, we will provide detailed explanations about EMS including operational scheduling processes, specifications in modeling the electrical load profile, power generation and storage components, and mission scenarios, in order to build the submarine as an organic machinery.

\subsection{Energy Management System and Operational Scheduling}

EMS accesses all data acquisition points in the submarine including power generation and storage systems, and every subsystem is controlled and monitored remotely by EMS. In addition to that, EMS is responsible for running energy management algorithms and generating energy schedules under the operators' supervision. According to an electrical load profile, specifications of power generation and storage systems, and mission scenarios, the algorithms utilize the data to optimize the resources in order to maximize underwater 
endurance of the submarine, while minimizing the snorkeling hours. The algorithms can produce energy schedules which offer whole pictures of missions from the standpoint of how to manage energy resources and when is suitable time for snorkeling, in responding to tactical purposes of naval operations. The algorithms mainly focus on the snorkeling hours and timings whilst not violating various constraints of missions; therefore, the

\section{Energy Management System}

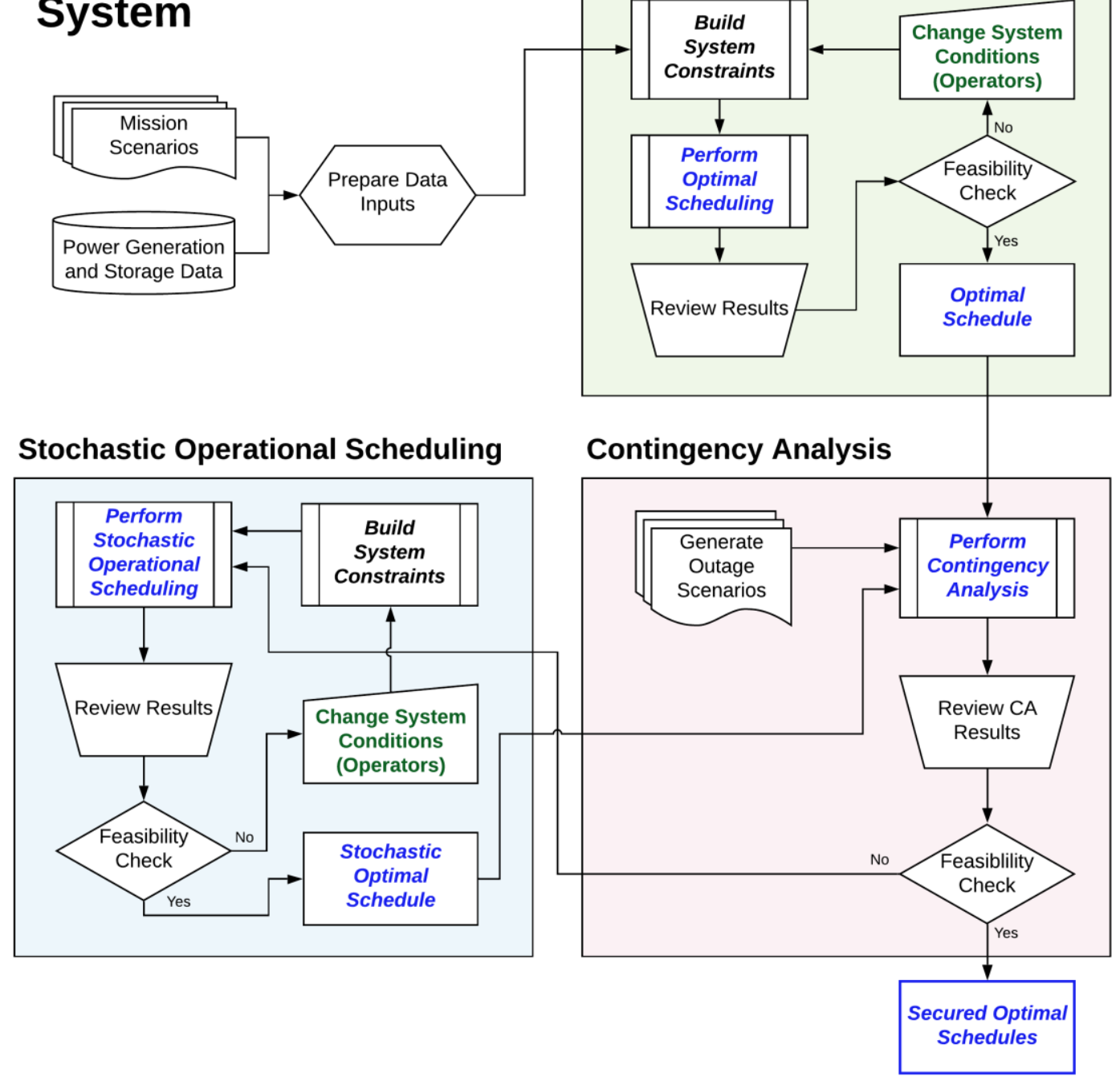

Figure 7. Flow Chart of Operational Scheduling Process 
objective of the algorithms is to minimize the snorkeling hours for duration of a mission.

From the officer's point of view, it is very difficult to predict what will be occurring during missions at sea before actual deployments. Even if military intelligence is provided to the officers, these uncertainties make the officers conservative and defensive with respect to scheduling energy resources. However, if EMS can present reliable optimal energy schedules by running algorithms, the officers will be able to execute missions even more actively and aggressively. Moreover, if EMS can show how the systems will react to outages, such as a diesel-electric generator shutdown or a fuel cell module malfunction. Furthermore, if adjusted optimal energy schedules corresponding to the outages are produced by EMS, the officers will be able to prepare for contingent situations, which may be observed during missions, by inspecting their executive plans prior to deployments. In this work, in order to produce energy schedules for these situations, EMS employs deterministic and stochastic operational scheduling processes, which share the same input data as shown in Figure 7.

\subsubsection{Deterministic Operational Scheduling}

The first block produces optimal schedules for missions in normal situations, while the second block imposes various outages of components on the optimal schedules to check whether the missions are still feasible or not, and if so, it produces secured optimal schedules for all outage scenarios.

Above all, EMS performs optimal scheduling process by building constraints, which represent physical conditions of power generation and storage systems, energy resources as well as mission scenarios. Basically, EMS runs the algorithms to determine an optimal schedule for a specific mission without any outages on the systems. This optimal schedule 
shows all system information including when and how many hours the submarine needs to snorkel, power levels of fuel cells, and energy levels in battery cells as time goes on. Therefore, the officers can plan missions in advance of deployments, based on the results of this optimal scheduling process.

\subsubsection{Deterministic Operational Scheduling Formulation}

Optimal scheduling model of deterministic operational scheduling is presented in (3.1)-(3.60). The objective function, minimizing total snorkeling time (TST), is described in (3.1). Constraint (3.2) models the binary commitment decision of FC and DG, and constraint (3.3)-(3.4) limit snorkeling only available in the nighttime. The balance between generation and load across the systems is assured by (3.5). BC capacity is enforced by (3.6)-(3.8) and constraint (3.9) determines the minimum BC levels. BC output limits are

presented by (3.10) and (3.11), while constraints (3.12) and (3.13) show DG output, and FC output limits are ensured by (3.14) and (3.15). Minimum up and down time constraints for DG and FC are enforced by (3.16)-(3.21). Constraints (3.22)-(3.24) represent diesel fuel storage capacity and consumption rate, and constraints (3.25)-(3.30) model the capacities of LOX and $\mathrm{H}_{2}$ storages as well as consumption rates. Daily load (DL) is guaranteed by (3.31). Total propulsion load (PL) limits are modeled through (3.32)-(3.36), and subordinate PLs limits are shown in (3.37)-(3.40). Maximum snorkel speed is enforced by (3.41). Total hotel load (HL) limits are ensured by (3.42)-(3.46), and subordinate HLs limits are presented by (3.47)-(3.50), while constraint (3.51) models comport level (CL) for the living condition of the crew. Constraints (3.52)-(3.56) represent total auxiliary load (AL) limits, and constraints (3.57)-(3.60) ensure subordinate ALs limits. 
Minimize: $\sum_{t} u s_{c, t}$

$\forall t, c \in\{0\}$

Subject to

$$
\begin{aligned}
& u s_{c, t}+u f_{c, t} \leq 1 \\
& u s_{c, t} \geq 0 \\
& u s_{c, t}=0 \\
& P b_{c, t}=P s_{c, t}+P f_{c, t}-L p_{c, t}-L h_{c, t}-L a_{c, t} \\
& B C_{c, t}=B C_{c, t-1}+P b_{c, t} \\
& B C_{c, t} \leq B C_{c, t}^{\max } \\
& B C_{c, t} \geq B C_{c, t}^{\min } \\
& B C_{c, t}^{\min }=B C_{c, t}^{\max } \cdot B C_{c, t}^{\min l v l} \\
& P b_{c, t} \leq P b_{c, t}^{\max } \\
& P b_{c, t} \geq P b_{c, t}^{\min } \\
& P s_{c, t} \leq P s_{c, t}^{\max } \cdot u s_{c, t} \\
& P s_{c, t} \geq P s_{c, t}^{\min } \cdot u s_{c, t} \\
& P f_{c, t} \leq P f_{c, t}^{\max } \cdot u f_{c, t} \\
& P f_{c, t} \geq P f_{c, t}^{\min } \cdot u f_{c, t} \\
& \sum_{t-U T s_{m}+1}^{t} v s_{c, t} \leq u s_{c, t} \\
& \sum_{t-D T s_{m}+1}^{t} w s_{c, t} \leq 1-u s_{c, t} \\
& v s_{c, t}-w s_{c, t} \leq u s_{c, t}-v s_{c, t-1} \\
& \sum_{t-U T f_{m}+1}^{t} v f_{c, t} \leq u f_{c, t} \\
& \sum_{t-D T f_{c}+1}^{t} w f_{c, t} \leq 1-u f_{c, t}
\end{aligned}
$$$$
\forall t, c \in\{0\}
$$$$
t \in\{t \% 24>15\}, c \in\{0\}
$$$$
t \in\{t \% 24 \leq 15\}, c \in\{0\}
$$$$
\forall t, c \in\{0\}
$$$$
\forall t, c \in\{0\}
$$$$
\forall t, c \in\{0\}
$$$$
\forall t, c \in\{0\}
$$

$\forall m, t \in\left\{U T s_{m}, \ldots, T\right\}, c \in\{0\}$

$\forall m, t \in\left\{D T s_{m}, \ldots, T\right\}, c \in\{0\}$

$$
\forall t>1, c \in\{0\}
$$

$\forall m, t \in\left\{U T f_{m}, \ldots, T\right\}, c \in\{0\}$

$\forall m, t \in\left\{D T f_{m}, \ldots, T\right\}, c \in\{0\}$ 


$$
\begin{aligned}
& v f_{c, t}-w f_{c, t} \leq u f_{c, t}-v f_{c, t-1} \\
& \forall t>1, c \in\{0\} \\
& F C_{c, t}=F C_{c, t-1}-F l c_{c, t} \\
& \forall t, c \in\{0\} \\
& F l c_{c, t} \leq\left(P s_{c, t} / P s^{\max }\right) \cdot F l c^{\max } \cdot u s_{c, t} \\
& \forall t, c \in\{0\} \\
& \forall t, c \in\{0\} \\
& \forall t, c \in\{0\} \\
& \forall t, c \in\{0\} \\
& \forall t, c \in\{0\} \\
& \forall t, c \in\{0\} \\
& L X c_{c, t} \geq L X c^{\min } \cdot u f_{c, t} \\
& \forall t, c \in\{0\} \\
& H 2_{c, t}=H 2_{c, t-1}-H 2 c_{c, t} \\
& H 2 c_{c, t}=\left(P f_{c, t} / P f^{\max }\right) \cdot H 2 c^{\max } \\
& \forall t, c \in\{0\} \\
& D L \leq \sum_{s=t-23}^{t}\left(L p_{c, s}+L h_{c, s}+L a_{c, s}\right) \\
& t \in\{t+23, \ldots, T\}, c \in\{0\} \\
& L p_{c, t}=\sum_{p} L p_{c, p, t} \\
& \forall p, t, c \in\{0\} \\
& L p_{c, t} \leq L p_{c, t}^{\max } \\
& \forall t, c \in\{0\} \\
& L p_{c, t} \geq L p_{c, t}^{\min } \\
& \forall t, c \in\{0\} \\
& L p_{c, t}^{\max }=\sum_{p} L p_{c, p, t}^{\max } \\
& \forall p, t, c \in\{0\} \\
& L p_{c, t}^{\min }=\sum_{p} L p_{c, p, t}^{\min } \\
& \forall p, t, c \in\{0\} \\
& \forall p, t, c \in\{0\} \\
& \forall p, t, c \in\{0\} \\
& L p_{c, p, t} \geq L p_{c, p, t}^{\min } \\
& \forall p, t, c \in\{0\} \\
& \forall p, t, c \in\{0\} \\
& L p_{c, p, t}^{\min }=L p_{p}^{\min }+x p s_{p} \cdot u s_{c, t}+x p f_{p} \cdot u f_{c, t} \\
& L p_{c, 1, t}^{\max }=L p_{1}^{\max } \cdot\left(1-u s_{c, t}\right)+S 10 k t s \cdot u s_{c, t}
\end{aligned}
$$




$$
L h_{c, t}=\sum_{h} L h_{c, h, t}
$$

$L h_{c, t} \leq L h_{c, t}^{\max }$

$L h_{c, t} \geq L h_{c, t}^{\min }$

$L h_{c, t}^{\max }=\sum_{h} L h_{c, h, t}^{\max }$

$L h_{c, t}^{\min }=\sum_{h} L h_{c, h, t}^{\min }$

$L h_{c, h, t} \leq L h_{c, h, t}^{\max }$

$L h_{c, h, t} \geq L h_{c, h, t}^{\min }$

$L h_{c, h, t}^{\max }=L h_{h}^{\max }+x h s_{h} \cdot u s_{c, t}+x h f_{h} \cdot u f_{c, t}$

$L h_{c, h, t}^{\min }=L h_{h}^{\min }+x h s_{h} \cdot u s_{c, t}+x h f_{h} \cdot u f_{c, t}$

$L h_{c, t} \geq L h_{c, t}^{\min } \cdot(1+0.01 * \mathrm{Com})$

$L a_{c, t}=\sum_{a} L a_{c, a, t}$

$L a_{c, t} \leq L a_{c, t}^{\max }$

$L a_{c, t} \geq L a_{c, t}^{\min }$

$L a_{c, t}^{\max }=\sum_{a} L a_{c, a, t}^{\max }$

$L a_{c, t}^{\min }=\sum_{a} L a_{c, a, t}^{\max }$

$L a_{c, a, t} \leq L a_{c, a, t}^{\max }$

$L a_{c, a, t} \geq L a_{c, a, t}^{\min }$

$L a_{c, a, t}^{\max }=L a_{a}^{\max }+x a s_{a} \cdot u s_{c, t}+x a f_{a} \cdot u f_{c, t}$

$L a_{c, a, t}^{\min }=L a_{a}^{\min }+x a s_{a} \cdot u s_{c, t}+x a f_{a} \cdot u f_{c, t}$ $\forall h, t, c \in\{0\}$

$\forall t, c \in\{0\}$

$\forall t, c \in\{0\}$

$\forall h, t, c \in\{0\}$

$\forall h, t, c \in\{0\}$

$\forall h, t, c \in\{0\}$

$\forall h, t, c \in\{0\}$

$\forall h, t, c \in\{0\}$

$\forall h, t, c \in\{0\}$

$\forall t \in\{t \% 4=3\}, c \in\{0\}$

$\forall a, t, c \in\{0\}$

$\forall t, c \in\{0\}$

$\forall t, c \in\{0\}$

$\forall a, t, c \in\{0\}$

$\forall a, t, c \in\{0\}$

$\forall a, t, c \in\{0\}$

$\forall a, t, c \in\{0\}$

$\forall a, t, c \in\{0\}$

$\forall a, t, c \in\{0\} \quad(3.60)$ 


\subsubsection{Contingency Analysis}

Once an optimal schedule is achieved, EMS passes it to the next block for CA. Let us think about how many hours the submarine needs to snorkel, if one of the diesel-electric generators is out of operation in the middle of a mission? Is it possible for the officers to predict that they will be able to complete the given mission with the remaining generators? The answer will be "They do not know exactly" or "It depends on the situation". They desire to figure out what the consequences of outages look like in order to prepare for the future and complete the mission. This is the reason why the second block performs CA. In this work, 17 outage cases are applied every day on missions, for example if a mission lasts for 30 days, total 510 outage scenarios will be tested via CA process. The 17 outage cases are the combinations of the failures in diesel-electric generators (DG), fuel cell (FC) modules, and battery cells (BC) as shown in Table 1. For example, Case 1 represents that $50 \%$ of the battery cells are out of operation, and Case 17 shows that only 2 DGs, $2 \mathrm{FCs}$, and $50 \%$ of BCs are available. Note that even if the outages occur on DGs and FCs, the resources which are diesel fuel and $\mathrm{H}_{2} / \mathrm{LOX}$ remain unchanged in the storages. Additionally, when the outages which include $50 \%$ of BCs occur, the minimum BC levels which the submarine must maintain will be lowered in accordance with the original levels. In doing so, EMS can decide which cases are feasible or not, and the officers can access the feasible optimal schedules which may require additional hours of snorkeling to compensate for the shortage in energy due to the outages.

Once we achieve the optimal schedules for each mission, two relaxations are employed during $\mathrm{CA}$ and stochastic operational scheduling. First, when outage scenarios have the cases of losing $50 \%$ of $\mathrm{BCs}$, the minimum $\mathrm{BC}$ levels will be relaxed differentially 
Table 1. 17 Outage Cases for Contingency Analysis

\begin{tabular}{cccccccc}
\hline Case & $\begin{array}{c}\text { DGs } \\
{[\text { Unit }]}\end{array}$ & $\begin{array}{c}\text { FCs } \\
{[\text { Unit }]}\end{array}$ & $\begin{array}{c}\text { BCs } \\
{[\%]}\end{array}$ & Case & $\begin{array}{c}\text { DGs } \\
{[\text { Unit }]}\end{array}$ & $\begin{array}{c}\text { FCs } \\
{[\text { Unit }]}\end{array}$ & $\begin{array}{c}\text { BCs } \\
{[\%]}\end{array}$ \\
\hline 1 & 4 & 4 & 50 & 10 & 3 & 2 & 100 \\
2 & 4 & 3 & 100 & 11 & 3 & 2 & 50 \\
3 & 4 & 3 & 50 & 12 & 2 & 4 & 100 \\
4 & 4 & 2 & 100 & 13 & 2 & 4 & 50 \\
5 & 4 & 2 & 50 & 14 & 2 & 3 & 100 \\
6 & 3 & 4 & 100 & 15 & 2 & 3 & 50 \\
7 & 3 & 4 & 50 & 16 & 2 & 2 & 100 \\
8 & 3 & 3 & 100 & 17 & 2 & 2 & 50 \\
9 & 3 & 3 & 50 & & & & \\
\hline
\end{tabular}

* The number of units and percentages indicate available number of each component.

depending on the original levels as shown in Table 2. Second, the availability of FCs opens for phase three of missions, when outage scenarios have the cases that have less than 4 FCs. Because if the outages of FC modules occur, the resources for FCs such as LOX and hydrogen are not able to be fully utilized by the limited modules during phase two and remain in the storages after phase two. By opening the window for FCs during phase three, EMS can exhaust all the resources and minimize snorkeling hours at the same time.

Contingency analysis is useful and beneficial to the officers at the planning stage, since many outages can be examined beforehand. Even though this process can be done every day throughout missions, in the view of optimality for entire period of a mission, total hours for snorkeling might not be the minimum. For instance, if the officers follow an optimal schedule of 30 days which is generated by the first block until the 15th day when an outage occurs, and then new feasible optimal schedule for the outage replaces the original one. In this case, the total snorkel hours become the summation of the hours before and after the 
Table 2. Relaxation Data of Battery Levels

\begin{tabular}{ccccccccc}
\hline \multicolumn{4}{c}{ The Original BC LVLs } & \multicolumn{4}{c}{ The BC LVLs When Outage Occurs } \\
\hline $\begin{array}{c}\text { Pre-set } \\
\text { Min. } \\
\text { LVL } \\
{[\%]}\end{array}$ & $\begin{array}{c}\text { Max. } \\
\text { Capacity } \\
{[\mathrm{kWh}]}\end{array}$ & $\begin{array}{c}\text { Min. } \\
\text { Capacity } \\
{[\mathrm{kWh}]}\end{array}$ & $\begin{array}{c}\text { Gap } \\
{[\mathrm{kWh}]}\end{array}$ & $\begin{array}{c}\text { Relaxed } \\
\text { Min. } \\
\text { LVL }[\%]\end{array}$ & $\begin{array}{c}\text { Max. } \\
\text { Capacity } \\
{[\mathrm{kWh}]}\end{array}$ & $\begin{array}{c}\text { Min. } \\
\text { Capacity } \\
{[\mathrm{kWh}]}\end{array}$ & $\begin{array}{c}\text { Gap } \\
{[\mathrm{kWh}]}\end{array}$ \\
\hline 95 & 115,000 & 109,250 & 5,750 & $\rightarrow$ & 90 & 57,500 & 51,750 & 5,750 \\
85 & 115,000 & 97,750 & 17,250 & $\rightarrow$ & 80 & 57,500 & 46,000 & 11,500 \\
80 & 115,000 & 92,000 & 23,000 & $\rightarrow$ & 70 & 57,500 & 40,250 & 17,250 \\
75 & 115,000 & 86,250 & 28,750 & $\rightarrow$ & 60 & 57,500 & 34,500 & 23,000 \\
70 & 115,000 & 80,500 & 34,500 & $\rightarrow$ & 50 & 57,500 & 28,750 & 28,750 \\
\hline
\end{tabular}

outage. Even though the total obviously is not the minimum number of hours, this is the best option for the officers if the new schedule is feasible. However, if the schedule turns out to be infeasible, the easiest option but not the best or only option for the operators is to relax constraints, which make violations, within allowable range. This possibly degrades original purposes of operational scheduling process including even the objective of missions.

Before we take this step, we should consider what can be the best options. What if EMS can include outage scenarios along with normal scenario from the beginning? EMS could save energy or would have produced more energy in advance in order to overcome the outages effectively. The submarine could have, then snorkeled less hours in total when compared to the prior case. This perspective leads us to stochastic operational scheduling process. 


\subsubsection{Contingency Analysis Formulation}

In CA formulation, the objective function and the constraints remain unchanged from deterministic operational scheduling, however several constraints are added in order to account for the outage scenarios. The objective function, minimizing total snorkeling time (TST) for every scenario, is described in (3.61). All the variables and available resources at the hour $\left(O_{c, g}\right)$, when each outage occurs, are taken from the optimal schedule. The 17 outage cases are modeled by decreasing the outputs of BC, DG, and FC through (3.62)(3.66). Constraints (3.62) models limit BC capacity, and constraints (3.63)-(3.65) restrict the outputs of BC, DG and FC. The minimum BC levels are adjusted by constraint (3.66). Responding to these constraints, all the related constraints model the outage scenarios from the hour $\left(O_{c, g}\right)$, when each outage appears, to the end of missions. Constraints (3.67)-(3.125) are the same set of constraints with deterministic operational scheduling.

Minimize: $\sum_{t} u s_{c, t}$

$\forall t, c$

Subject to

$$
\begin{array}{lr}
B C_{c, t}^{\max }=B C_{c, g}^{\max } & \forall c, t \in\left\{O_{c, g}, \ldots, T\right\}, g \in\{G\} \\
P b_{c, t}^{\max }=P b_{c, g}^{\max } & \forall c, t \in\left\{O_{c, g}, \ldots, T\right\}, g \in\{G\} \\
P s_{c, t}^{\max }=P s_{c, g}^{\max } & \forall c, t \in\left\{O_{c, g}, \ldots, T\right\}, g \in\{G\} \\
P f_{c, t}^{\max }=P f_{c, g}^{\max } & \forall c, t \in\left\{O_{c, g}, \ldots, T\right\}, g \in\{G\} \\
B C_{c, t}^{\min l v l}=B C_{c, g}^{\min l v l} & \forall c, t \in\left\{O_{c, g}, \ldots, T\right\}, g \in\{G\} \\
u s_{c, t}+u f_{c, t} \leq 1 & \\
u s_{c, t} \geq 0 & \forall c, t \in\{t \% 24>15\} \\
u s_{c, t}=0 & \forall c, t \in\{t \% 24 \leq 15\}
\end{array}
$$




$$
\begin{aligned}
& P b_{c, t}=P s_{c, t}+P f_{c, t}-L p_{c, t}-L h_{c, t}-L a_{c, t} \quad \forall t, c \quad \text { (3.70) } \\
& B C_{c, t}=B C_{c, t-1}+P b_{c, t} \quad \forall t, c \\
& B C_{c, t} \leq B C_{c, t}^{\max } \quad \forall t, c \\
& B C_{c, t} \geq B C_{c, t}^{\min } \quad \forall t, c \\
& B C_{c, t}^{\min }=B C_{c, t}^{\max } \cdot B C_{c, t}^{\min l v l} \quad \forall t, c \\
& P b_{c, t} \leq P b_{c, t}^{\max } \quad \forall t, c \\
& P b_{c, t} \geq P b_{c, t}^{\min } \quad \forall t, c \\
& P s_{c, t} \leq P s_{c, t}^{\max } \cdot u s_{c, t} \quad \forall t, c \\
& P s_{c, t} \geq P s_{c, t}^{\min } \cdot u s_{c, t} \quad \forall t, c \\
& P f_{c, t} \leq P f_{c, t}^{\max } \cdot u f_{c, t} \quad \forall t, c \\
& P f_{c, t} \geq P f_{c, t}^{\min } \cdot u f_{c, t} \quad \forall t, c \\
& \sum_{t-U T s_{m}+1}^{t} v s_{c, t} \leq u s_{c, t} \quad \forall c, m, t \in\left\{U T s_{m}, \ldots, T\right\} \\
& \sum_{t-D T s_{m}+1}^{t} w s_{c, t} \leq 1-u s_{c, t} \quad \forall c, m, t \in\left\{D T s_{m}, \ldots, T\right\} \\
& v s_{c, t}-w s_{c, t} \leq u s_{c, t}-v s_{c, t-1} \quad \forall c, \forall t \notin\{0\} \\
& \sum_{t-U T f_{m}+1}^{t} v f_{c, t} \leq u f_{c, t} \quad \forall c, m, t \in\left\{U T f_{m}, \ldots, T\right\} \\
& \sum_{t-D T f_{c}+1}^{t} w f_{c, t} \leq 1-u f_{c, t} \quad \forall c, m, t \in\left\{D T f_{m}, \ldots, T\right\} \\
& v f_{c, t}-w f_{c, t} \leq u f_{c, t}-v f_{c, t-1} \quad \forall c, \forall t \notin\{0\} \\
& F C_{c, t}=F C_{c, t-1}-F l c_{c, t} \quad \forall t, c \\
& F l c_{c, t} \leq\left(P s_{c, t} / P s^{\max }\right) \cdot F l c^{\max } \cdot u s_{c, t} \quad \forall t, c \\
& F l c_{c, t} \geq F l c^{\min } \cdot u s_{c, t} \quad \forall t, c \\
& L X_{c, t}=L X_{c, t-1}-L X c_{c, t} \quad \forall t, c
\end{aligned}
$$




$$
\begin{aligned}
& L X c_{c, t}=\left(P f_{c, t} / P f^{\max }\right) \cdot L X c^{\max } \quad \forall t, c \quad \text { (3.91) } \\
& L X c_{c, t} \leq L X c^{\max } \cdot u f_{c, t} \quad \forall t, c \quad \text { (3.92) } \\
& L X c_{c, t} \geq L X c^{\min } \cdot u f_{c, t} \quad \forall t, c \quad \text { (3.93) } \\
& H 2_{c, t}=H 2_{c, t-1}-H 2 c_{c, t} \quad \forall t, c \quad \text { (3.94) } \\
& H 2 c_{c, t}=\left(P f_{c, t} / P f^{\max }\right) \cdot H 2 c^{\max } \quad \forall t, c \quad \text { (3.95) } \\
& D L \leq \sum_{s=t-23}^{t}\left(L p_{c, s}+L h_{c, s}+L a_{c, s}\right) \quad \forall c, t \in\{t+23, \ldots, T\} \\
& L p_{c, t}=\sum_{p} L p_{c, p, t} \quad \forall p, t, c \\
& L p_{c, t} \leq L p_{c, t}^{\max } \quad \forall t, c \quad \text { (3.98) } \\
& L p_{c, t} \geq L p_{c, t}^{\min } \quad \forall t, c \\
& L p_{c, t}^{\max }=\sum_{p} L p_{c, p, t}^{\max } \quad \forall p, t, c \quad \text { (3.100) } \\
& L p_{c, t}^{\min }=\sum_{p} L p_{c, p, t}^{\min } \quad \forall p, t, c \\
& L p_{c, p, t} \leq L p_{c, p, t}^{\max } \quad \forall p, t, c \\
& L p_{c, p, t} \geq L p_{c, p, t}^{\min } \quad \forall p, t, c \quad \text { (3.103) } \\
& L p_{c, p, t}^{\max }=L p_{p}^{\max }+x p s_{p} \cdot u s_{c, t}+x p f_{p} \cdot u f_{c, t} \quad \forall p, t, c \\
& L p_{c, p, t}^{\min }=L p_{p}^{\min }+x p s_{p} \cdot u s_{c, t}+x p f_{p} \cdot u f_{c, t} \quad \forall p, t, c \\
& L p_{c, 1, t}^{\max }=L p_{1}^{\max } \cdot\left(1-u s_{c, t}\right)+S 10 k t s \cdot u s_{c, t} \quad \forall t, c \quad \text { (3.106) } \\
& L h_{c, t}=\sum_{h} L h_{c, h, t} \quad \forall h, t, c \quad \text { (3.107) } \\
& L h_{c, t} \leq L h_{c, t}^{\max } \quad \forall t, c \quad(3.108) \\
& L h_{c, t} \geq L h_{c, t}^{\min } \quad \forall t, c \quad \text { (3.109) } \\
& L h_{c, t}^{\max }=\sum_{h} L h_{c, h, t}^{\max } \quad \forall h, t, c \quad \text { (3.110) } \\
& L h_{c, t}^{\min }=\sum_{h} L h_{c, h, t}^{\min } \quad \forall h, t, c \quad \text { (3.111) }
\end{aligned}
$$




$$
\begin{aligned}
& L h_{c, h, t} \leq L h_{c, h, t}^{\max } \quad \forall h, t, c \\
& L h_{c, h, t} \geq L h_{c, h, t}^{\min } \quad \forall h, t, c \\
& L h_{c, h, t}^{\max }=L h_{h}^{\max }+x h s_{h} \cdot u s_{c, t}+x h f_{h} \cdot u f_{c, t} \quad \forall h, t, c \quad \text { (3.114) } \\
& L h_{c, h, t}^{\min }=L h_{h}^{\min }+x h s_{h} \cdot u s_{c, t}+x h f_{h} \cdot u f_{c, t} \quad \forall h, t, c \quad \text { (3.115) } \\
& L h_{c, t} \geq L h_{c, t}^{\min } \cdot(1+0.01 * C o m) \quad \forall t \in\{t \% 4=3\}, \forall c \\
& L a_{c, t}=\sum_{a} L a_{c, a, t} \quad \forall a, t, c \\
& L a_{c, t} \leq L a_{c, t}^{\max } \quad \forall t, c \\
& L a_{c, t} \geq L a_{c, t}^{\min } \quad \forall t, c \\
& L a_{c, t}^{\max }=\sum_{a} L a_{c, a, t}^{\max } \quad \forall a, t, c \\
& L a_{c, t}^{\min }=\sum_{a} L a_{c, a, t}^{\max } \quad \forall a, t, c \\
& L a_{c, a, t} \leq L a_{c, a, t}^{\max } \quad \forall a, t, c \\
& L a_{c, a, t} \geq L a_{c, a, t}^{\min } \quad \forall a, t, c \\
& L a_{c, a, t}^{\max }=L a_{a}^{\max }+x a s_{a} \cdot u s_{c, t}+x a f_{a} \cdot u f_{c, t} \quad \forall a, t, c \\
& L a_{c, a, t}^{\min }=L a_{a}^{\min }+x a s_{a} \cdot u s_{c, t}+x a f_{a} \cdot u f_{c, t} \quad \forall a, t, c
\end{aligned}
$$

\subsubsection{Stochastic Operational Scheduling}

If the officers can predict most probable outages and their estimated timings, according to intensive energy demanding days in missions or cumulative operating hours of the components, EMS can possibly involve the outages in stochastic operational scheduling process. For example, if three probable outages are assumed to arise on particular days, EMS runs the algorithm in accordance with four total scenarios which are normal scenario and three particular outages all together. The results will show secured optimal schedule ensuring three outages with the minimum snorkel hours, by equating the schedule of the 
non-outage setup with the schedules of the three outages until each outage occurs. This TST might be higher than or equal to the optimal schedule of deterministic operational scheduling process. In short, secured optimal schedule enforces power generation and storage systems to preserve energy ahead of time, since EMS foresees when and what outages come up during missions.

However, we do not want outages to occur in the middle of missions at all, and it is not practical to predict when and what type of outages will take place in the future. Instead of leaning on the probability, the officers will just follow the optimal schedule, and then, move to pre-solved CA results, secured optimal schedules, as outages appear. In order to handle infeasible results from CA, stochastic operational scheduling process is utilized as an extension of operational scheduling process. After CA, infeasible scenarios will transfer to stochastic operational scheduling process to obtain feasible solutions. If all infeasible scenarios turn out to be feasible, this stochastic optimal schedule becomes new optimal schedule for the next CA process. Whereas, if EMS still cannot produce operational schedules even after this process, it is time for operators to intervene and relax constraints which violate the limits, if guaranteed that the relaxed constraints do not violate the fundamental goals of EMS and missions as illustrated in Figure 7. This workflow will continue to loop until all outage scenarios become feasible and secured optimal schedules are obtained by EMS.

\subsubsection{Stochastic Optimization Model Formulation}

In this process, the structure of deterministic model is applied to stochastic model. Additionally, constraint (3.126)-(3.140) construct stochastic operational scheduling process. The objective function, minimizing TST of all the scenarios simultaneously, is 
presented in (3.126). Constraints (3.127)-(3.135) require the variables from the outage scenarios to be equal to the ones from normal scenario, until each outage occurs. Constraints (3.127) and (3.128) force the commitments of DG and FC among all scenarios to be the same. Constraint (3.129) makes BC capacity equal among all scenarios, and constraints (3.130)-(3.135) ensure the power injection and withdrawal to be the same until the hour $\left(O_{c, g}\right)$ of outage through the scenarios. BC capacity is reduced by (3.136), and the outputs of BC, DG and FC are restricted by constraints (3.137)-(3.139) respectively. The minimum BC levels are adjusted by constraint (3.140). The outage scenarios are described by employing the last five constraints, from the hour $\left(O_{c, g}\right)$ to the end of missions. Constraints (3.141)-(3.199) are the same set of constraints with deterministic operational scheduling.

Minimize: $\sum_{c} \sum_{t} u s_{c, t}, \quad \forall c, t \quad$ (3.126)

Subject to

$$
\begin{array}{ll}
u s_{0, t}=u s_{c, t} & \forall c, t \in\left\{1, \ldots, O_{c, g}\right\} \\
u f_{0, t}=u f_{c, t} & \forall c, t \in\left\{1, \ldots, O_{c, g}\right\} \\
B C_{0, t}=B C_{c, t} & \forall c, t \in\left\{1, \ldots, O_{c, g}\right\} \\
P b_{0, t}=P b_{c, t} & \forall c, t \in\left\{1, \ldots, O_{c, g}\right\} \\
P s_{0, t}=P s_{c, t} & \forall c, t \in\left\{1, \ldots, O_{c, g}\right\} \\
P f_{0, t}=P f_{c, t} & \forall c, t \in\left\{1, \ldots, O_{c, g}\right\} \\
L p_{0, t}=L p_{c, t} & \forall c, t \in\left\{1, \ldots, O_{c, g}\right\} \\
L h_{0, t}=L h_{c, t} & \forall c, t \in\left\{1, \ldots, O_{c, g}\right\} \\
L a_{0, t}=L a_{c, t} & \forall c, t \in\left\{1, \ldots, O_{c, g}\right\}
\end{array}
$$




$$
\begin{aligned}
& B C_{c, t}^{\max }=B C_{c, g}^{\max } \\
& \forall c \notin\{0\}, t \in\left\{O_{c, g}, \ldots, T\right\}, g \in\{G\} \\
& P b_{c, t}^{\max }=P b_{c, g}^{\max } \\
& \forall c \notin\{0\}, t \in\left\{O_{c, g}, \ldots, T\right\}, g \in\{G\} \\
& P s_{c, t}^{\max }=P s_{c, g}^{\max } \\
& \forall c \notin\{0\}, t \in\left\{O_{c, g}, \ldots, T\right\}, g \in\{G\} \\
& P f_{c, t}^{\max }=P f_{c, g}^{\max } \\
& \forall c \notin\{0\}, t \in\left\{O_{c, g}, \ldots, T\right\}, g \in\{G\} \\
& \forall c \notin\{0\}, t \in\left\{O_{c, g}, \ldots, T\right\}, g \in\{G\} \\
& \forall t, c \\
& \forall c, t \in\{t \% 24>15\} \\
& \forall c, t \in\{t \% 24 \leq 15\} \\
& \forall t, c \quad(3.144) \\
& P b_{c, t}=P s_{c, t}+P f_{c, t}-L p_{c, t}-L h_{c, t}-L a_{c, t} \\
& \forall t, c \quad(3.145) \\
& B C_{c, t}=B C_{c, t-1}+P b_{c, t} \\
& \forall t, c \quad(3.146) \\
& B C_{c, t} \leq B C_{c, t}^{\max } \\
& \forall t, c \quad(3.147) \\
& B C_{c, t} \geq B C_{c, t}^{\min } \\
& \forall t, c \quad(3.148) \\
& B C_{c, t}^{\min }=B C_{c, t}^{\max } \cdot B C_{c, t}^{\min l v l} \\
& P b_{c, t} \leq P b_{c, t}^{\max } \\
& \forall t, c \quad(3.149) \\
& P b_{c, t} \geq P b_{c, t}^{\min } \\
& \forall t, c \quad(3.150) \\
& P s_{c, t} \leq P s_{c, t}^{\max } \cdot u s_{c, t} \\
& \forall t, c \quad(3.151) \\
& P s_{c, t} \geq P s_{c, t}^{\min } \cdot u s_{c, t} \\
& \forall t, c \quad(3.152) \\
& P f_{c, t} \leq P f_{c, t}^{\max } \cdot u f_{c, t} \\
& \forall t, c \quad(3.153) \\
& P f_{c, t} \geq P f_{c, t}^{\min } \cdot u f_{c, t} \\
& \forall t, c \quad(3.154) \\
& \sum_{t-U T s_{m}+1}^{t} v s_{c, t} \leq u s_{c, t} \\
& \forall \mathrm{c}, m, t \in\left\{U T s_{m}, \ldots, T\right\} \\
& \sum_{t-D T s_{m}+1}^{t} w s_{c, t} \leq 1-u s_{c, t} \\
& \forall c, m, t \in\left\{D T s_{m}, \ldots, T\right\}
\end{aligned}
$$




$$
\begin{aligned}
& v s_{c, t}-w s_{c, t} \leq u s_{c, t}-v s_{c, t-1} \\
& \forall c, \forall t \notin\{0\} \quad(3.157) \\
& \sum_{t-U T f_{m}+1}^{t} v f_{c, t} \leq u f_{c, t} \\
& \forall \mathrm{c}, m, t \in\left\{U T f_{m}, \ldots, T\right\} \\
& \sum_{t-D T f_{c}+1}^{t} w f_{c, t} \leq 1-u f_{c, t} \\
& \forall c, m, t \in\left\{D T f_{m}, \ldots, T\right\} \quad \text { (3.159) } \\
& v f_{c, t}-w f_{c, t} \leq u f_{c, t}-v f_{c, t-1} \\
& \forall c, \forall t \notin\{0\} \quad(3.160) \\
& F C_{c, t}=F C_{c, t-1}-F l c_{c, t} \\
& \forall t, c \quad(3.161) \\
& F l c_{c, t} \leq\left(P s_{c, t} / P s^{\max }\right) \cdot F l c^{\max } \cdot u s_{c, t} \\
& \forall t, c \quad(3.162) \\
& F l c_{c, t} \geq F l c^{\min } \cdot u s_{c, t} \\
& \forall t, c \quad(3.163) \\
& L X_{c, t}=L X_{c, t-1}-L X c_{c, t} \\
& \forall t, c \quad(3.164) \\
& L X c_{c, t}=\left(P f_{c, t} / P f^{\max }\right) \cdot L X c^{\max } \\
& \forall t, c \quad(3.165) \\
& L X c_{c, t} \leq L X c^{\max } \cdot u f_{c, t} \\
& \forall t, c \quad(3.166) \\
& L X c_{c, t} \geq L X c^{\min } \cdot u f_{c, t} \\
& \forall t, c \quad(3.167) \\
& H 2_{c, t}=H 2_{c, t-1}-H 2 c_{c, t} \\
& \forall t, c \quad(3.168) \\
& H 2 c_{c, t}=\left(P f_{c, t} / P f^{\max }\right) \cdot H 2 c^{\max } \\
& \forall t, c \quad(3.169) \\
& D L \leq \sum_{s=t-23}^{t}\left(L p_{c, s}+L h_{c, s}+L a_{c, s}\right) \\
& \forall c, t \in\{t+23, \ldots, T\} \quad(3.170) \\
& L p_{c, t}=\sum_{p} L p_{c, p, t} \\
& \forall p, t, c \quad(3.171) \\
& L p_{c, t} \leq L p_{c, t}^{\max } \\
& \forall t, c \quad(3.172) \\
& L p_{c, t} \geq L p_{c, t}^{\min } \\
& \forall t, c \quad(3.173) \\
& L p_{c, t}^{\max }=\sum_{p} L p_{c, p, t}^{\max } \\
& \forall p, t, c \quad(3.174) \\
& L p_{c, t}^{\min }=\sum_{p} L p_{c, p, t}^{\min } \\
& \forall p, t, c \quad(3.175) \\
& L p_{c, p, t} \leq L p_{c, p, t}^{\max } \\
& \forall p, t, c \quad(3.176) \\
& L p_{c, p, t} \geq L p_{c, p, t}^{\min } \\
& \forall p, t, c \quad(3.177)
\end{aligned}
$$




$$
\begin{aligned}
& L p_{c, p, t}^{\max }=L p_{p}^{\max }+x p s_{p} \cdot u s_{c, t}+x p f_{p} \cdot u f_{c, t} \\
& \forall p, t, c \quad(3.178) \\
& L p_{c, p, t}^{\min }=L p_{p}^{\min }+x p s_{p} \cdot u s_{c, t}+x p f_{p} \cdot u f_{c, t} \\
& L p_{c, 1, t}^{\max }=L p_{1}^{\max } \cdot\left(1-u s_{c, t}\right)+S 10 k t s \cdot u s_{c, t} \\
& L h_{c, t}=\sum_{h} L h_{c, h, t} \\
& L h_{c, t} \leq L h_{c, t}^{\max } \\
& L h_{c, t} \geq L h_{c, t}^{\min } \\
& L h_{c, t}^{\max }=\sum_{h} L h_{c, h, t}^{\max } \\
& L h_{c, t}^{\min }=\sum_{h} L h_{c, h, t}^{\min } \\
& L h_{c, h, t} \leq L h_{c, h, t}^{\max } \\
& L h_{c, h, t} \geq L h_{c, h, t}^{\min } \\
& L h_{c, h, t}^{\max }=L h_{h}^{\max }+x h s_{h} \cdot u s_{c, t}+x h f_{h} \cdot u f_{c, t} \\
& L h_{c, h, t}^{\min }=L h_{h}^{\min }+x h s_{h} \cdot u s_{c, t}+x h f_{h} \cdot u f_{c, t} \\
& L h_{c, t} \geq L h_{c, t}^{\min } \cdot(1+0.01 * C o m) \\
& L a_{c, t}=\sum_{a} L a_{c, a, t} \\
& L a_{c, t} \leq L a_{c, t}^{\max } \\
& L a_{c, t} \geq L a_{c, t}^{\min } \\
& L a_{c, t}^{\max }=\sum_{a} L a_{c, a, t}^{\max } \\
& L a_{c, t}^{\min }=\sum_{a} L a_{c, a, t}^{\max } \\
& L a_{c, a, t} \leq L a_{c, a, t}^{\max } \\
& L a_{c, a, t} \geq L a_{c, a, t}^{\min } \\
& \forall t \in\{t \% 4=3\}, \forall c \\
& \forall a, t, c \\
& \forall t, c \\
& \forall t, c \\
& \forall a, t, c \quad \text { (3.194) } \\
& \forall a, t, c \quad(3.195) \\
& \forall a, t, c \quad(3.196) \\
& \forall a, t, c \quad(3.197) \\
& L a_{c, a, t}^{\max }=L a_{a}^{\max }+x a s_{a} \cdot u s_{c, t}+x a f_{a} \cdot u f_{c, t} \\
& \forall a, t, c \quad(3.198)
\end{aligned}
$$




$$
L a_{c, a, t}^{\min }=L a_{a}^{\min }+x a s_{a} \cdot u s_{c, t}+x a f_{a} \cdot u f_{c, t}
$$

$\forall a, t, c$

\subsection{Electrical Load Profile}

Submarines have mainly three types of electrical loads: propulsion load (PL), hotel load (HL), and auxiliary load (AL), with each one of them having several subordinate systems demanding electrical energy to function individually or cooperatively. The propulsion system including an electric motor and a propeller is the most energydemanding single huge element of the submarine. Hence, the critical determinant of how much energy required for a certain period of time is the speed of the submarine which directly affects PL [2], [3], [34]. In other words, if the submarine is at a high-speed like in a battle or a quick transit, its propulsion system will consume energy rapidly, and the battery cells will need to be charged more frequently. On the contrary, normally, the submarine moves at an economic speed to save energy and to minimize unnecessary charging processes, which commonly include snorkeling. When comparing to PL, HL and AL typically vary between relatively much smaller ranges, thus they are far less influential on the total electrical load.

The subordinate systems interact with one another physically and systematically rather than operating separately. For instance, while submarines are snorkeling to charge the battery cells, it is necessary that ventilation, heating, and air conditioning systems must be operated to adjust the air inside the hull since the snorkel system sucks atmospheric air which has different compositions. In addition, trimming and compensating systems are required to stabilize the hull in order to keep its balance near the surface.

From these points of view, base load needs to be set as a crucial criterion for determining specifications of the power generation and storage systems. In this work, BL, 
which includes all of the three types of loads, is defined as $250 \mathrm{~kW}$ for the submarine at the economic speed of $5 \mathrm{knot}(1 \mathrm{knot} \approx 1.852 \mathrm{~km} / \mathrm{h})$, in normal submerged condition [2], [3], [34].

In order to model more practical submarine, the subordinate systems are grouped by the three main types of load along with their maximum and minimum electrical demands, which are categorized as 'Normal Submerged', 'In Snorkeling', and 'AIP System in Operation', and numerically suggested as shown in Table 3.

The load of the propulsion system is a function of its maneuvering speed $(u)$ in knot and the submerged displacement $(D)$ in $\mathrm{kg}[2]$,

$$
P_{\text {prop }}=0.0026 \cdot\left(\frac{D}{1000}\right)^{2 / 3} \cdot\left(\frac{u}{1.852}\right)^{3}
$$

For instance, in an hour, the submarine whose displacement is 4,000,000 kg consumes 81.9 $\mathrm{kWh}$, at the economic speed of 5 knot. When the submarine is snorkeling, the snorkel system needs more electrical energy to run the diesel engines and related machineries like cooling pumps. Similarly, while AIP system is in operation, PL is higher than BL due to the same reason.

HL includes the systems of fresh/sewage water, galley, atmospheric control, lighting, and ventilation, heating, and air conditioning. These systems are specifically required to support the crew in order to sustain life on the submarine. These systems consume the least energy among all; however, they are essential parts to support the other subsystems. 
Table 3. Maximum and Minimum Electrical Loads of All Systems in the Submarine

\begin{tabular}{|c|c|c|c|c|c|c|c|}
\hline \multirow{2}{*}{ Category } & \multirow{2}{*}{ Systems } & \multicolumn{2}{|c|}{$\begin{array}{c}\text { Normal } \\
\text { Submerged }[k W]\end{array}$} & \multicolumn{2}{|c|}{ Snorkel [kW] } & \multicolumn{2}{|c|}{ AIP $[k W]$} \\
\hline & & Min & Max & Min & Max & Min & Max \\
\hline Propulsion \#1 & Propulsion & 81.9 & 5241.3 & 81.9 & 5241.3 & 81.9 & 5241.3 \\
\hline Propulsion \#2 & Snorkel system (DGs) & 2 & 4 & 14 & 16 & 2 & 4 \\
\hline Propulsion \#3 & AIP system (FCs) & 0.75 & 1.5 & 0.75 & 1.5 & 12.75 & 13.5 \\
\hline Propulsion Load (PL) & Sub Total & 84.6 & 5246.8 & 96.6 & 5258.8 & 96.6 & 5258.8 \\
\hline Hotel \#1 & Fresh/sewage water & 5 & 8 & 5 & 9 & 5 & 8 \\
\hline Hotel \#2 & Galley equipment & 3.5 & 5.6 & 3.5 & 5.6 & 3.5 & 5.6 \\
\hline Hotel \#3 & Atmospheric control & 14 & 16 & 10 & 12 & 14 & 16 \\
\hline Hotel \#4 & Lighting & 6 & 8 & 6 & 8 & 6 & 8 \\
\hline Hotel \#5 & $\begin{array}{l}\text { Ventilation, heating } \\
\text { and air conditioning }\end{array}$ & 12.5 & 17.5 & 17.5 & 22.5 & 12.5 & 17.5 \\
\hline Hotel \#6 & Personal use & 2.5 & 4 & 2.5 & 4 & 2.5 & 4 \\
\hline Hotel Load (HL) & Sub Total & 43.5 & 59.1 & 44.5 & 61.1 & 43.5 & 59.1 \\
\hline Auxiliary \#1 & Weapon control & 12.5 & 20 & 15 & 22.5 & 12.5 & 20 \\
\hline Auxiliary \#2 & SONAR & 28 & 36 & 30 & 38 & 28 & 36 \\
\hline Auxiliary \#3 & Navigation & 10 & 13 & 12 & 15 & 10 & 13 \\
\hline Auxiliary \#4 & Communication & 4.5 & 6 & 12 & 13.5 & 4.5 & 6 \\
\hline Auxiliary \#5 & Hydraulic & 15 & 18 & 24 & 27 & 15 & 18 \\
\hline Auxiliary \#6 & Compressed air & 3 & 4.5 & 3 & 9 & 3 & 4.5 \\
\hline Auxiliary \#7 & Trimming & 10 & 12.5 & 17.5 & 20 & 10 & 12.5 \\
\hline Auxiliary \#8 & Compensating & 5 & 12.5 & 12.5 & 20 & 5 & 12.5 \\
\hline Auxiliary \#9 & Ship Control & 10 & 14 & 14 & 18 & 10 & 14 \\
\hline Auxiliary \#10 & Elec. distribution & 15 & 17.5 & 18.8 & 21.3 & 18.8 & 21.3 \\
\hline Auxiliary \#11 & Salvage and rescue & 5 & 7 & 5 & 8 & 5 & 7 \\
\hline Auxiliary \#12 & Auxiliaries & 5 & 7 & 5 & 8 & 5 & 7 \\
\hline Auxiliary Load (AL) & Sub Total & 123 & 168 & 168.8 & 220.3 & 126.8 & 171.8 \\
\hline TOTAL & & 251.1 & 5473.9 & 309.9 & 5540 & 266.9 & 5490 \\
\hline
\end{tabular}


AL contains the other systems such as weapon control, SONAR, navigation, communication, hydraulic, compressed air, trimming, compensating, ship control, electric distribution, salvage and rescue.

\subsection{Power Generation and Storage Components}

In this work, 4 diesel-electric generators, 4 PEMFC modules, thousands of Li-ion battery cells, and their storages are implemented on the submarine. All components are selected and designed to fulfill the operational conditions and the proportions of the weight and volume stated in the section 3.1 .

\subsubsection{Snorkel System - Diesel-Electric Generators and Diesel Fuel Tanks}

Four units of "Diesel Generator Set MTU 12 V4000 DS1550", which has 1,550 kWe per unit as a rated power, provide main electrical power to the submarine [17], [49]. Total $6,200 \mathrm{kWe}$ can be supplied from the generators at the maximum, which means that the four units have ability to generate $6,200 \mathrm{kWh}$ of energy for an hour of snorkeling. They have the weight of $10,877 \mathrm{~kg}$ and the volume of $19.61 \mathrm{~m}^{3}$ for each unit, making it $43,508 \mathrm{~kg}$ and $78.44 \mathrm{~m}^{3}$ in total [49]. Diesel fuel tanks have the capacity of 150,0001 in total, with the weight and volume being $124,800 \mathrm{~kg}$ and $150 \mathrm{~m}^{3}$ respectively, in accordance with the density of $0.832 \mathrm{~kg} / \mathrm{m}^{3}$. Fuel consumption rates per unit are $420.4 \mathrm{l} / \mathrm{hr}$ at $100 \%, 312.4 \mathrm{l} / \mathrm{hr}$ at $75 \%$ and $221.7 \mathrm{1} / \mathrm{hr}$ at $50 \%$ of rated power respectively. Four units at $100 \%$ of rated power consume $1681.6 \mathrm{l} / \mathrm{hr}$, and the full diesel fuel tanks of 150,000 1 can serve about 90 hours continuously which is equivalent to the energy of 553,045 kWh. With this energy, the submarine can keep staying at sea for about 92 days if it only consumes BL without other power generation. 


\subsubsection{AIP System - PEMFC and Oxygen/Hydrogen Storages}

PEMFC is the most applicable and reliable AIP system for submarines along with the storages such as reversible metal hydrides for hydrogen carrier and LOX tanks. Four units of "Siemens PEM Fuel Cells 135 module"[50] are implemented for extending underwater endurance with each unit having $135 \mathrm{kWe}$ of the maximum rated power and $540 \mathrm{kWe}$ in total. This AIP system aims 18 days of underwater endurance at BL, $250 \mathrm{~kW}$, without any other power sources. The amount of energy demanded for 18 days at $\mathrm{BL}$ is $108,000 \mathrm{kWh}$, and this energy can be achieved by converting the stored hydrogen and oxygen by operating PEMFC modules. The weight and volume of the hydrogen and oxygen storages can be calculated based on the required energy, $108,000 \mathrm{kWh}$, and the specifications of the AIP system such as its conversion efficiency and the lower heating value of hydrogen.

The total moles of $\mathrm{H}_{2}\left(\mathrm{~N}_{\mathrm{H} 2}\right), 3,677,592.79 \mathrm{~mol}$, required to produce the total energy demand $\left(E_{T}\right), 108,000 \mathrm{kWh}$, is given by,

$$
N_{H 2}=\frac{E_{T}}{\Delta H} \cdot \frac{1}{\eta_{\text {overall }}}
$$

where $\Delta H$ is the lower heating value of $H_{2}$ (LHV) which is $0.06714 \mathrm{kWh} / \mathrm{mol}$. The reason why LHV is applied to the equation is that the operation temperature is approximately 158 $\sim 176^{\circ} \mathrm{F}\left(70 \sim 80^{\circ} \mathrm{C}\right) . \eta_{\text {overall }}$, about $49 \%$, is overall efficiency of the system, given by,

$$
\eta_{\text {overall }}=\eta_{D C / D C} \cdot \eta_{F C}
$$

where $\eta_{D C / D C}, 90 \%$, is efficiency of DC/DC converter and $\eta_{F C}, 54 \%$, is efficiency of the fuel cell modules. The weight of the required hydrogen $\left(W_{H 2}\right), 6,619.67 \mathrm{~kg}$, is given by,

$$
W_{H 2}=N_{H 2} \cdot M_{H 2}
$$

where $M_{H 2}, 0.0002 \mathrm{~kg} / \mathrm{mol}$, is gravimetric storage. 
Therefore, the weight of the metal hydride storage $\left(W_{H 2}\right.$ storage $)$ including stored hydrogen, $2.942 \mathrm{E} 5 \mathrm{~kg}$, is given by,

$$
W_{H 2 \text { storage }}=\frac{W_{H 2}}{W T_{\text {perc }}}
$$

where $W T_{\text {perc }}, 2.25 \%$, is the gravimetric storage in percent. Additionally, the volume of the metal hydride storage $\left(V_{H 2}\right.$ storage $), 185.19 \mathrm{~m}^{3}$, is given by,

$$
V_{H 2 \text { storage }}=\frac{E_{T}}{E_{\text {vol }}} \cdot \frac{1}{\eta_{\text {overall }}}
$$

where $E_{v o l}, 1,200 \mathrm{kWh} / \mathrm{m}^{3}$, is the volumetric energy density.

For oxygen storage, LOX tank has implemented by compressing oxygen at $70 \mathrm{MPa}$ to store as stable liquid. Since PEMFC modules make the reaction which has two-to-one volumetric ratio between hydrogen and oxygen, one mole of hydrogen and half mole of oxygen is utilized to generate the electricity. The total moles of $O_{2}\left(N_{O 2}\right)$ can be simply calculated as 1.654E6 mol, which is the half of $N_{H 2}$. The reaction occurs at 1:8 ratio by weight, hence the total weight of the oxygen $\left(W_{O 2}\right)$ is $5.296 \mathrm{E} 4 \mathrm{~kg}$ which is eight times heavier than $W_{H 2}$. The weight of the LOX tank $\left(W_{\text {LOX Tank }}\right), 8.682 \mathrm{E} 4 \mathrm{~kg}$, including tank itself and LOX is obtained by,

$$
W_{\text {LOX Tank }}=\frac{N_{O 2} \cdot M_{O 2}}{r_{\text {grav }}}
$$

where $M_{O 2}, 32 \mathrm{~g} / \mathrm{mol}$, is the molecular weight of oxygen and $r_{\text {grav }}, 0.61$, is the gravimetric fraction. Additionally, the volume of the LOX tank $\left(V_{\text {LOX Tank }}\right), 132.61 \mathrm{~m}^{3}$, is given by,

$$
V_{\text {LOX Tank }}=\frac{N_{O 2} \cdot M_{O 2}}{r_{v o l} \cdot \rho_{L O X}}
$$

where $r_{v o l}, 0.35$, is the volumetric fraction and $\rho_{L O X}, 1,141 \mathrm{~kg} / \mathrm{m}^{3}$, is the density of LOX. 


\subsubsection{Lithium-Ion Battery Cells}

When it comes to battery cells in submarines, they not only function as an energy bank which stores electrical energy generated by DGs and FCs, but also play a crucial role in keeping the submarines upright under water using the restoring force which is originated from their heavy weight, even if the tide hits the hull in any direction. As a result, they are installed as a layer of batteries and evenly distributed on the bottom of the hull along the keel from bow to stern.

The physical available space for the battery cells primarily depends on the crosssectional area of the hull. Considering 4,000-ton of the displacement, the cross-sectional area of midplane from the bow to the stern can be estimated as approximately $900 \mathrm{~m}^{2}$ in accordance with the length of $90 \mathrm{~m}$ and the width of $10 \mathrm{~m}$, and $65 \%$ of the area can be allocated to the battery cells. Hence, the $65 \%$ of the total cross-sectional area, $585 \mathrm{~m}^{2}$, is accountable as two battery rooms, but more than $10 \%$ of the battery rooms has to be devoted to gaps among the battery cells for preventing excessive temperature rise.

In this work, thousands of "Samsung SDI E3-M123 Module"[51] are employed as Liion battery cells, replacing the popular lead-acid battery cells for decades [52], [53]. Single module, which stores electrical energy of $12.3 \mathrm{kWh}$, is designed to form a large rack or a container by grouping multiple modules. The module weighs $90 \mathrm{~kg}$, and its dimensions as a rectangular parallelepiped are $344 \mathrm{~mm} \times 1,012 \mathrm{~mm} \times 160 \mathrm{~mm}$. Considering the crosssectional area of each module, $0.05504 \mathrm{~m}^{2}(344 \mathrm{~mm} \times 160 \mathrm{~mm})$, the total available area, $585 \mathrm{~m}^{2}$, can be covered with 9,350 modules including the gaps, and as a result, the area for

only battery cells is $515 \mathrm{~m}^{2}$ and the gaps occupy the rest of the area which is $70 \mathrm{~m}^{3}$. The modules, 9,350 battery cells, weigh $841,500.00 \mathrm{~kg}$ with the volume of $520.78 \mathrm{~m}^{3}$. 
Approximately $115,000 \mathrm{kWh}$ of electrical energy can be deposited into the energy bank which supplies this energy to all systems in the submarine through the distribution system. With full charged battery cells, the submarine can stay under water for about 19 days consuming only BL without any generation.

\subsubsection{Evaluation of Power Generation and Storage Systems}

Throughout the section 3.4, the power generation and storage systems are discussed in detail in accordance with the required specifications to power the submarine, while the systems meet the operational conditions which are presented earlier. Based on the total displacement, 4,000,000 $\mathrm{kg}$ in weight and 3,907.78 $\mathrm{m}^{3}$ in volume, the calculated weights, volumes as well as their percentages are listed and evaluated in Table 4. As shown on the bottom of Table 4, the power generation and storage systems take up $34.97 \%$ in weight, and $49.06 \%$ in volume of the submarine, which confirms that they do not exceed the maximum percentages.

When comparing to the calculated weights and volumes of all components and storages, it are confirmed that the fundamental design factor, which is that power generation and storage systems take $35 \%$ of the total weight and $50 \%$ of the total volume in the submarine, is completely satisfied. 
Table 4. The Proportions of Power Generation and Storage Systems.

\begin{tabular}{ccccc}
\hline Systems & \multicolumn{2}{c}{ weight } & \multicolumn{2}{c}{ volume } \\
& {$[\mathbf{k g}]$} & {$[\mathbf{w} / \mathbf{0}, \mathbf{\%}]$} & {$\left[\mathbf{m}^{3}\right]$} & {$[\mathbf{v} / \mathbf{0}, \mathbf{\%}]$} \\
\hline Diesel Gen Sets & $43,510.00$ & 1.09 & 78.44 & 2.01 \\
Diesel Fuel Tanks & $124,800.00$ & 3.12 & 150.00 & 3.84 \\
Battery Cells & $841,500.00$ & 21.04 & 520.78 & 13.33 \\
Fuel Cell Modules & $3,600.00$ & 0.09 & 50.00 & 1.28 \\
LOX Tanks & $86,820.00$ & 2.17 & 132.61 & 3.39 \\
Hydrogen Tanks & $294,200.00$ & 7.36 & 185.19 & 4.74 \\
Propulsion Motor & $3,500.00$ & 0.09 & 200.00 & 5.12 \\
Auxiliary parts & $1,000.00$ & 0.03 & 600.00 & 15.35 \\
Total & $\mathbf{1 , 3 9 9 , 0 0 0 . 0 0}$ & $\mathbf{3 4 . 9 7}$ & $\mathbf{1 , 9 1 7 . 0 1}$ & $\mathbf{4 9 . 0 6}$ \\
Reference & $1,400,000.00$ & 35.00 & $1,953.89$ & 50.00 \\
\hline
\end{tabular}

\subsection{Submarine Warfare and Missions}

In modern naval warfare, submarines are often considered as the yardstick for how powerful and advanced navies are, because abilities of their submarines could determine success or failure of national strategic objectives in a war. Many countries are eager to build submarines capable of multi-mission, and upgrade their existed submarines to advanced version, since modern naval warfare requires submarines have longer underwater endurance, more ammunitions, and higher performance. Moreover, modern submarines are assigned to carry out more complex missions, beyond typical roles as deterrent or stand-by force. Considering the characteristics of modern naval warfare, five clearly designed 
missions are selected to examine the performance of the power generation and storage systems of the 4,000-ton class submarine model. The five missions are as follows:

- Mission one (M1): Surveillance and Information Gathering

- Mission two (M2): Landing of Special Operations Forces

- Mission three (M3): Attack of Land Targets

- Mission four (M4): Protection of task forces and merchant shipping

- Mission five (M5): Denial of sea areas to an enemy

All these missions have not only common ground but also distinctive features in accordance with time and energy-demanding situations. Characteristics of the missions need to be specified to construct the optimization model, and they have been described as constraints in section 3.2. Each mission has a duration which is divided into three phases, and each phase has several constraints such as maximum and minimum speeds, available power generation components, DL, as well as minimum battery level.

Out of the five, M1, M2 and M3 last for 30 day each, and M4 has 20 days, while M5 lasts for 25 days. All these mission scenarios are designed to begin at 5 a.m. of the first day and end at 5 a.m. of the last day. The time is the most important factor, because all systems are set to obey strictly time-based rules. More importantly, the submarine can snorkel in phase one (P1) and phase three (P3) regardless of the time of day and night, however snorkeling is only available during the nighttime in phase two (P2) in all missions. The daytime is 14 hours from 5 a.m. to 7 p.m., and the nighttime last for 10 hours starting at 7 p.m. and ending at 5 a.m.

DL is the minimum daily electrical load, which is imposed to the submarine included in the mission scenarios. This makes the scenarios more practical, because all detailed 
actions to conduct the missions cannot be described specifically, that is, instead of restricting the submarine into certain situations in time, by assigning DL, the submarine can respond to the situations by itself, essentially by utilizing EMS. In other words, the scenarios let the submarine determine the time and the amount of energy to consume under the certain conditions depending on level of difficulty and demand in energy. DL is expressed as percentages of BL for 24 hours. For example, if DL is $9,000 \mathrm{kWh}, 150 \%$ of BL ( $250 \mathrm{kWh}$ ) for 24 hours will be the minimum energy that the submarine must consume in a day.

The power generation and storage systems must accommodate the constraints of the missions effectively, so that the submarine can complete the missions successfully, while the submarine is staying underwater maintaining the state of stealth. In terms of level of difficulty, how much energy demanded is the most critical factor of determining the level which mainly depends on the speed. The five mission scenarios are designed to test the submarine's performance from low to high energy demanding circumstances which have different levels of difficulty.

\subsubsection{Surveillance and Information Gathering}

M1 consists of three phases as shown in Figure 8, and the submarine navigates from five knots of the economic speed to 20 knots of the maximum speed as necessary. The first and third phase are transits that take five days each, from its base to the mission area and back to the base. The second phase as 20 days is devoted to actual mission in which the submarine surveils the area and gathers information near an enemy territory by employing its sensors such as SONAR, periscope, and communication system. 


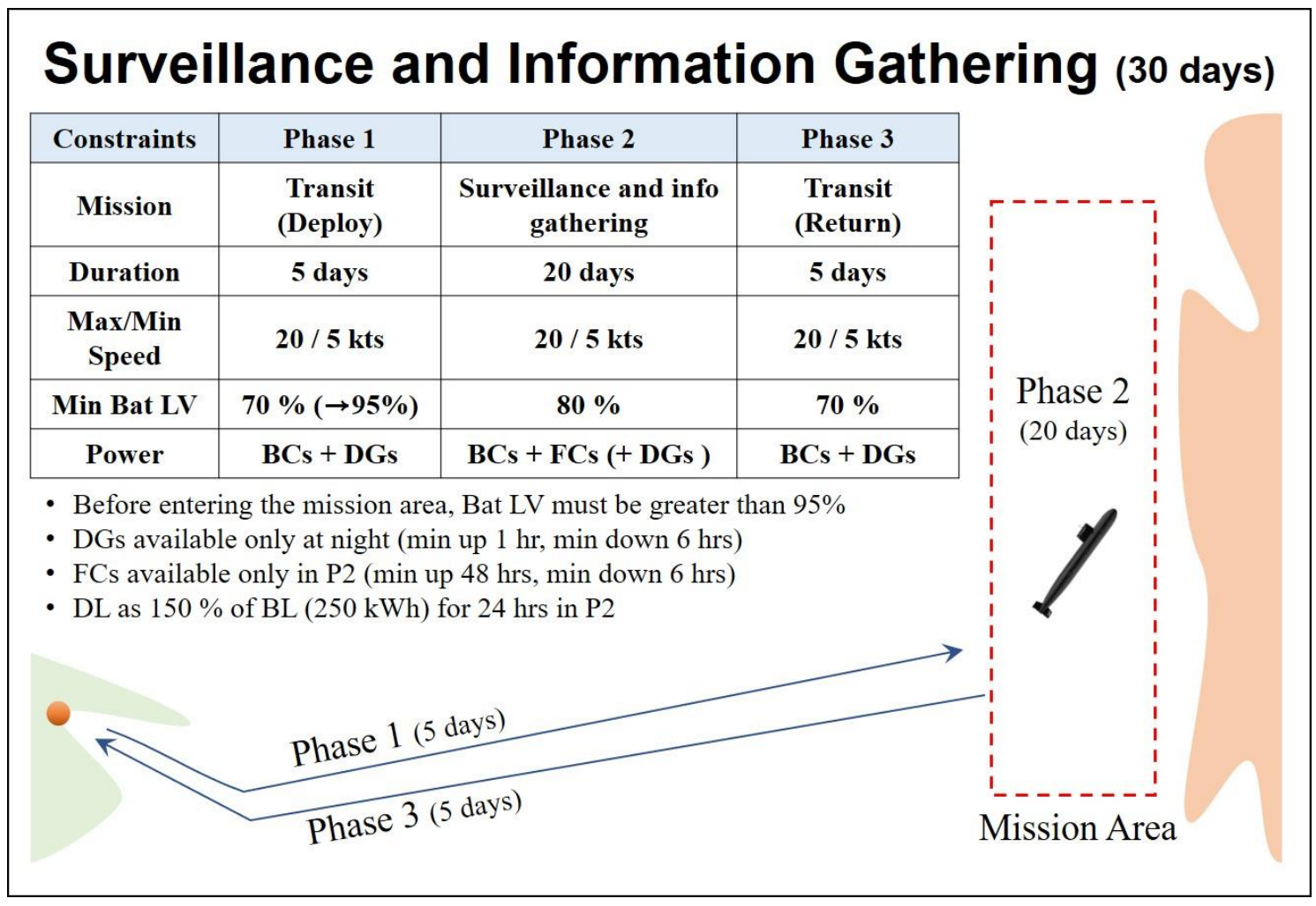

Figure 8. Description of M1.

Snorkeling is available to charge the BCs during entire mission, whereas fuel cells can be operated only in P2 in order to maximize its underwater endurance by operating fuel cells as much as possible in the mission area, and not during transits. During transits the submarine needs to keep battery level above $70 \%$, but it is increased to $95 \%$ before entering the mission area and settles at $80 \%$ in $\mathrm{P} 2$ to respond to an emergency or an unexpected battle. The minimum up and down time are 1 hour and 6 hours for DGs, and 48 hours and 6 hours for FCs respectively. DL as $150 \%$ of BL for 24 hours applied to the systems in P2 to cover the additional energy required to conduct the mission.

\subsubsection{Landing of Special Operations Force}

M2 has a period of 30 days which divides into three phases as illustrated in Figure 9. Deployment and return, P1 and P3, takes five days each, whereas P2 lasts 20 days, having 


\section{Landing of Special Operations Forces (30 days)}

\begin{tabular}{|c|c|c|c|c|c|}
\hline Constraints & Phase 1 & \multicolumn{3}{|c|}{ Phase 2-1, Phase 2-2 } & Phase 3 \\
\hline Mission & $\begin{array}{c}\text { Transit } \\
\text { (Deploy) }\end{array}$ & $\begin{array}{l}\text { Approach } \\
\text { \&Dispatch }\end{array}$ & Standby & $\begin{array}{l}\text { Withdraw } \\
\text { \&Transit }\end{array}$ & $\begin{array}{c}\text { Transit } \\
\text { (Return) }\end{array}$ \\
\hline Duration & 5 days & 1.5 days & 7 days & 1.5 days & 5 days \\
\hline $\begin{array}{c}\text { Max/Min } \\
\text { Speed }\end{array}$ & $20 / 5$ kts & $20 / 5$ kts & $20 / 5$ kts & $20 / 8$ kts & $20 / 5$ kts \\
\hline Min Bat LV & $\begin{array}{c}70 \% \\
(\rightarrow 95 \%)\end{array}$ & $80 \%$ & $80 \%$ & $\begin{array}{c}70 \% \\
(\rightarrow 95 \%)\end{array}$ & $70 \%$ \\
\hline Power & $\begin{array}{c}\text { BCs }+ \\
\text { DGs }\end{array}$ & $\mathrm{BCs}+\mathrm{FCs}$ & $\mathrm{BCs}+\mathrm{FCs}$ & BCs + DGs & $\begin{array}{c}\text { BCs + } \\
\text { DGs }\end{array}$ \\
\hline
\end{tabular}

- Before entering the mission areas, Bat LV must be greater than 95\%

- DGs available only in transits at night (min up $1 \mathrm{hr}$, min down $6 \mathrm{hrs}$ )

- FCs available only in P2 (min up 48 hrs, min down 6 hrs)

- DL as $120 \%$ of Base load (250 kWh) for 24 hrs in P2

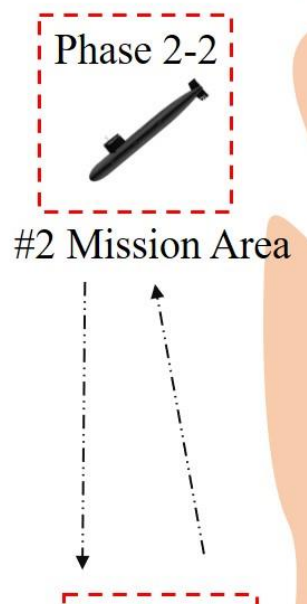

O

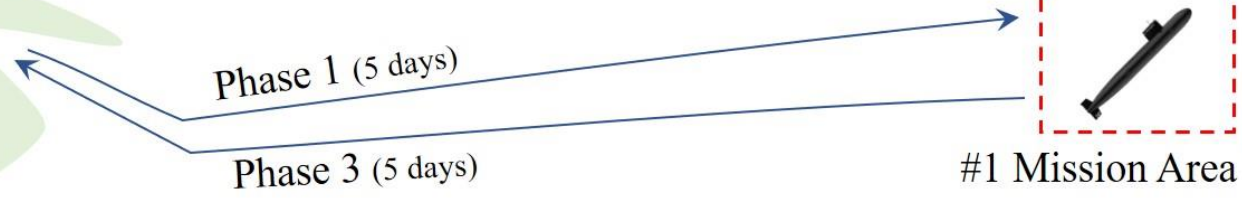

Figure 9. Description of M2.

two parts with each part having ten days: P2-1 and P2-2. In P2, the submarine approaches the first mission area, a littoral area of an enemy territory, and dispatches special operations team to the shore during the first one and half days. After the dispatch, the submarine stays for next seven days in the area, supporting the special operation team until they finish their own mission and return. For the next one and half days, the submarine moves to the other mission area with a medium speed of eight knots. P2-2 is nothing but the repetition of P21.

The submarine must maintain BC level above $80 \%$ except Transits which require 70\% of $\mathrm{BC}$ level at the minimum, however the $\mathrm{BCs}$ should be charged above $95 \%$ before entering each mission area. Snorkeling is not available during approach, dispatch and standby in P2, but fuel cells are only available during the same time. The minimum up and 
down time are the same as M1. DL as $120 \%$ of BL for 24 hours is imposed on the systems in $\mathrm{P} 2$.

\subsubsection{Attack of Land Targets}

In M3, the submarine launches missiles on the designated targets according to the orders from its headquarters as presented in Figure 10. Once the submarine enters the mission areas, it observes closely activities of enemy assets and communicate with the headquarters waiting for further instructions for five days, and the submarine fires missiles during the next two days in accordance with directions. For these seven days, snorkeling is not available in order to avoid exposures while the submarine must consume DL as $150 \%$ of BL for 24 hours. After firing the missiles, the submarine jumps to the next mission area at the speed of 8 knots charging BCs by snorkeling during Transit, since FCs need to be

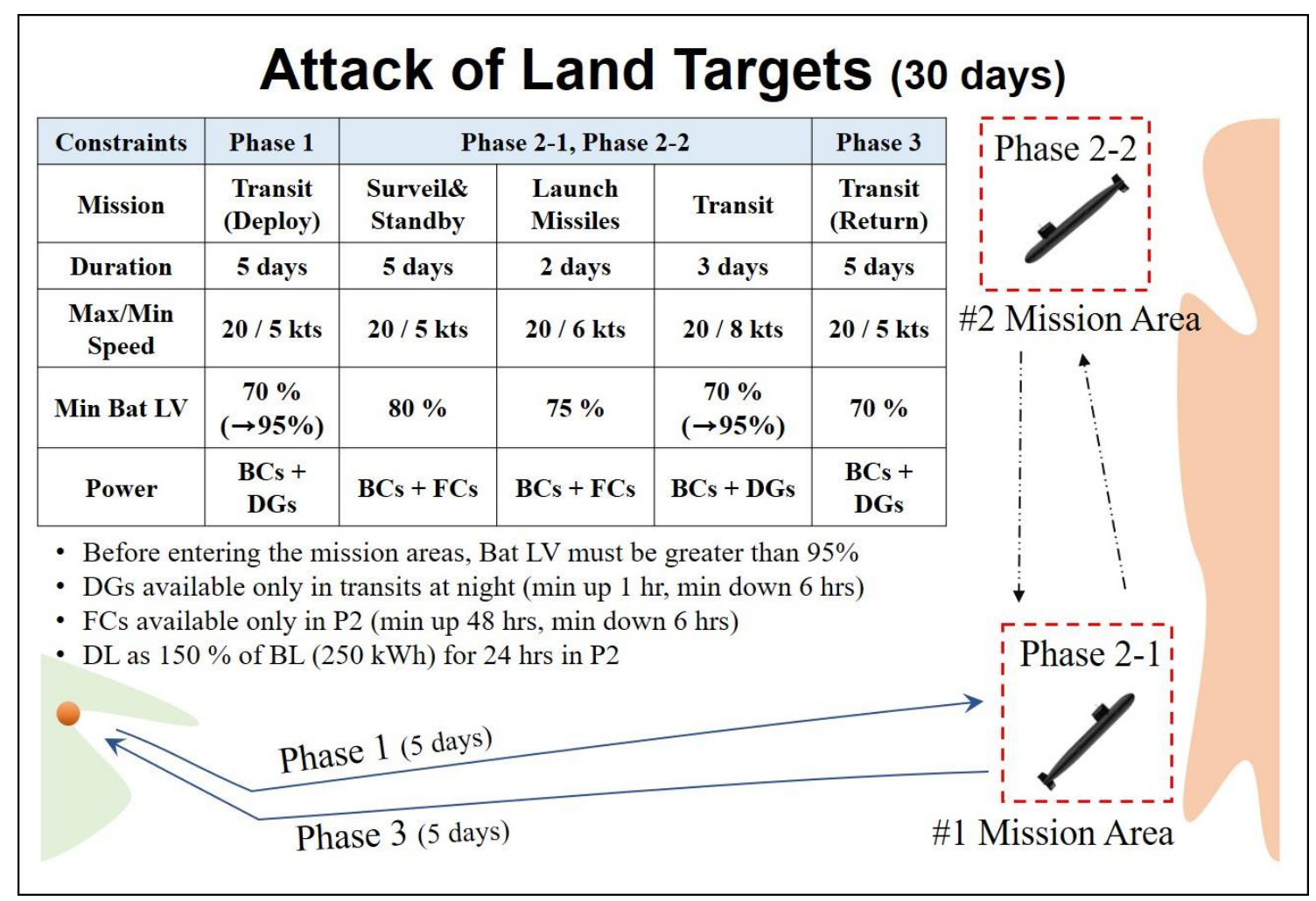

Figure 10. Description of M3. 
saved for the next seven days to serve the DL without snorkeling. The BC level should be maintained above $80 \%$ in surveil and standby and $75 \%$ in launch missiles. In transits, the BC level becomes lowered to $70 \%$ at the minimum, however it must be above $95 \%$ prior to the beginning of P2-1 and P2-2. The minimum up and down time for DGs and FCs are the same for M1 and M2.

\subsubsection{Protection of Task Forces and Merchant Shipping}

M4 requires higher speeds and more energy than the prior missions because of including engagements with enemy assets like submarines and surface ships. M4 lasts 20 days with three phases as presented in Figure 11. In P2, the first three days are devoted to searching and attacking the mission area for enemy submarines which may hide and wait

\begin{tabular}{|c|c|c|c|c|}
\hline Constraints & Phase 1 & Phase 2-1 & Phase 2-2 & Phase 3 \\
\hline Mission & Transit (Deploy) & Presearch\&ASW & Convoying\&ASuW & Transit (Return) \\
\hline Duration & 5 days & 3 days & 7 days & 5 days \\
\hline $\begin{array}{c}\text { Max/Min } \\
\text { Speed }\end{array}$ & $20 / 5 \mathrm{kts}$ & $20 / 6 \mathrm{kts}$ & $20 / 9$ kts & $20 / 5$ kts \\
\hline Min Bat LV & $70 \%(\rightarrow 95 \%)$ & $80 \%(\rightarrow 95 \%)$ & $70 \%$ & $70 \%$ \\
\hline Power & BCs + DGs & BCs + FCs + DGs & BCs + FCs + DGs & BCs + DGs \\
\hline
\end{tabular}

- Before entering the mission area, Bat LV must be greater than $95 \%$

- When ASW or ASuW, speed at $20 \mathrm{kts}$ for 2 hours required * ASW: Anti Submarine Warfare, ASuW : Anti Surface ship Warfare

- DGs available only at night (min up $1 \mathrm{hr}$, min down $4 \mathrm{hrs}$ )

- FCs available only in P2 (min up 24 hrs, min down $4 \mathrm{hrs}$ )

- DL as $180 \%$ and $200 \%$ of BL in $\mathrm{P} 2-1$ and $\mathrm{P} 2-2$ respectively
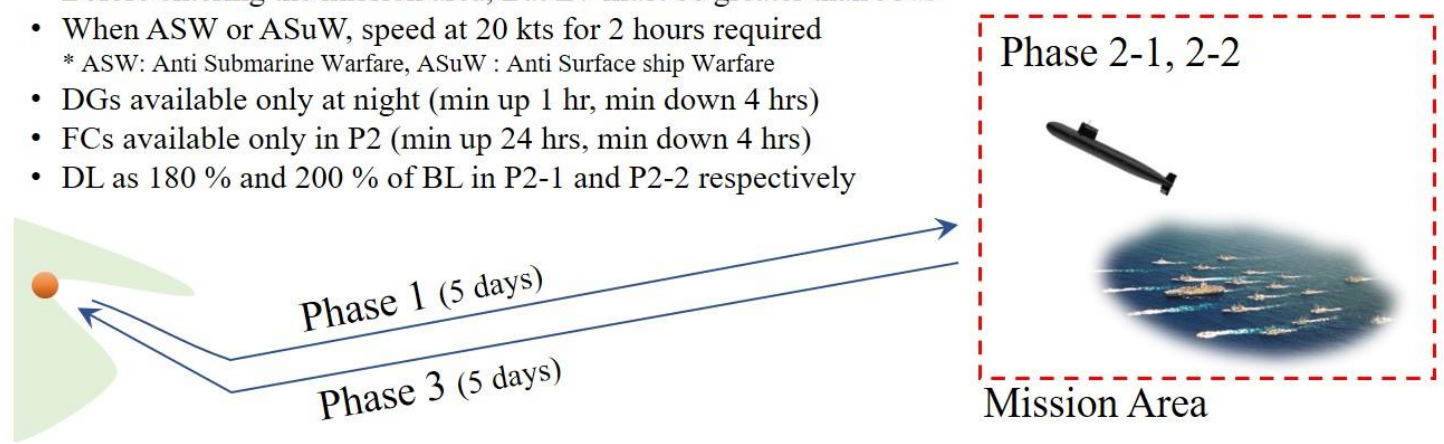

Figure 11. Description of M4. 
to attack friendly task forces, before they enter the area. The next seven days are dedicated to protecting the task forces and merchant shipping while they are passing the area, and the submarine must be able to maneuver at the speed of 9 knots or higher in order to convoy them and attack enemy assets intruding and trying to attack friendly forces.

M4 includes five engagements which require the submarine to proceed at the maximum speed of 20 knots for two hours. Two battles during the first three days and three battles during the next seven days are given randomly in time throughout $\mathrm{P} 2$. The battles demand extremely high energy consumption within short period of time without snorkeling and as a result the $\mathrm{BC}$ level decreases rapidly. The $\mathrm{BC}$ level should be maintained above $80 \%$ in $\mathrm{P} 2-1$ otherwise $70 \%$, however the level must be above $95 \%$ prior to the beginning of P2. The minimum up and down time are 1 hour and 4 hours for DGs, and 24 hours and 4 hours for FCs respectively. DLs as $180 \%$ and $200 \%$ of BL for 24 hours are imposed on P2-1 and P2-2 respectively.

\subsubsection{Denial of Sea Areas to An Enemy}

M5 has a duration of 25 days including ten engagements in P2 as illustrated in Figure 12. In this mission, the submarine patrols a strait which is a highly anticipated route that enemy assets are passing through and the passage needs to remain free to friendly forces. The ten engagements deplete the energy levels in BCs every time and additionally DL as $150 \%$ of $\mathrm{BL}$ for 24 hours enforces FCs to be operating at the maximum rated power in $\mathrm{P} 2$. In order to maintain battery level above the designated minimum level, the submarine needs more frequent and longer snorkels. However, consecutive engagements do not allow the submarine to snorkel at any time it needs to, since imminent threats exists in the area and the minimum up and down time do not allow the submarine to snorkel continuously. 


\section{RESULTS AND DISCUSSIONS}

In this chapter, we will virtually deploy the 4,000-ton class conventional submarine equipped with EMS into the five missions. As presented in Figure 7, EMS will follow the sequential procedure of operational scheduling process to generate optimal schedules in accordance with the specifications of power generation and storage systems as well as the mission scenarios.

First, EMS executes data acquisition and investigates the power generation and storage systems. Once the algorithm finishes building system constraints, EMS loads a mission scenario and produces an optimal schedule, including the minimum TSTs. The optimal schedule becomes the most efficient timeline from an energy utilization point of view. However, if the schedule is infeasible, operators need to intervene in the process and change the constraints.

Second, EMS performs CA by introducing the outage scenarios, applying the 17 outage cases on each day of the missions based on the optimal schedules. As a result of CA, EMS generates a set of operational schedules which are survived from the outages. These operational schedules can be used as secured optimal schedules only if they are feasible, whereas infeasible scenarios are required to take further step.

Third, EMS operates stochastic operational scheduling process with the infeasible scenarios from CA. In this process, EMS combines a normal scenario and the multiple infeasible scenarios simultaneously from the beginning of the mission. That is to say, the infeasible scenarios are linked to the normal scenario respectively until the occurrence of each outage by equalizing all variables such as the commitments of DGs and FCs. By doing so, EMS can produce secured optimal schedules for the infeasible scenarios. If they all 
become feasible from stochastic operational scheduling, the stochastic optimal schedule is prepared for the next round of CA process.

Last but not the least, if EMS still cannot result feasible operational schedules, it is necessary that the operators must interfere directly in the process and modify the system constraints. EMS starts over from CA and keeps circulating the same loop until the operators achieve secured optimal schedules for all outage scenarios.

\subsection{M1: Surveillance and Information Gathering}

The optimal schedule which has 16 hours of TST for M1 is presented as four sections in Figure 13. The four sections share the $\mathrm{x}$ axis representing the duration of M1 which is 720 hours (30 days), and the y axis indicates four different numerical quantities.

The first section shows commitments of DGs and FCs, and the lines reach one when they are in operation, otherwise they stay at zero, however they are not operating simultaneously. The second section shows actual battery level and pre-set minimum battery level in percentage. The latter level is determined by the operators to prevent the systems

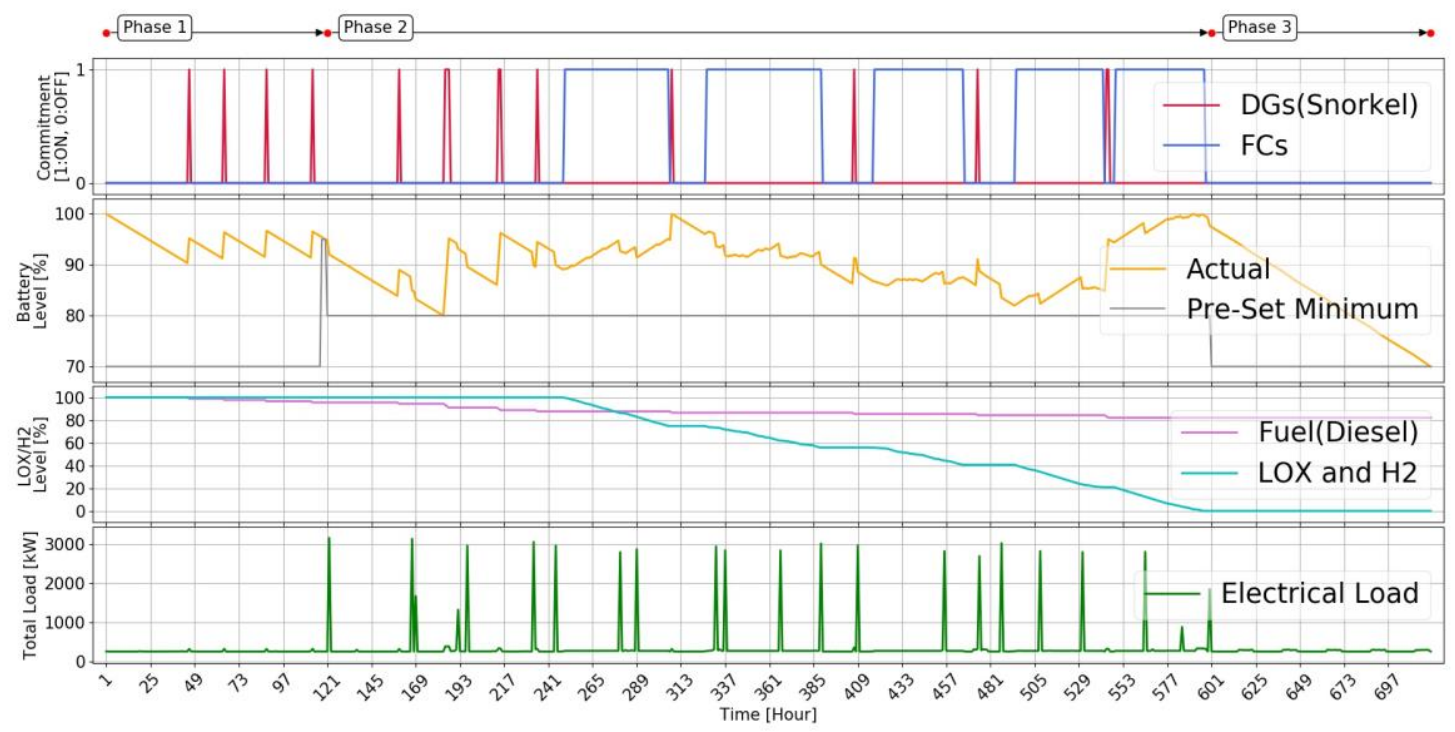

Figure 13. Optimal Schedule for M1 (TST: 16 hours). 
from consuming energy in batteries below the allowable lower bound, which is quite critical in order to respond to urgent situations requiring plenty of energy. EMS demands the systems to charge BCs above $95 \%$ before proceeding to $\mathrm{P} 2$ and entering the mission area as shown at hour 120 in the second section of Figure 13. Diesel fuel level decreases when DGs are running, but it remains at relatively high level at the end of the mission, because the TST is only 16 hours and the fuel tanks have enough capacity to meet the conditions stated in section 3.1. LOX and hydrogen storage levels start reducing at the beginning of $\mathrm{P} 2$ and become empty near the end of $\mathrm{P} 2$, which means FCs are being fully utilized through P2 in order to minimize TST. In the fourth section, total electrical load in $\mathrm{kW}$ is fluctuating between the minimum and maximum bounds. During P2, the submarine moves at relatively high speeds for several hours a day in order to achieve the given mission. As discussed in the prior chapter, DL is imposed by EMS to cover additional electrical loads. For example, the submarine navigates faster to avoid unnecessary encounters with enemy assets, and weapon and SONAR systems need additional energy to prepare for potential conflicts, while surveillance systems like communication systems and periscopes require more energy to operate extra equipment.

EMS performs CA on the optimal schedule to examine whether the systems can survive through the outage scenarios. The TSTs of 510 outage scenarios, which were made by 17 outage cases for 30 days, are shown in Figure 14. As time goes on, TSTs are decreasing and essentially merging to 16 hours of snorkeling time, which is the TST of the optimal schedule, since the outages affect the systems less and less as approaching the end of mission. When Case 17, which is obviously the most severe case, occurs at day one, TST increases to 34 hours, which is a significantly higher number compared to 16 hours 


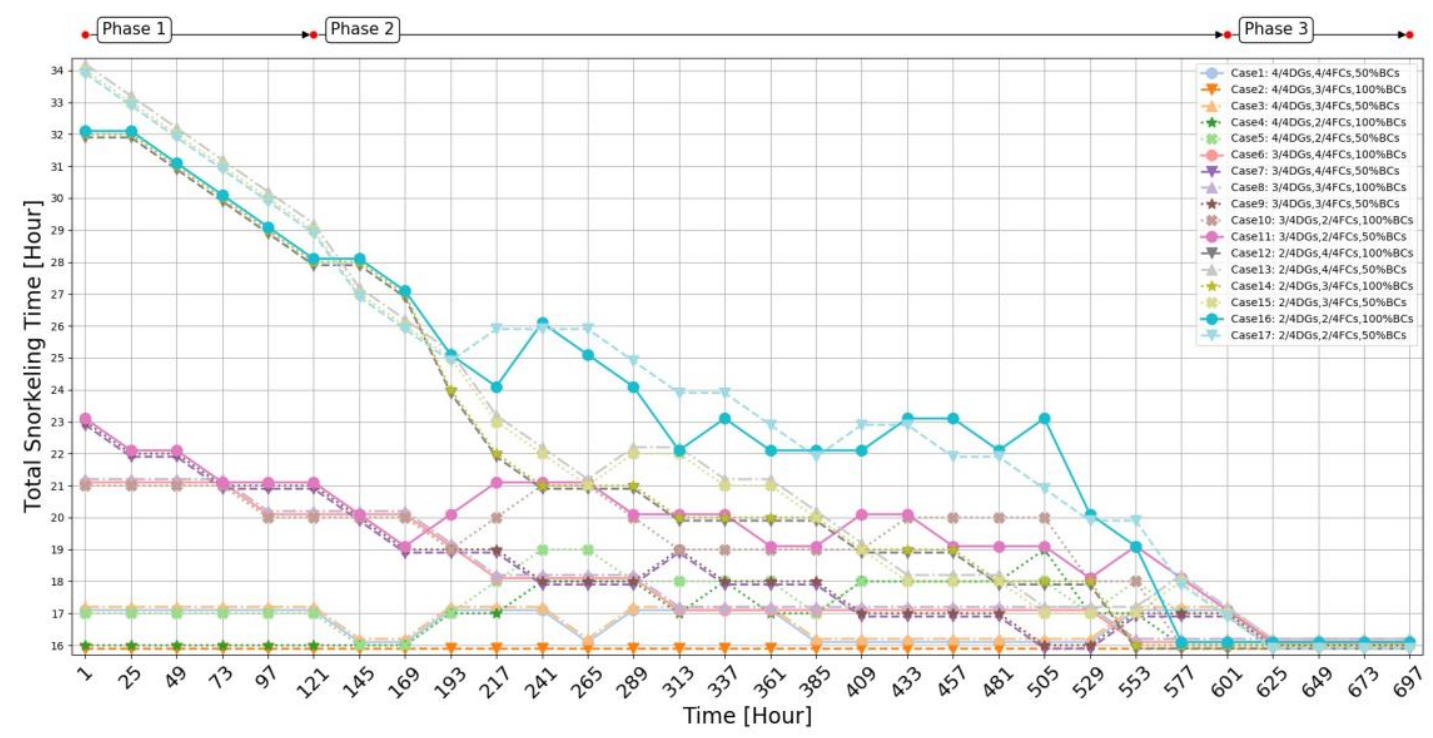

Figure 14. CA Results for M1 (510 scenarios).

from the optimal schedule. Whereas, case two shows 16 hours of TST throughout the mission, because even though single FC module breaks down, EMS can handle the outage and fill up the shortage in power with other components.

Through CA, it is confirmed that the submarine can survive from the 510 scenarios with increased snorkeling time in most scenarios. In addition, the remarkable fact is that EMS produces 510 different secured optimal schedules. Furthermore, this whole process can be executed at the planning stage in port, as well as during missions at sea.

\subsection{M2: Landing of Special Operations Forces}

The TST of M2 is recorded as 13 hours for 720 hours (30 days) as shown in the first section of Figure 15. In this mission, snorkeling is not available from hour 121 to 325 and hour 361 to 565, which are the periods of Approach, Dispatch and Standby in P2. However, it is available during Transits when the pre-set minimum battery level decreases to $70 \%$. It is observed that the commitments of FCs go up only during Approach, Dispatch and Standby, which means that the submarine does not snorkel in the mission areas by running 


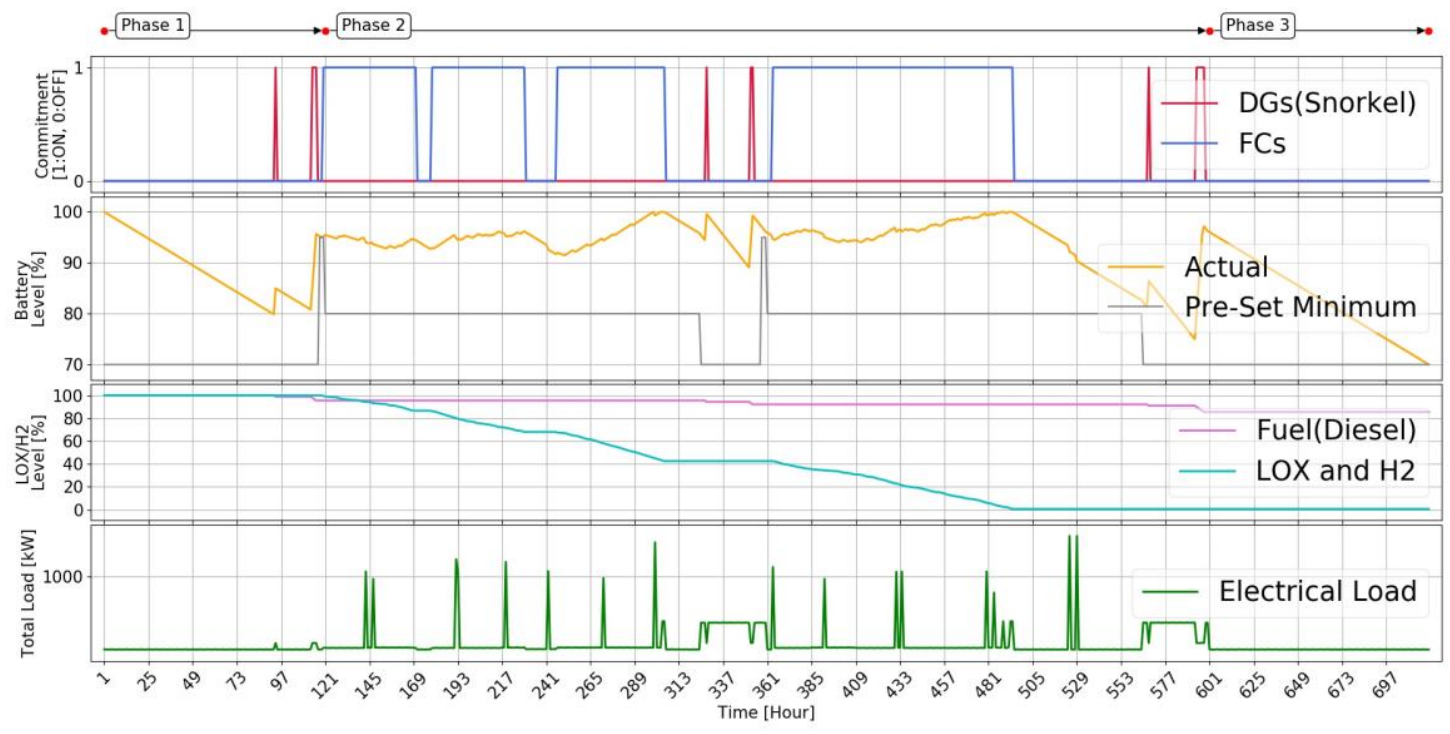

Figure 15. Optimal Schedule for M2 (TST: 13 hours).

FCs in order to avoid exposures. In the second section, actual battery level stays over the minimum battery level while BCs continue charging and discharging. In the third section, EMS employs FCs completely during P2 since LOX and hydrogen are fully exhausted. In the fourth section, it is shown that DL as 120\% of BL for 24 hours is imposed in Approach, Dispatch and Standby of P2, and the submarine is required to maneuver at least 8 knots in Transits of $\mathrm{P} 2$.

The 510 TSTs from the outage scenarios are shown in Figure 16. Scenario 17, which has outage case 17 on day one, requires 26 hours of snorkeling time for the submarine to complete the mission. Most of the feasible scenarios have higher or the same number of TSTs than 13 hours of the optimal schedule. On the contrary, 15 scenarios have 12 hours of TST, which is even an hour less than the optimal schedule. The 15 scenarios consist of outage cases one, three, and five, which have 4 DGs and $50 \%$ of BCs, at hour 49, 73, 97, 553, and 577. While EMS has full capacity of DGs, these scenarios can save an hour of snorkeling in these specific circumstances since the outage cases of $50 \%$ of BCs 


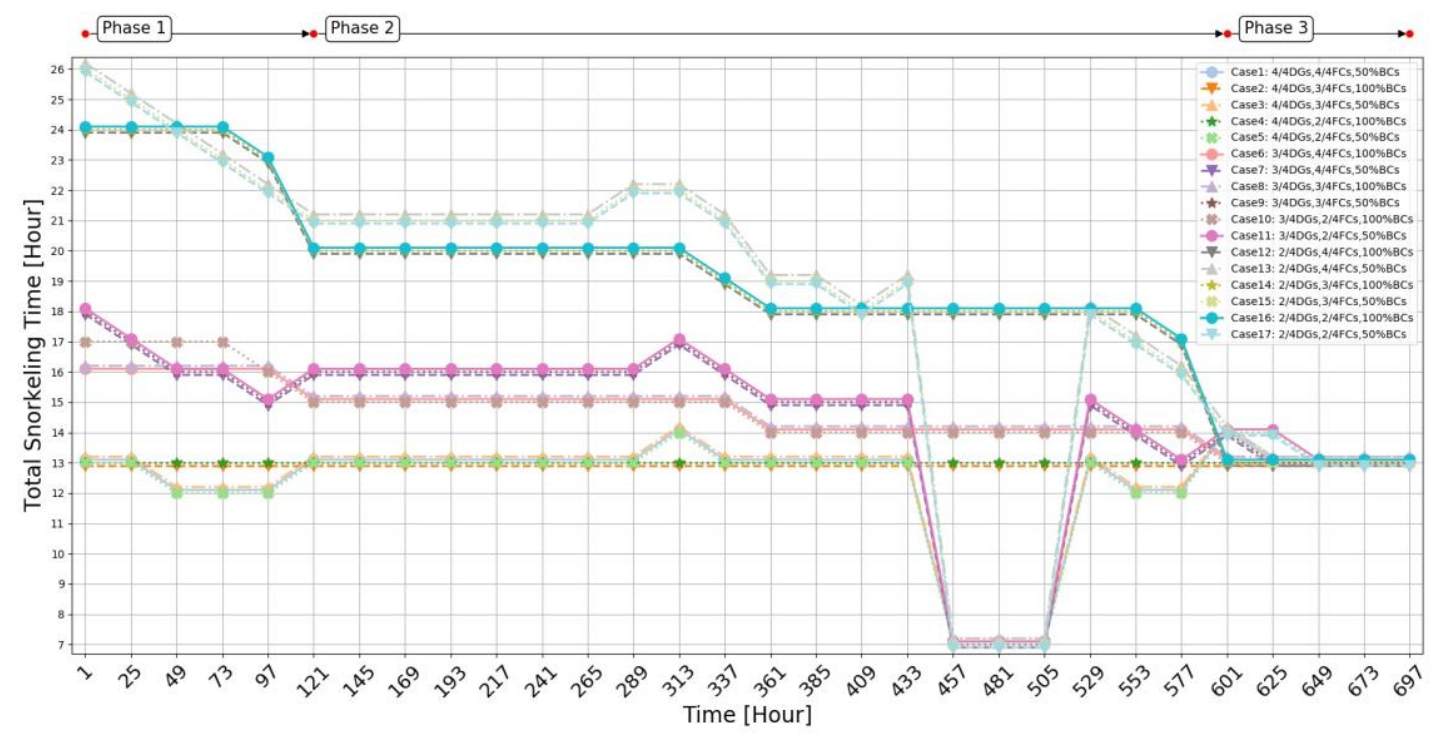

Figure 16. Results of CA on Optimal Schedule for M2 (510 Cases).

accompany the relaxation of the minimum $\mathrm{BC}$ levels. However, this reduction of an hour does not indicate that they are better schedules than the optimal schedule because the relaxation already made the submarine vulnerable in responding to high energy-demanding situations.

The CA results present that 483 scenarios turn out to be feasible, but 27 scenarios fail to obtain the optimal schedules. All the 27 infeasible scenarios contain $50 \%$ of BCs, which are the same 9 outage cases, at hour 457, 481, and 505 respectively. Because FCs are fully utilized at hour 493 and snorkeling is not available until hour 541 in the optimal schedule, if 50\% of BCs are out of operation, it is impossible for EMS to keep the energy level of BCs above the minimum level even though it is relaxed at the moment. This is the reason why the scenarios become infeasible within these hours. Simply, the operators easily overcome this situation by lowering the minimum battery level even more, in order to afford the lacking energy until snorkeling is available. However, since EMS already relaxed the minimum level during $\mathrm{CA}$, if the minimum level goes down even lower than 


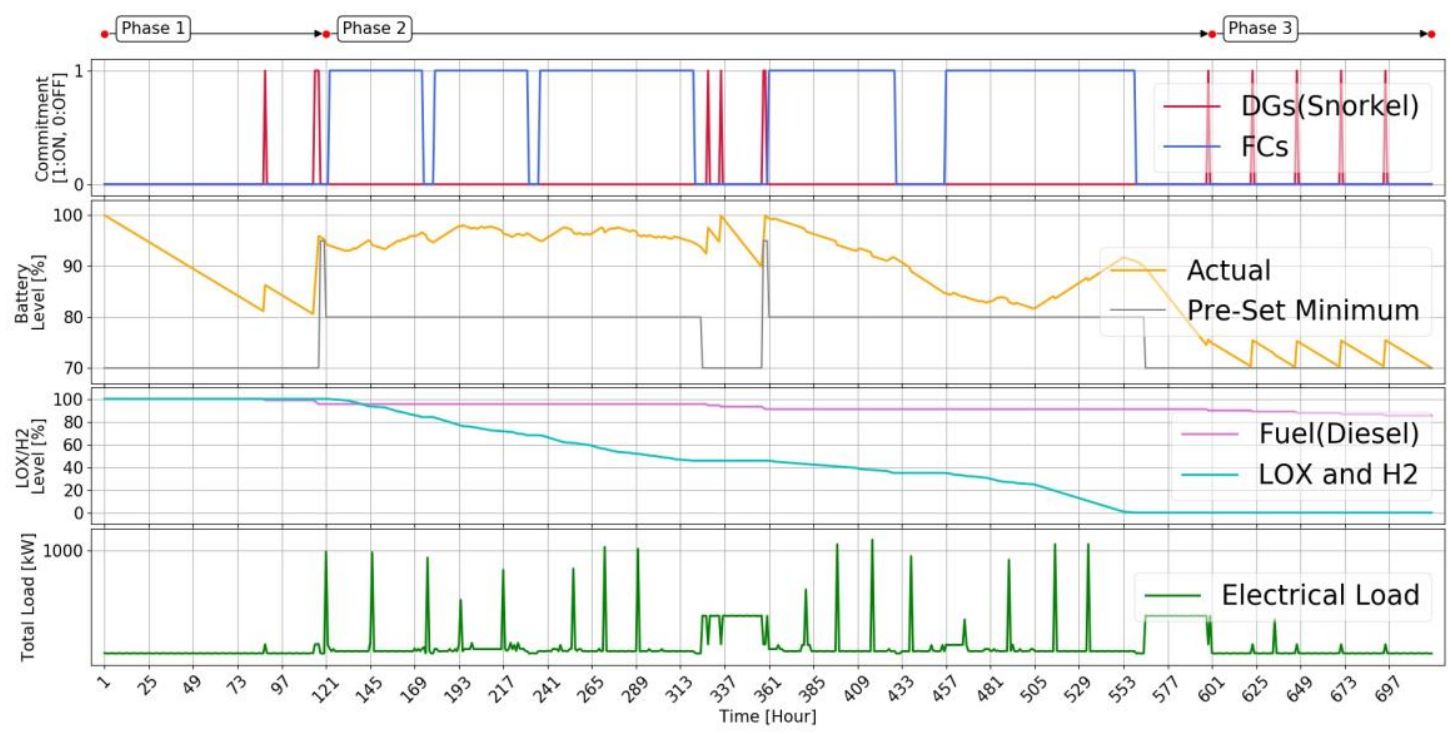

Figure 17. Stochastic Optimal Schedule for M2 (TST: 13 hours).

the relaxed level, the ability to cope with emergency situations will decrease significantly, and EMS might not be able to recover the original energy level unless EMS establish snorkeling in dangerous areas by breaking the state of stealth.

Instead of the operators' intervention, EMS conveys these 27 infeasible scenarios to stochastic operational scheduling process. In this step, EMS examines if the submarine can preserve more energy before the outages appear on the systems in order to overcome the failures. The 27 scenarios bind with the normal scenario that does not have any outages, and with this setup, EMS performs stochastic operational scheduling. As a result, the TST of the normal scenario recorded as 13 hours, as shown in Figure 17, which is the same amount of time with the TST of the optimal schedule from deterministic operational scheduling. Moreover, the 27 scenarios turn into feasible optimal schedules by saving more energy prior to the appearances of the outages. However, this stochastic operational scheduling does not guarantee that the stochastic optimal schedule ensures all 510 outage scenarios are feasible because only 27 scenarios have been considered in this process. EMS 


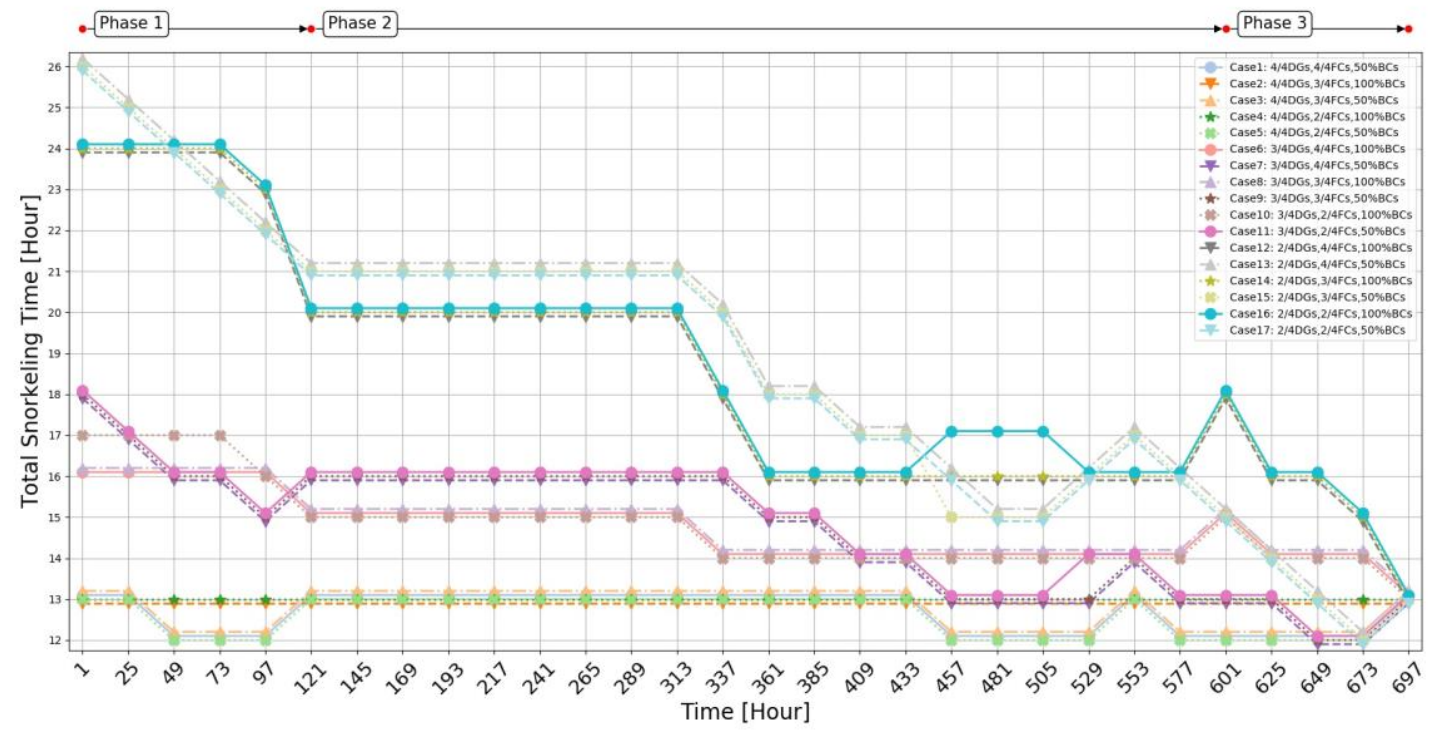

Figure 18. Results of CA on Stochastic Optimal Schedule for M2 (510 Cases).

sends this stochastic optimal schedule which has no outage back to CA process in order to examine whether the schedule can be survived through the 510 scenarios. As shown in Figure 18, 510 new secured optimal schedules are obtained through CA, and the stochastic optimal schedule becomes the new optimal schedule for M1.

\subsection{M3: Attack of Land Targets}

The optimal schedule is presented with 19 hours of TST for 720 hours of M3 as shown in the first section of Figure 19. Snorkeling is only available in Transits, but EMS utilizes FCs and BCs during P2. The battery level keeps changing between $100 \%$ and the minimum pre-set level repeatedly, following generation and consumption as illustrated in the second section. FCs are entirely employed during P2, which is ideal, as shown in the third section. The fourth section represents total electrical load consumed by the systems, which is greater than or equal to DL that is $150 \%$ of BL for 24 hours.

As described in Figure 20, 486 scenarios with TSTs, which are equal to or greater than 18 hours, survive from the outages, and 24 scenarios, which have TSTs less than 18 hours, 


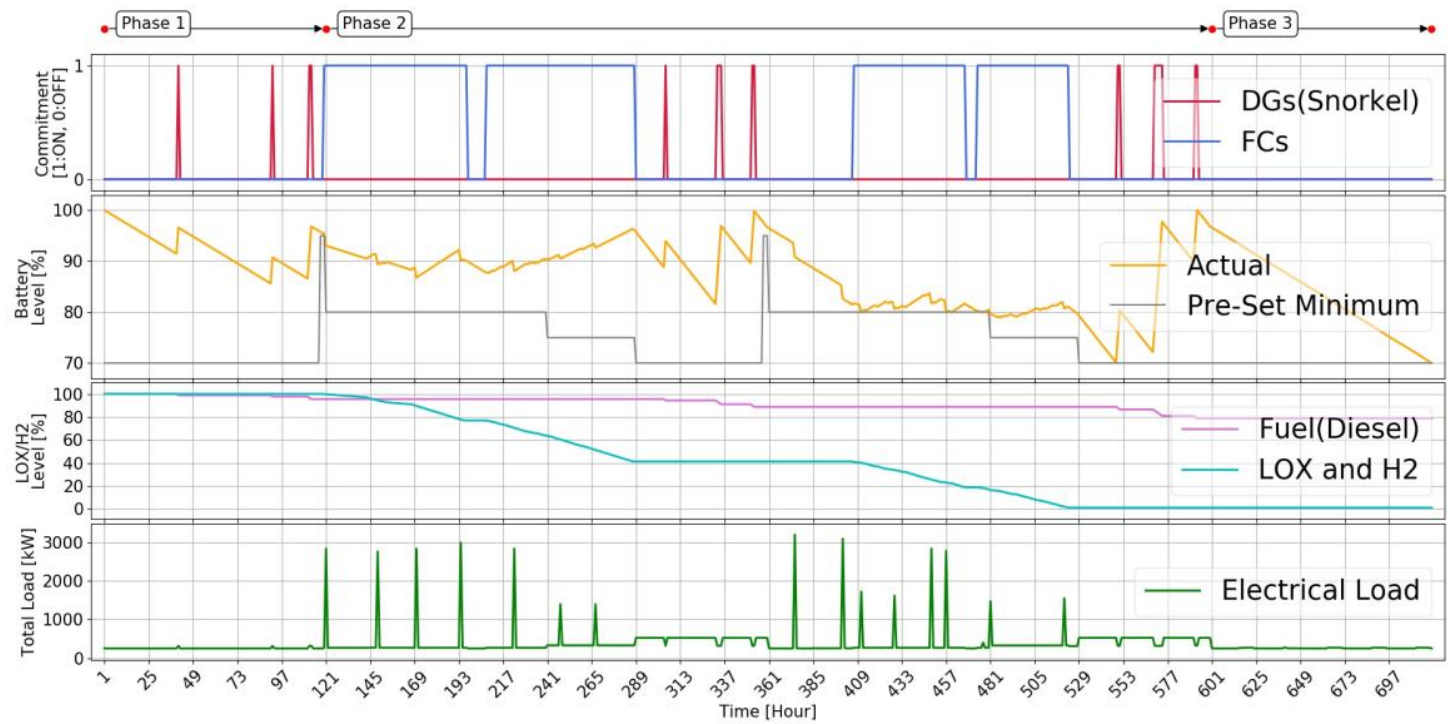

Figure 19. Optimal Schedule for M3 (TST: 19 hours).

turn out to be infeasible. The highest TST as 39 hours is recorded from outage case 13, 15, and 17 at day one, which have only 2 DGs and $50 \%$ of $\mathrm{BCs}$, and therefore, it is obvious that 2 DGs require more snorkeling time than 4 DGs to generate the same amount of energy. However, 16 scenarios, which have full capacity of DGs and 50\% of BCs, show 18 hours of snorkeling time, which is an hour less than the optimal schedule, and these reductions

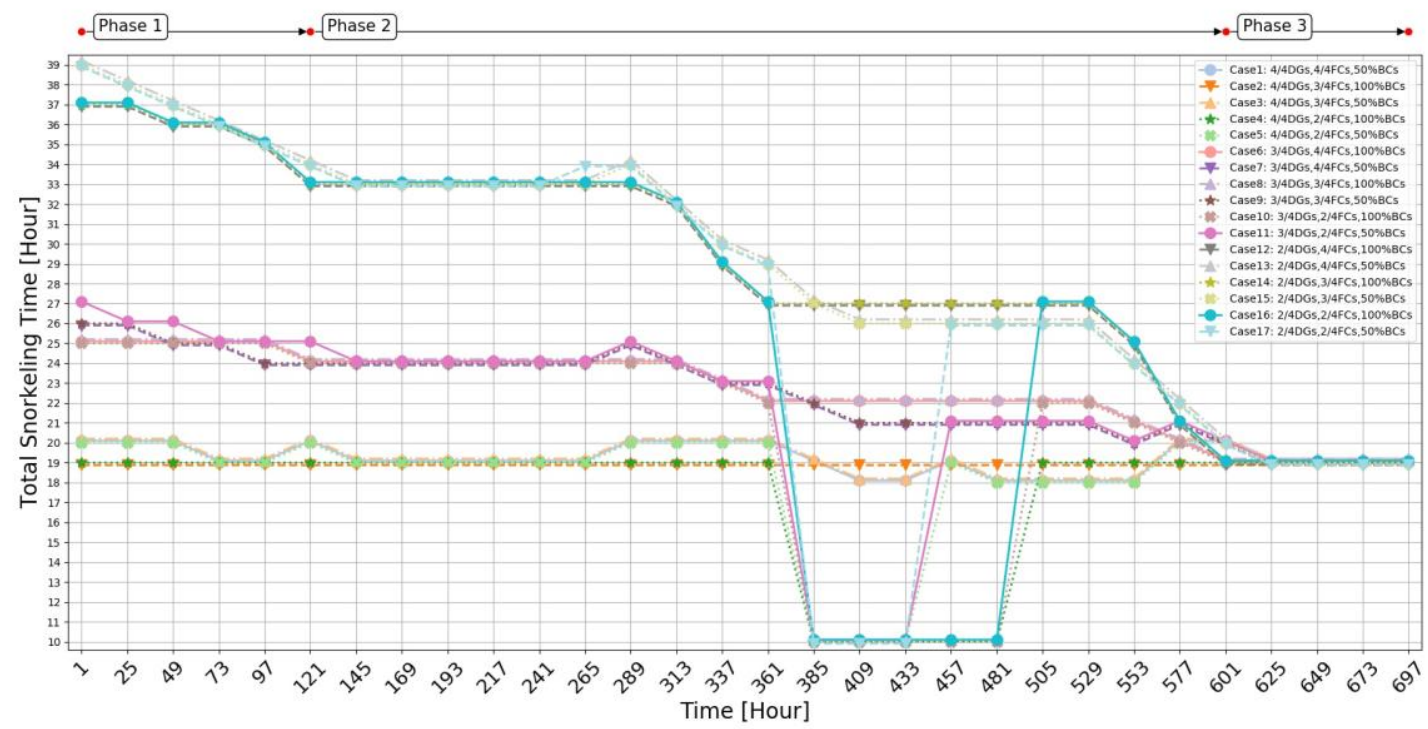

Figure 20. CA Results for M3 (510 Cases). 


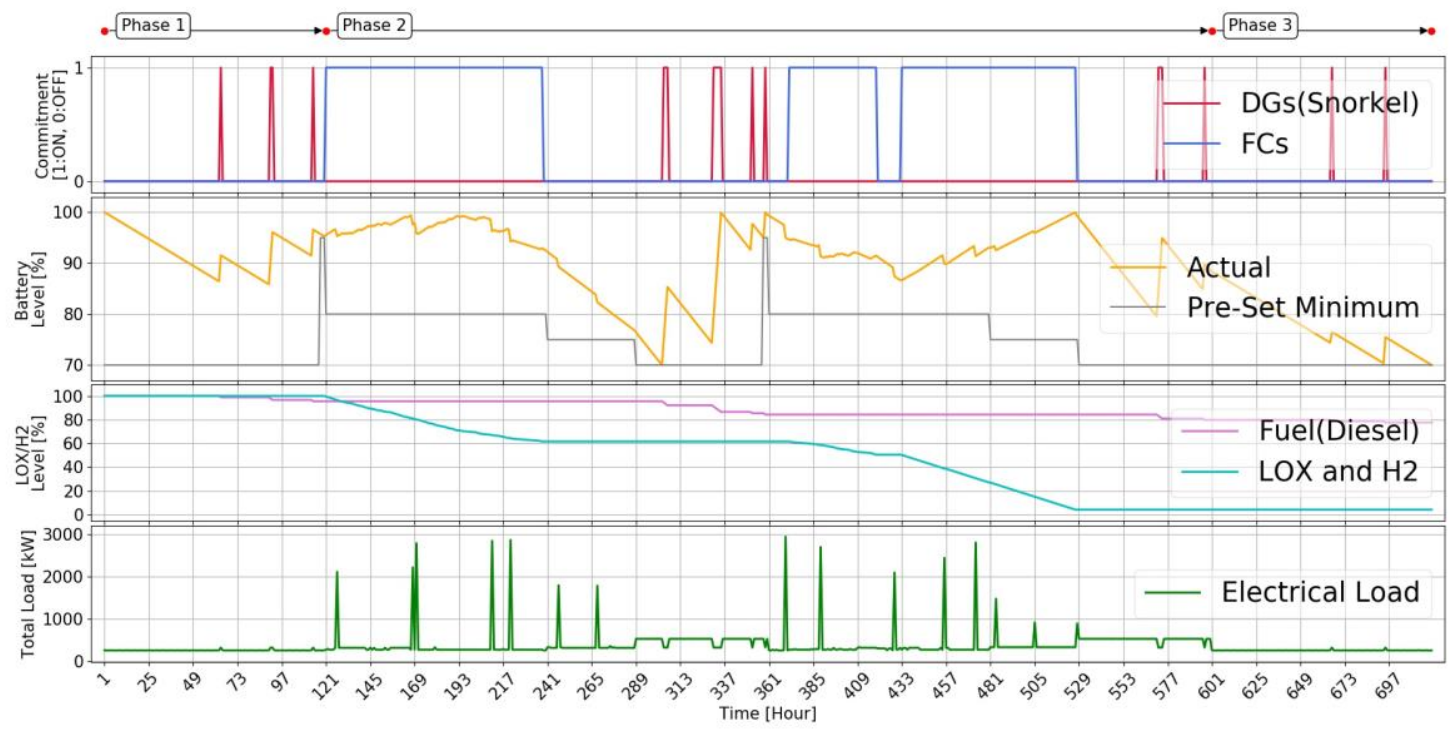

Figure 21. Stochastic Optimal Schedule for M3 (TST: 20 hours).

occur between hour 409 and 553. In this time window, the battery level barely maintains above the minimum level as shown in Figure 19. Even though they lose 50\% of BCs, EMS obtains more room for energy since the minimum level decrease due to the relaxation, this energy gap enables the 16 scenarios to save an hour of snorkeling in the future, as long as they have full power of DGs.

All the 24 infeasible scenarios fail between hour 385 and 481, and a noticeable common feature is that they have only 2 FCs. In this time period of P2-2, FCs become crucial energy supplier since snorkeling is not available until hour 529. Therefore, the loss of 2 FCs triggers a violation on the systems, and EMS is unable to generate enough energy to keep the lower bound of the battery level.

Throughout the stochastic operational scheduling process, the 24 scenarios obtain optimal schedules, which have the same schedule with the normal scenarios until the outages break out. The normal scenario takes the role of stochastic optimal schedule which ensures that all 24 scenarios are coverable from this process. This stochastic optimal 


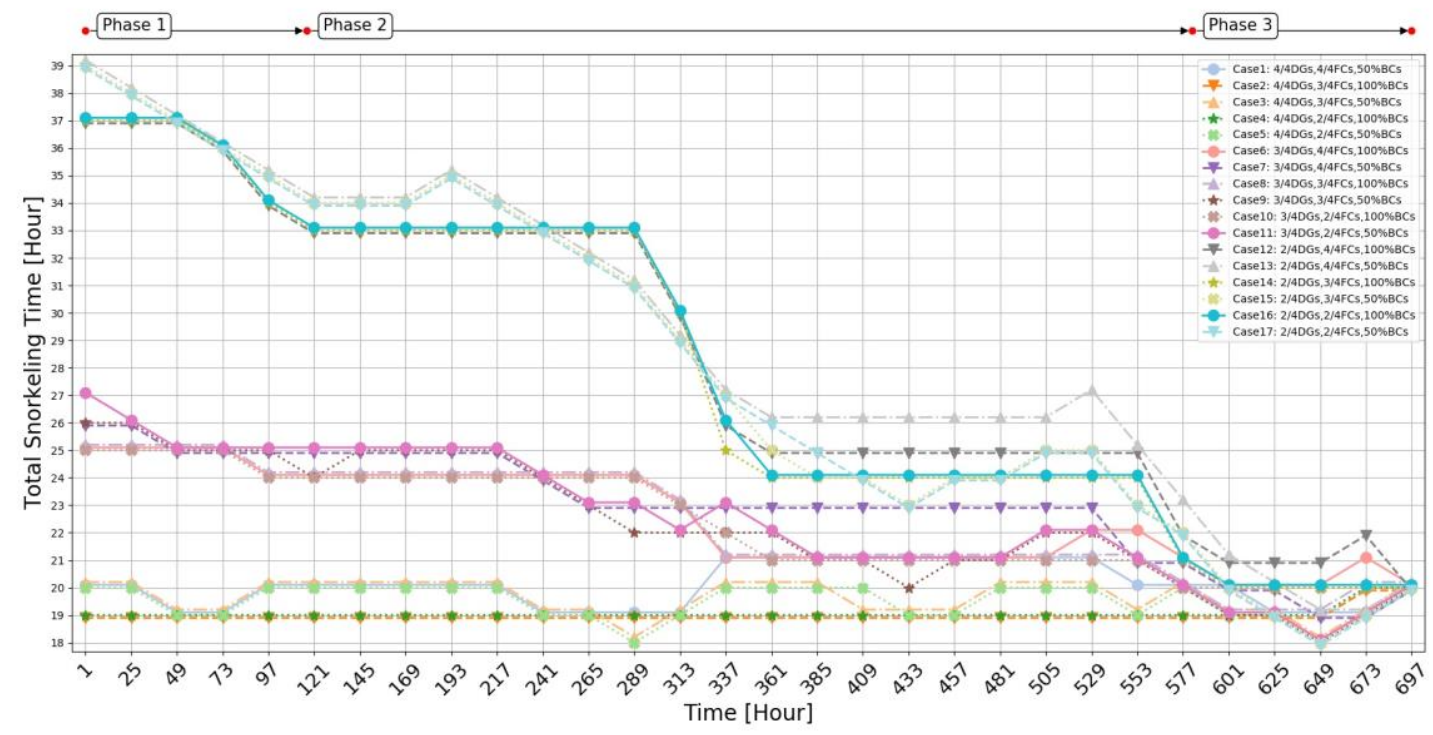

Figure 22. Results of CA on Stochastic Optimal Schedule for M3 (510 Cases).

schedule has 20 hours of TST, which is an hour more than the optimal schedule as illustrated in Figure 21. Furthermore, EMS sends this schedule back to CA process, which applies 510 outage scenarios again. As shown in Figure 22, this schedule becomes the new optimal schedule since the 510 scenarios are proved feasible, even though the TST increased from 19 to 20 hours.

\subsection{M4: Protection of Task Forces and Merchant Shipping}

The optimal schedule demands 17 hours of TST as shown in Figure 21. This mission has relatively shorter duration than the prior missions, but quite energy-intensive situations make EMS inflexible to perform operational scheduling process. EMS is required to consume DLs as $180 \%$ and $200 \%$ of BL for 24 hours in $\mathrm{P} 2-1$ and $\mathrm{P} 2-2$ respectively, and the submarine must be able to move at 9 knots of the medium range speed, which is essential for the submarine to keep pace with the task forces in P2-2. Moreover, P2 includes five engagements, which necessitate the submarine to proceed at the maximum speed of 


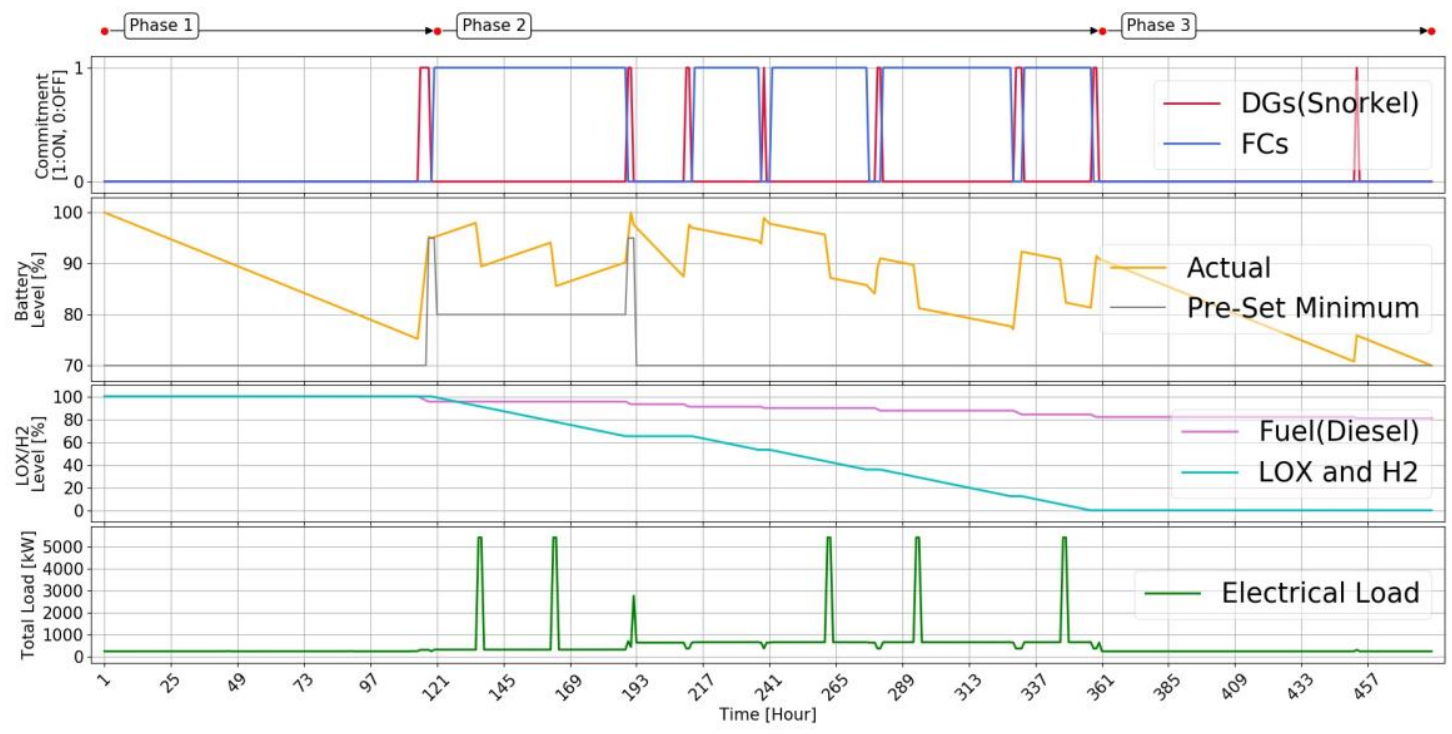

Figure 23. Optimal Schedule for M4 (TST: 17 hours).

20 knots for two hours each time, as a result, the five high-load rises are spotted in the fourth section, and in response, the five huge drops in the battery level are detected at the same time in the second section in Figure 23. In the first section, FCs operate consecutively except the hours for snorkeling in order to exhaust the resources as much as possible in P2.

Only three scenarios out of 340 scenarios turn out to be infeasible as presented in

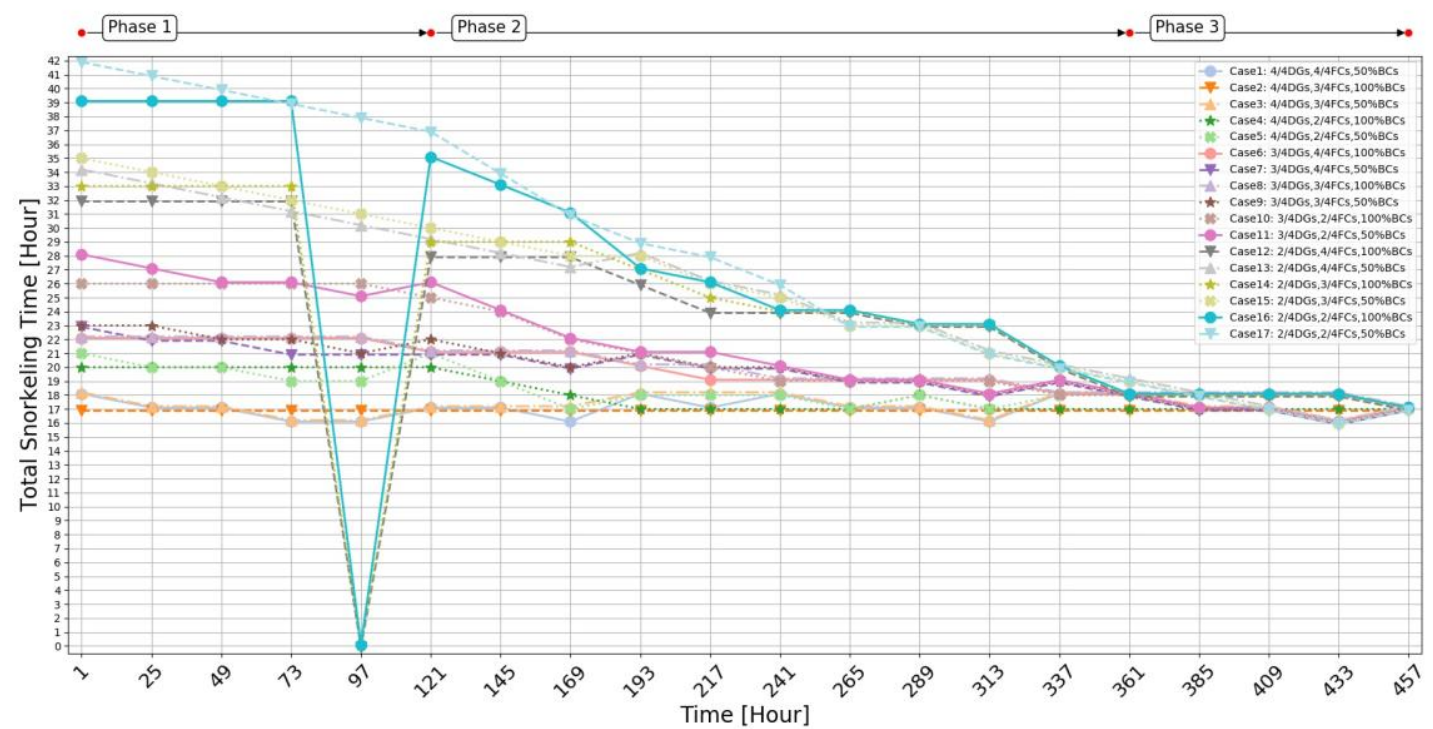

Figure 24. CA Results for M4 (340 Cases). 


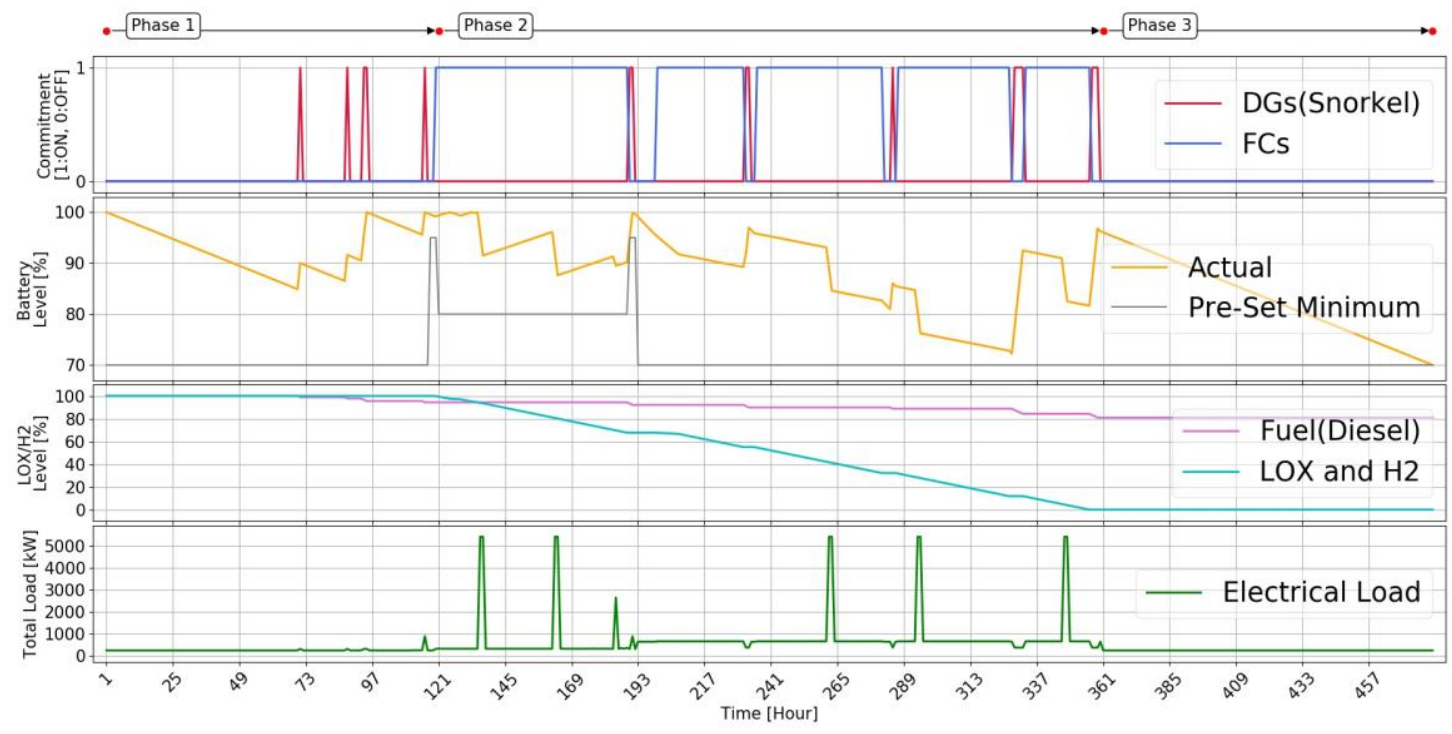

Figure 25. Stochastic Optimal Schedule for M4 (TST: 17 hours).

Figure 24. The three scenarios represent losing 2 DGs on the fifth day, when EMS needs to start snorkeling to charge BCs up to $95 \%$, and hence, EMS is not able to produce enough energy with only 2 DGs during this short period of time. However, 16 scenarios result 16 hours of TST which is an hour less than the optimal schedule due to the same reasons which are explained in $\mathrm{M} 2$ and $\mathrm{M} 3$.

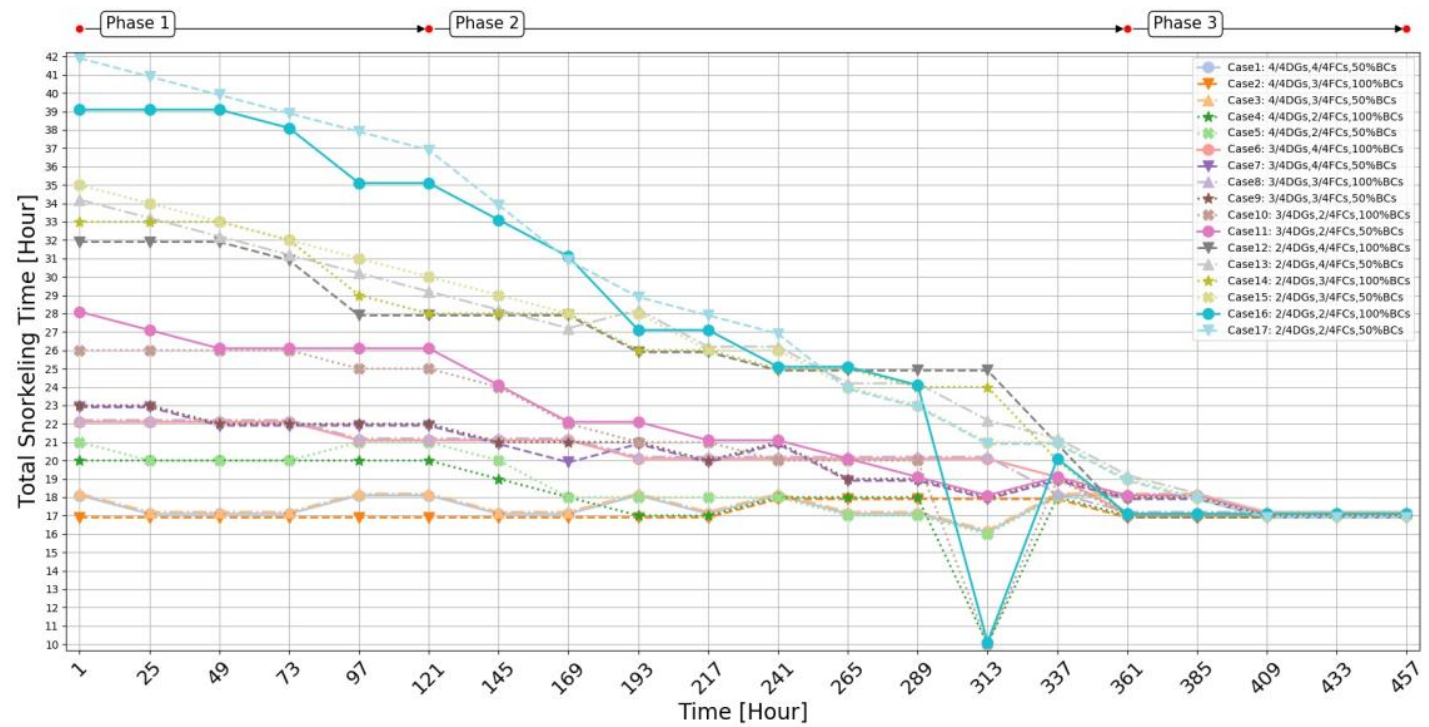

Figure 26. Results of CA on Stochastic Optimal Schedule for M4 (340 Cases). 
Through stochastic operational scheduling process, the three scenarios turn into feasible optimal schedules by equalizing with the normal scenario until the occurrences of the outages respectively. The TST of the normal scenario recorded as 17 hours as shown in Figure 25, which is the same amount of time with the TST of the optimal schedule. EMS assigns this stochastic optimal schedule to CA module; thus new 340 outage scenarios are consequently produced. However, another three infeasible scenarios are produced from this second CA process. In these scenarios, $2 \mathrm{FCs}$ at hour 313 are lost when the $\mathrm{BC}$ level is close to the minimum level, besides there is no relaxation on the $\mathrm{BC}$ level since they do not have any $\mathrm{BC}$ outage. As a result, EMS forwards these scenarios to stochastic operational scheduling process once again.

New stochastic optimal schedule forces EMS to have 18 hours of snorkeling, which is an hour more than the prior optimal schedules, as presented in Figure 27. Because the three infeasible scenarios achieve the optimality, EMS promotes this stochastic optimal schedule to the new optimal schedule for the next step. From the third CA process, finally all the

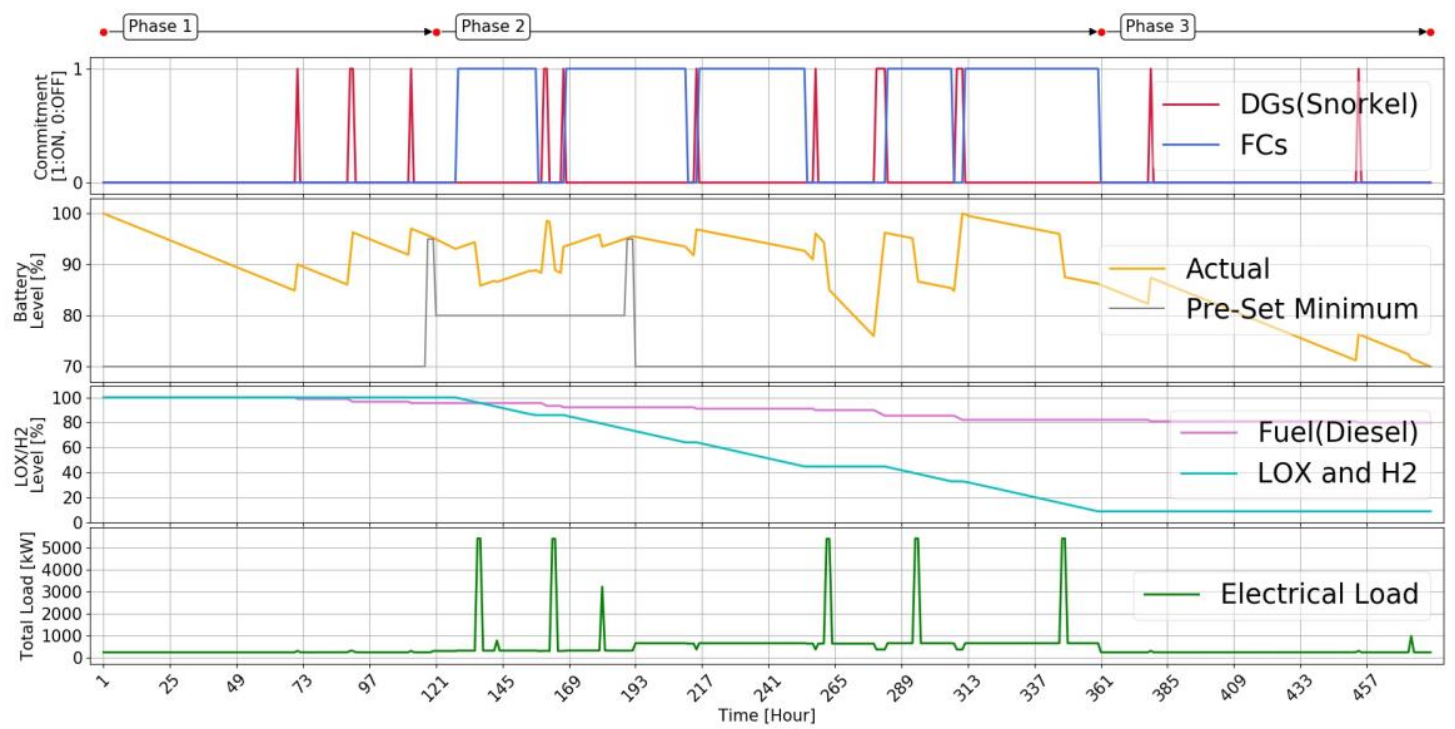

Figure 27. Stochastic Optimal Schedule for M4 (TST: 18 hours). 


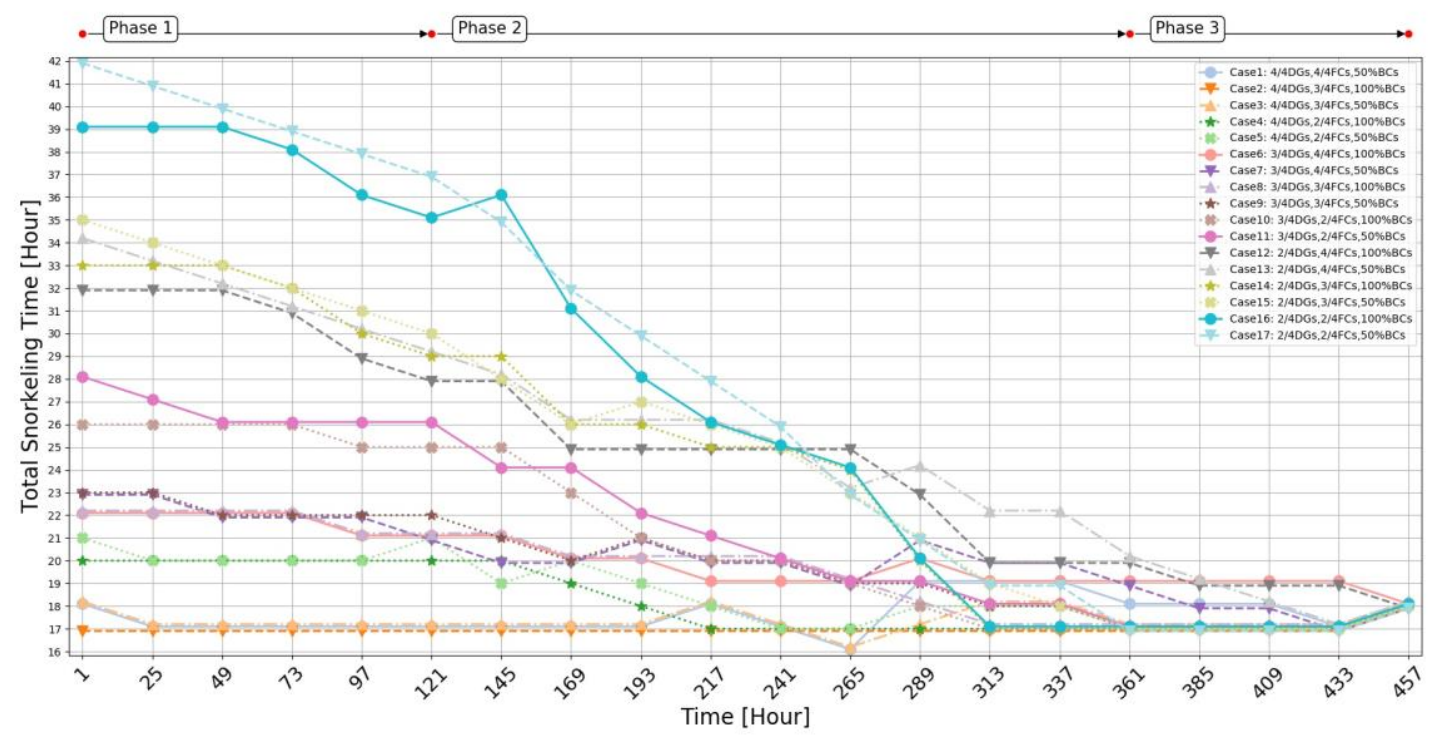

Figure 28. Results of CA on Stochastic Optimal Schedule for M4 (340 Cases).

340 scenarios are validated as secured optimal schedules as described in Figure 28.

In this mission, the final optimal schedule and the secured optimal schedules are obtained ultimately by the third loop of operational scheduling process. It can be easily a couple of loops or even more than tens of loops, depending on the complexity of mission scenarios and EMS algorithms. Nevertheless, essentially EMS should be able to generate secured optimal schedules, otherwise the operators need to change conditions of the systems or relax related constraints of the algorithms.

\subsection{M5: Denial of Sea Areas to An Enemy}

The optimal schedule claims 23 hours of TST throughout 600 hours as shown in the first section of Figure 29. In the second section, the BC level is fluctuating violently above the minimum level due to the high penetrations of electrical load as presented in the fourth section. In $\mathrm{P} 2$, the submarine experiences 10 engagements, which require tremendous amount of energy to process them while EMS imposes DL as 150\% of BL for 24 hours. 


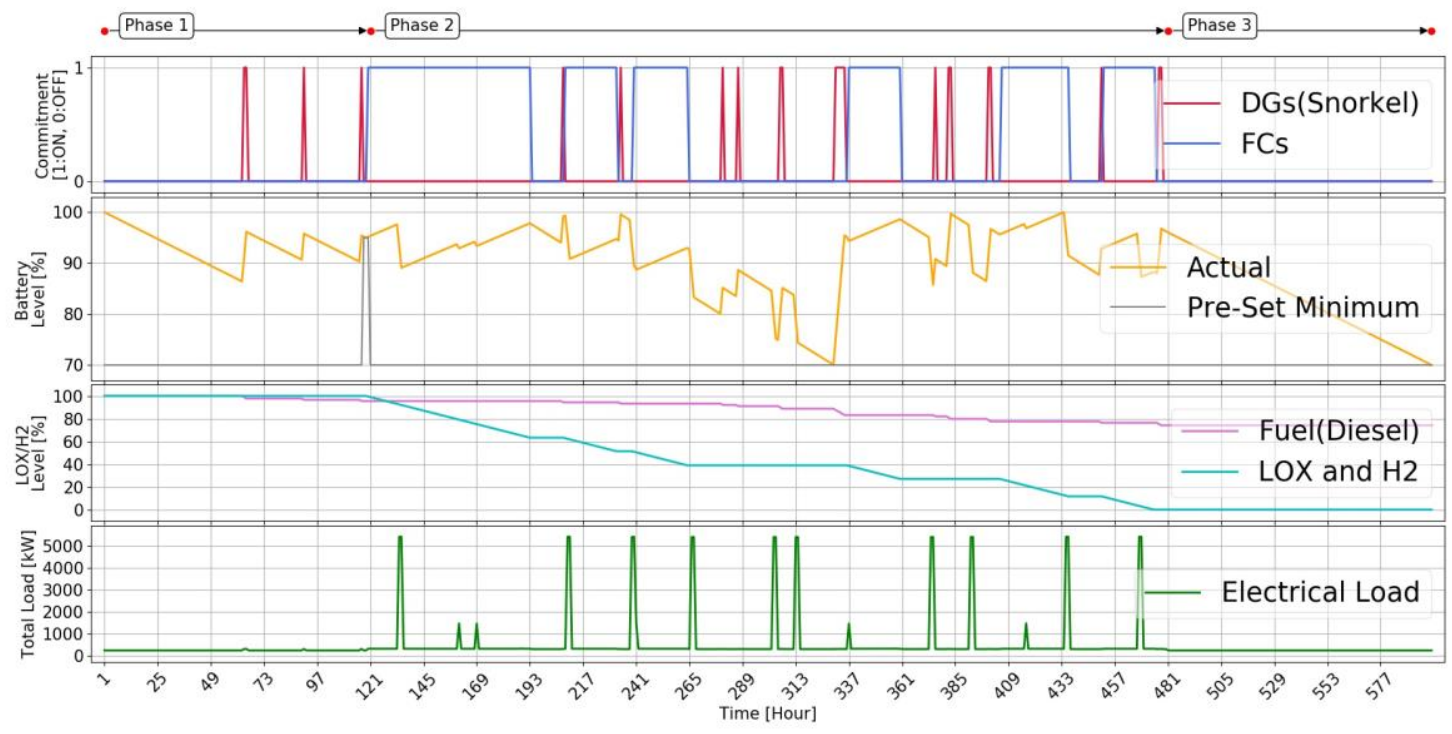

Figure 29. Optimal Schedule for M5 (TST: 23 hours).

As energy demand increases, EMS needs to execute snorkeling process to charge BCs more frequently and generate larger amount of energy at a time since FCs are not enough to respond to huge and quick drain in BCs.

As expected, more snorkeling hours than other missions are observed in the optimal schedule as well as in the CA results as presented in Figure 30. The highest TST is 49 hours

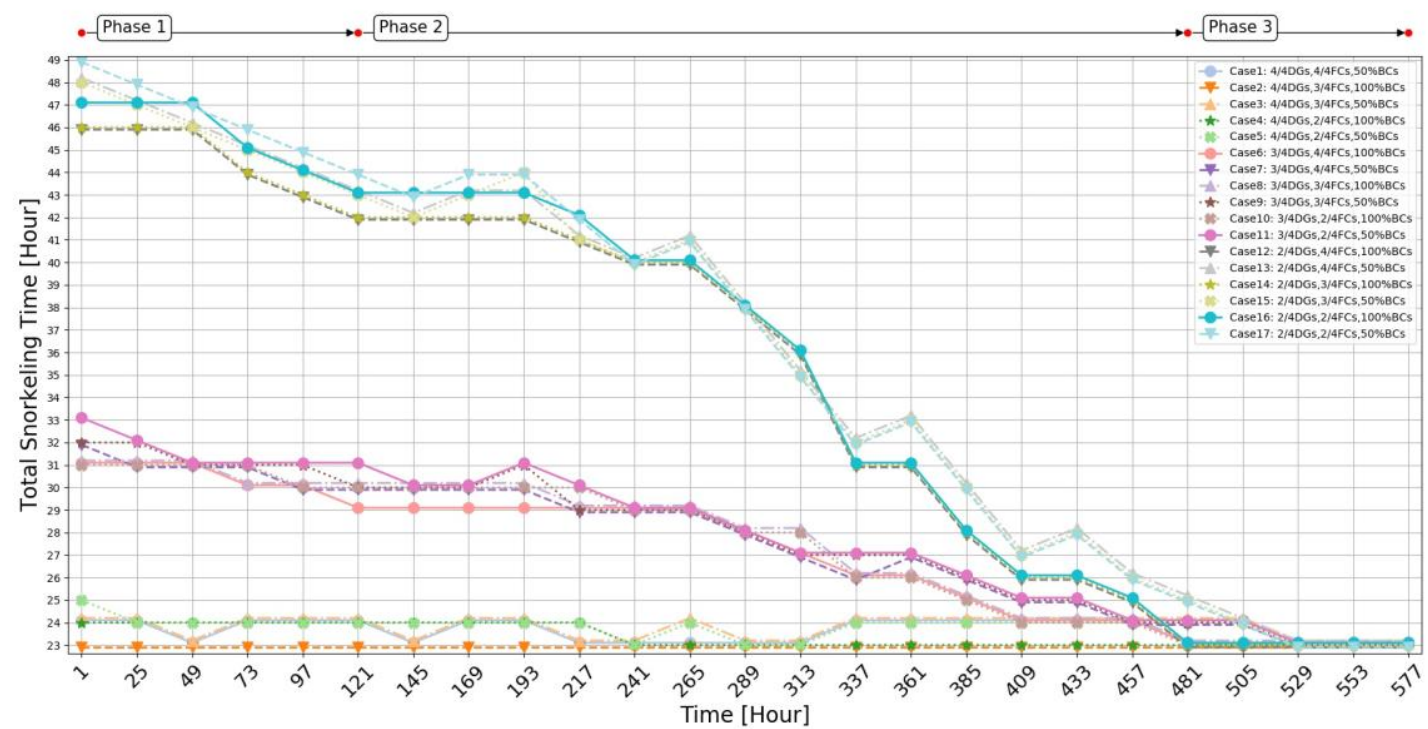

Figure 30. CA Results for M5 (425 scenarios). 
when outage case 17 occurs on the first day. When comparing to M4, although the number of engagements, which are battles, becomes doubled, EMS produces secured optimal schedules through a single CA process of all 425 outage scenarios. Since the submarine moves at the economic speed of 5 knots in normal situations in accordance with the lower DL than M4, EMS does not spend much energy in normal situations, specifically between the battles, showing that EMS can save enough energy for the next battle. 


\section{CONCLUSION AND FUTURE WORK}

\subsection{Conclusion}

The energy management system (EMS) for the 4,000-ton class conventional submarine is designed and analyzed through the five missions. The objective of modeling EMS is to generate optimal energy schedules with the minimum total snorkeling times (TST) in order to assist the officers to operate the submarines. Furthermore, EMS includes outage scenarios in the scheduling processes to respond to contingency situations. The power generation and storage systems, which consist of four diesel generators (DG), four proton exchange membrane fuel cell (PEMFC) modules, 9,350 lithium-ion battery cells (Li-ion BC) and subordinate storages, are specified based on the submarine design principles to power the submarine. In addition, five mission scenarios are modeled to examine the performance of EMS in accordance with the characteristics of the naval warfare.

In this thesis, the proposed EMS has been fully scrutinized by deploying the submarine model into the mission scenarios. It was explicitly proved that this EMS can produce the secured optimal schedules along with the minimum TSTs over the five mission scenarios, while the operational conditions and the mission constraints are successfully satisfied. The EMS produced the secured optimal schedules in the single operational scheduling process in M1 and M5, but it had to pass through multiple loops of the process in M2, M3 as well as M4. While investigating the manifold results through the loops, TSTs of the optimal schedules may increase as the process repeats. The noteworthy fact is that a few hours rise in TSTs of optimal schedules is worth the risk if guaranteed that all outage scenarios can produce secured optimal schedules via CA. More importantly, since EMS is designed to 
obey the constraints of the energy management algorithms in order to maintain the integrity of tactical purposes of submarine operations, the operators' intervention in the process should be the last option when it is indispensable. For example, if the operators lower the pre-set minimum battery level as often as they need to avoid violations, the capability to handle high energy-demanding situations will be considerably reduced and even EMS might not be able to recuperate from the situations without initiating snorkeling in risky circumstances.

In order to overcome the limitations of conventional submarines, especially the critical drawbacks from snorkeling, EMS is required to be precise and effective in order to generate operational schedules in the isolated environment, having limited energy resources. Moreover, modern naval warfare demands this type of 4,000-ton Class conventional submarines to be built with the capability of extended underwater endurance and additional payload along with AIP systems, especially among the countries who do not have nuclearpowered submarines. The significance and the engineering worth of this work strongly reflects these trends.

\subsection{Future Work}

Although conventional submarines have their own advantages such as quietness and littoral operations, the limited power resources put them in danger due to the necessity of snorkeling, and BC capacity quickly diminishes while they are running at the maximum speed even for just a few hours. In order to supplement their weaknesses, modern technologies for energy management and AIP systems have been developed drastically in recent years. Nevertheless, in terms of consistent power supply, the technologies have not established superiority over the nuclear power generation systems in submarines until now. 
However, as discussed in the literature review, nuclear-powered submarines also have drawbacks related to excessive heat dissipation and noise from the moving parts.

As a compromise, hybrid nuclear/AIP systems [54] can be used as a reasonably effective power system in submarines. Eventually, the purpose of this hybrid power system is to embody advantages from both conventional and nuclear-powered submarines, and hence, this type of hybrid submarine becomes capable of high-speed transits powered by nuclear energy and low-speed operations powered by AIP systems. Additionally, by introducing the technologies in hydrogen production from nuclear energy [55], [56], submarines do not need limited storages for hydrogen. Due to the complexity and the restrictions of combining and operating those systems under the isolated environment, the power generation and storage systems are required to be operated and managed precisely. As a result, EMS for this hybrid nuclear/AIP systems should be specifically modeled. Furthermore, when considering the enhanced capability of this hybrid submarine model, more complicated mission scenarios which demand longer underwater endurance must be designed, and the submarine model needs to be examined in these new mission scenarios. In order to investigate performance of the submarine model with respect to the mission scenarios, the proposed EMS of this work will certainly be a better implementation. 


\section{REFERENCES}

[1] Defencyclopedia, "Explained : How Air Independent Propulsion (AIP) Works!," Defencyclopedia, 6 July 2016. [Online]. Available: https://defencyclopedia.com/2016/07/06/explained-how-air-independentpropulsion-aip-works/. [Accessed 24 February 2020].

[2] P. C. Ghosh and U. Vasudeva, "Analysis of 3000T class submarines equipped with polymer electrolyte fuel cells," Energy, vol. 36, no. 5, pp. 3138-3147, 2011.

[3] J. Buckingham, "The Balance of Transit Range v Patrol Duration," in UDT Europe, Cannes, 2009.

[4] S. F. B. G. R. Chickering, A World at Total War: Global Conflict and the Politics of Destruction, 1937-1945, vol. 24, Cambridge: Cambridge University, 2004, p. 392.

[5] N. C. Polmar and N. Friedman, "Nuclear Propulsion," Encyclopædia Britannica, inc., 10 June 2019. [Online]. Available:

https://www.britannica.com/technology/submarine-naval-vessel. [Accessed 24 February 2020].

[6] M. Walker and A. Krusz, "There's a Case for Diesels," U.S. Naval Institute, June 2018. [Online]. Available:

https://www.usni.org/magazines/proceedings/2018/june/theres-case-diesels. [Accessed 24 February 2020].

[7] H. J. Ohff, "Nuclear versus diesel-electric: the case for conventional submarines for the RAN," Australian Strategic Policy Institute, 11 July 2017. [Online]. Available: https://www.aspistrategist.org.au/nuclear-versus-diesel-electric-caseconventional-submarines-ran/. [Accessed 24 February 2020].

[8] N. C. Polmar and N. Friedman, "Toward diesel-electric power," Encyclopædia Britannica, inc. , 10 June 2019. [Online]. Available:

https://www.britannica.com/technology/submarine-naval-vessel/Toward-dieselelectric-power. [Accessed 24 February 2020].

[9] Federation of American Scientists, "Naval Nuclear Propulsion: Assessing Benefits and Risks," Federation of American Scientists, Washington, DC, 2015. 
[10] T. Heinrich, "Why the US Needs Conventional Submarines," The Diplomat, 14 April 2016. [Online]. Available: https://thediplomat.com/2016/04/why-the-usneeds-conventional-submarines/. [Accessed 24 February 2020].

[11] R. O'Rourke, "Navy Virginia (SSN-774) Class Attack Submarine Procurement: Background and Issues for Congress," Congressional Research Service, Washington, D.C., 2016.

[12] A. Panda, "Japan Launches First Lithium-Ion Equipped Soryu-class Submarine," The Diplomat, 5 May 2018. [Online]. Available: https://thediplomat.com/2018/10/japan-launches-first-lithium-ion-equipped-soryuclass-submarine. [Accessed 24 February 2020].

[13] International Atomic Energy Agency, "Chernobyl Nuclear Accident," International Atomic Energy Agency, April 2016. [Online]. Available: https://www.iaea.org/newscenter/focus/chernobyl. [Accessed 24 February 2020].

[14] B. B.F.Wittneben, "The impact of the Fukushima nuclear accident on European energy policy," Environmental Science \& Policy, vol. 15, no. 1, pp. 1-3, 2012.

[15] G. T. Reader and I. Potter, "Early Submarine Engine Development," Journal of Engines, vol. 105, pp. 1921-1926, 1997.

[16] Maritime Park Association, "DIESEL ENGINE PRINCIPLES," Maritime Park Association, 22 October 2004. [Online]. Available: https://maritime.org/doc/fleetsub/diesel/chap1.htm. [Accessed 24 February 2020].

[17] MTU, "MTU SUBMARINE ENGINES," MTU, [Online]. Available: https://www.mtu-solutions.com/eu/en/applications/defense/marine-defensesolutions/submarines.html. [Accessed 24 February 2020].

[18] E. C. Tupper, Introduction to Naval Architecture, Oxford: Elsevier, 2013.

[19] DCNS, "msema; AIP module for SSKs," 15 November 2008. [Online]. Available: http://www.dcnsgroup.com/files/pdf/Mesma.pdf. [Accessed 24 February 2020].

[20] "India Looks to Modify Scorpene Subs With MESMA AIP Propulsion," Defense Industry Daily, 1 March 2006. [Online]. Available: https://www.defenseindustrydaily.com/india-looks-to-modify-scorpene-subs-withmesma-aip-propulsion-01954/. [Accessed 24 February 2020].

[21] tyssenkrupp, "HDW Class 212A - supreme stealth," tyssenkrupp, [Online]. Available: https://www.thyssenkrupp-marinesystems.com/en/hdw-class-212a.html. [Accessed 24 February 2020]. 
[22] A. Psoma and G. Sattler, "Fuel cell systems for submarines: From the first idea to serial production," Journal of Power Sources, vol. 106, no. 1-2, pp. 381-383, 2002.

[23] J. B. Lakeman and D. J. Browning, "The Role of Fuel Cells in the Supply of Silent Power for Operations in Littoral Waters," QuinetiQ Centre for Marine Technology, Farnborough, 2004.

[24] F. Barbir, Pem Fuel Cells: Theory and Practice (2nd Edition), Academic Press, 2013.

[25] U.S. Department of Energy, "Hydrogen Storage," U.S. Department of Energy, [Online]. Available: https://www.energy.gov/eere/fuelcells/hydrogen-storage. [Accessed 24 February 2020].

[26] J. Szymborski, "Lead-acid batteries for use in submarine applications," in Proceedings of the 2002 Workshop on Autonomous Underwater Vehicles, San Antonio, 2002.

[27] D. R. Pendergast, E. P. DeMauro, M. Fletcher and J. C. M. Eric Stimson, "A rechargeable lithium-ion battery module for underwater use," Journal of Power Sources, vol. 196, no. 2, pp. 794-800, 2011.

[28] M.A.Hannan, M.S.H.Lipu, A.Hussain and A.Mohamed, "A review of lithium-ion battery state of charge estimation and management system in electric vehicle applications: Challenges and recommendations," Renewable and Sustainable Energy Reviews, vol. 78, pp. 834-854, 2017.

[29] E. Kurniawan, B. Rahmat, T. Mulyana and J. Alhilman, "Data analysis of Li-Ion and lead acid batteries discharge parameters with Simulink-MATLAB," in 2016 4th International Conference on Information and Communication Technology (ICoICT), Bandung, 2016.

[30] A. Depetro, "The Design and Safety Challenges of a Lithium-ion Main Storage Battery for Conventional Submarines," BMT Design \& Technology, Melbourne, 2017.

[31] G. Zubi, R. Dufo-López, M. Carvalho and G. Pasaoglu, "The lithium-ion battery: State of the art and future perspectives," Renewable and Sustainable Energy Reviews, vol. 89, pp. 292-308, 2018.

[32] F.-S. Gady, "South Korea Launches First-of-Class 3,000-ton KSS-III DieselElectric Attack Submarine," The Diplomat, 14 September 2018. [Online]. Available: https://thediplomat.com/2018/09/south-korea-launches-first-of-class3000-ton-kss-iii-diesel-electric-attack-submarine/. [Accessed 24 February 2020]. 
[33] J. Jeong, "New battery can double the operational time of submarines, says South Korea," DefenseNews, 16 November 2018. [Online]. Available: https://www.defensenews.com/industry/techwatch/2018/11/16/new-battery-candouble-the-operational-time-of-submarines-says-south-korea/. [Accessed 24 February 2020].

[34] R. Burcher and L. J. Rydill, Concepts in Submarine Design, Cambridge: Cambridge University Press, 1994.

[35] B. F. Wollenberg, "A Brief Review of Electric Power Energy Management Systems," University of Minnesota.

[36] H. Aki, T. Wakui and R. Yokoyama, "Optimal management of fuel cells in a residential area by Integrated-Distributed Energy Management System (IDEMS)," in IEEE Power \& Energy Society Innovative Smart Grid Technologies Conference (ISGT), Minneapolis, 2016.

[37] S. F. Tie and C. W. Tan, "A review of energy sources and energy management system in electric vehicles," Renewable and Sustainable Energy Reviews, vol. 20, pp. 82-102, 2013.

[38] U. Shen, B. Ramachandran, S. K. Srivastava, M. Andrus and D. A. Cartes, "Power and Energy Management in Integrated Power System," in IEEE Electric Ship Technologies Symposium, Alexandria, 2011.

[39] D. Tang, X. Yan, Y. Yuan, K. Wang and L. Qiu, "Multi-agent Based Power and Energy Management System for Hybrid Ships," in International Conference on Renewable Energy Research and Applications (ICRERA), Palermo, 2015.

[40] M. M. S. Khan and M. O. Faruque, "Management of Hybrid Energy Storage Systems for MVDC Power System of All Electric Ship," in 48th North American Power Symposium, Denver, 2016.

[41] J. Han, J.-F. Charpentier and T. Tang, "An Energy Management System of a Fuel Cell/Battery Hybrid Boat," Energies, vol. 7, no. 5, pp. 2799-2820, 2014.

[42] Z. Jin, G. Sulligoi, R. Cuzner, L. Meng, J. C. Vasquez and J. M. Guerrero, "NextGeneration Shipboard DC Power System: Introduction Smart Grid and dc Microgrid Technologies into Maritime Electrical Netowrks," IEEE Electrification Magazine, vol. 4, no. 2, pp. 45-57, 2016.

[43] K. Lai and M. S. Illindala, "Design and planning strategy for energy storage system in a shipboard dc hybrid power system," in 2017 IEEE/IAS 53rd Industrial 
and Commercial Power Systems Technical Conference (I\&CPS), Niagara Falls, 2017.

[44] K. Yiğit and B. Acarkan, "A new ship energy management algorithm to the smart electricity grid system," International Journal of Energy Research, vol. 42, no. 8, pp. 2741-2756, 2018.

[45] Jane's, Jane's Fighting Ships, London: IHS Markit, 2018.

[46] D. Mitsopoulos, "All the Nuclear Missile Submarines in the World in One Chart," Popular Mechanics, 8 June 2018. [Online]. Available: https://www.popularmechanics.com/military/navy-ships/a21204892/nuclearmissile-submarines-chart/. [Accessed 22 March 2020].

[47] C. A. W. a. J. C. H. K. Psallidas, "Design of conventional submarines with advanced air independent propulsion systems and determination of corresponding theater-level impacts," Nav. Eng. J., vol. 122, no. 1, pp. 111-123, 2010.

[48] SIEMENS, "SINAVY DC-Prop and SINAVY PERMASYN," 5 October 2018. [Online]. Available:

https://assets.new.siemens.com/siemens/assets/api/uuid:b91eb39c-65ca-4207-bff3a525943f65d1/version:1540972880/vrms-b10017-00-7600-ws-sinavy-dc-proppermasyn-300dpi.pdf. [Accessed 6 February 2020].

[49] MTU, "Diesel Generator Set MTU 12V4000 DS1550," September 2019. [Online]. Available: https://www.mtu-solutions.com/content/dam/mtu/products/powergeneration/diesel/50-hz/mtu-4000-ds_1600-4000kva/32310221_PG_spec_12V4000DS1550_1550kWe_FC_60Hz.pdf/_jcr_content/ renditions/original./32310221_PG_spec_12V4000DS1550_1550kWe_FC_60Hz.p df. [Accessed 24 February 2020].

[50] SIEMENS, "SINAVY PEM Fuel Cell For Submarines," 2013. [Online]. Available: https://assets.new.siemens.com/siemens/assets/public.1535009488.28615cde70250 d0e81b68ba466bd77d7f5c68c73.sinavy-pem-fuel-cells.pdf. [Accessed 24 February 2020].

[51] SAMSUNG SDI, "ESS Batteries by SAMSUNG SDI," May 2018. [Online]. Available: http://www.samsungsdi.com/upload/ess_brochure/201803_SamsungSDI\%20ESS_ EN.pdf. [Accessed 24 February 2020].

[52] O. Menzel, "The submarine revolution: lithium-ion battery system for a better performance," thyssenkrupp, 15 October 2019. [Online]. Available: 
https://engineered.thyssenkrupp.com/en/the-submarine-revolution-lithium-ionbattery-system-for-more-performance/. [Accessed 24 February 2020].

[53] K. Mizokami, "Introducing Japan's Lithium Ion Battery-Powered Submarine," Popular Mechanics, 14 November 2019. [Online]. Available: https://www.popularmechanics.com/military/navy-ships/a29798485/japan-lithiumion-submarine/. [Accessed 24 February 2020].

[54] R. Goodenough and A. Greig, "Hybrid nuclear/fuel-cell submarine," J. Nav. Eng, vol. 44, no. 3, pp. 455-471, 2008.

[55] G. F. Naterer, I. Dincer and C. Zamfirescu, Hydrogen Production from Nuclear Energy, London: Springer, 2013.

[56] U.S. Department of Energy, "https://www.energy.gov/ne/articles/could-hydrogenhelp-save-nuclear," U.S. Department of Energy, 26 November 2018. [Online]. Available: https://www.energy.gov/ne/articles/could-hydrogen-help-save-nuclear. [Accessed 24 February 2020].

[57] G. F. Naterer, D. Ibrahim and C. Zamfirescu, Hydrogen Production from Nuclear Energy, London: Springer, 2013.

[58] Defencyclopedia, "Explained : How Air Independent Propulsion (AIP) Works!," Defencyclopedia, 6 July 2016. [Online]. Available: https://defencyclopedia.com/2016/07/06/explained-how-air-independentpropulsion-aip-works/. [Accessed 24 February 2020].

[59] Woodbank Communications Ltd, "Cell Chemistries - How Batteries Work," Woodbank Communications Ltd, [Online]. Available: https://www.mpoweruk.com/chemistries.htm. [Accessed 24 February 2020].

[60] United State Nuclear Regulartory Commission, "Pressurized Water Reactors," United State Nuclear Regulartory Commission, 15 January 2015. [Online]. Available: https://www.nrc.gov/reactors/pwrs.html. [Accessed 24 February 2020].

[61] World Nuclear Association, "Nuclear-Powered Ships," World Nuclear Association, December 2019. [Online]. Available: https://www.worldnuclear.org/information-library/non-power-nuclear-applications/transport/nuclearpowered-ships.aspx. [Accessed 24 February 2020].

[62] U.S. Department of Energy; Department of the Navy, "The United States Naval Nuclear Propulsion Program," U.S. Department of Energy; Department of the Navy, 2015. 